\title{
COMPUTER AIDED DESIGN TOOL FOR ELECTRIC, HYBRID ELECTRIC AND PLUG-IN HYBRID ELECTRIC VEHICLES
}

\author{
A Dissertation \\ by \\ ALI ESKANDARI HALVAII \\ Submitted to the Office of Graduate Studies of \\ Texas A\&M University \\ in partial fulfillment of the requirements for the degree of \\ DOCTOR OF PHILOSOPHY
}

May 2011

Major Subject: Electrical Engineering 


\title{
COMPUTER AIDED DESIGN TOOL FOR ELECTRIC, HYBRID ELECTRIC AND PLUG-IN HYBRID ELECTRIC VEHICLES
}

\author{
A Dissertation \\ by \\ ALI ESKANDARI HALVAII
}

\begin{abstract}
Submitted to the Office of Graduate Studies of Texas A\&M University in partial fulfillment of the requirements for the degree of

DOCTOR OF PHILOSOPHY
\end{abstract}

Approved by:

Chair of Committee, Mehrdad Ehsani

Committee Members, Shankar P. Bhattacharyya

Karen Butler-Purry

Ben Zoghi

Head of Department, Costas N. Georghiades

May 2011

Major Subject: Electrical Engineering 


\author{
ABSTRACT \\ Computer Aided Design Tool for Electric, Hybrid Electric \\ and Plug-in Hybrid Electric Vehicles. (May 2011) \\ Ali Eskandari Halvaii, B.S.; M.S., University of Tehran \\ Chair of Advisory Committee: Dr. Mehrdad Ehsani
}

This research is focused on designing a new generation of CAD tools that could help a "hybrid vehicle" designer with the design process to come up with better vehicle configurations.

The conventional design process for any type of hybrid-electric vehicle would start from the vehicle performance criteria and continue by applying them to the physical models of different components of the vehicle. The final result would be strict and precise characteristics of all components in the vehicle; this scenario gives only one option for the desired vehicle.

A new perspective is introduced in developing a new methodology in the art of design. This new method enables the designer to see a wider picture of what he is designing and have access to all his options and capabilities. The method is designed to help the designer ask teh right questions about his design options, intelligently guide him through the design process by squeezing the space of solutions and take him to the final designed product.

The new methodology is implemented in this research with the following capabilities:

1. The proposed tool allows the designer to choose any arbitrary set of variable to be known and leave the rest as the ones to be solved for; either they are vehicle component characteristic variables or performance measures. This provides a great amount of flexibility and success in designing a vehicle from any available 
information about it.

2. Instead of starting from single values, the new tool can work with a range of possible values for the known variables and suggest range of feasible values for the unknown variables. This provides the capability of refining the design even further and performing sensitivity analysis.

3. The proposed tool is a package that offers both design and simulation capabilities. It includes analytical performance simulation as well as simulation with arbitrary drive cycles and engine controllers.

4. Capability of 1D, 2D and 3D representation of any arbitrary set of design variables in the solution space.

The idea is implemented in a pilot version software package for vehicle design. 
To My Mother 


\section{ACKNOWLEDGMENTS}

I would like to thank my committee chair, Dr. Mehrdad Ehsani, and my committee members, Dr. Shankar Bhattacharyya, Dr. Karen Butler and Dr. Ben Zoghi, for their guidance and support throughout the course of this research.

Thanks also go to my friends and colleagues and the department faculty and staff for making my time at Texas A\&M University a great experience. I also want to extend my gratitude to the Department of Engineering Technology and Industrial Distribution at Texas A\&M University, which provided the Graduate Assistant position for me through out my studies. 


\section{TABLE OF CONTENTS}

CHAPTER

INTRODUCTION . . . . . . . . . . . . . . . . . . . . . . . 1

A. History . . . . . . . . . . . . . . . . . . . . . . . 1

B. Dissertation Outline .............. 2

II ELECTRIC, HYBRID ELECTRIC, PLUG-IN HYBRID ELECTRIC AND SERIES HYBRID ELECTRIC VEHICLES . . . . . 4

A. Introduction . . . . . . . . . . . . . . 4

B. Vehicle Structure Configurations . . . . . . . . . . . 4

C. Engine Operation . . . . . . . . . . . . . 5

D. Controllers . . . . . . . . . . . . . . 6

1. Maximum State of Charge for the Peaking Power Source 7

2. Engine turn on/off . . . . . . . . . . . . . 99 9

E. Physical Equations Describing Different Components in the Vehicle. . . . . . . . . . . . . . . . 10

1. Electric Motor . . . . . . . . . . . . . . . 11

2. Transmission ................ . . 13

3. Engine . . . . . . . . . . . . . . 16

4. Peaking Power Source - Battery . . . . . . . . . . 19

5. Battery Energy Capacity . . . . . . . . . . . . 19

III CONVENTIONAL METHOD OF SERIES HYBRID ELECTRIC VEHICLE DESIGN . . . . . . . . . . . . . . . . . . . . 23

A. Introduction . . . . . . . . . . . . . . . . 23

B. Design Question ................ . . 23

C. Traction Motor . . . . . . . . . . . . . . 24

D. Gear Ratio . . . . . . . . . . . . . . . . 26

E. Gradeability and Acceleration Performance Verification . . 27

F. Engine . . . . . . . . . . . . . . . . 30

G. Peaking Power Source . . . . . . . . . . . . . . . 32

H. Simulation with Drive Cycle and Controller . . . . . . . 33

I. Summary . . . . . . . . . . . . . . . . . 33

IV THE NEW CAD/SIMULATION TOOL FOR VEHICLE DESIGN 35 
A. Concept of CAD/Simulation Tools for Vehicle Design, Their Evolution and Shortcomings . . . . . . . . . . . 35

1. Concept and Evolution . . . . . . . . . . . 35

2. Shortcomings . . . . . . . . . . . . 36

B. The New Design/Simulation Tool . . . . . . . . . 37

1. Design ................. . . 38

2. Simulation for Performance . . . . . . . . . . . 42

3. Graphs . . . . . . . . . . . . . . . 47

4. Simulation with Drive Cycle and Controller . . . . . . 47

V DESIGN EXAMPLES BY THE PROPOSED TOOL . . . . . 52

A. Introduction . . . . . . . . . . . . . 52

B. Series Hybrid Electric Vehicle Design . . . . . . . . . . . 52

1. Design Question ............. . . 53

2. Design Using the Proposed Tool . . . . . . . . . . . 53

C. Plug-in Series Hybrid Electric Vehicle Design . . . . . . . . 58

VI CONCLUSION AND FUTURE WORK . . . . . . . . . . 60

A. Conclusion . . . . . . . . . . . . . . . . 60

B. Future Work . . . . . . . . . . . . . . . . . 61

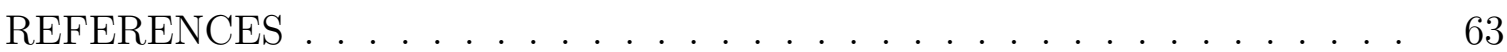

APPENDIX A USER'S MANUAL FOR THE PROPOSED TOOL . . . . . . . 64

A. Design ...................... 64

B. Simulation for Performance . . . . . . . . . . 67

C. Graphs . . . . . . . . . . . . . . . . . . . 74

D. Simulation with Drive Cycle and Controller . . . . . . . 74

E. Designing a Vehicle . . . . . . . . . . . . . . 78

1. Electric Vehicle Design . . . . . . . . . . . 78

a. Design Question . . . . . . . . . . . . . 78

b. Design Using the Proposed Tool . . . . . . . . . . 79

2. Series Hybrid Electric Vehicle Design . . . . . . . . 85

a. Design Question . . . . . . . . . . 85

b. Design Using the Proposed Tool . . . . . . . . . . 86

3. Plug-in Series Hybrid Electric Vehicle Design . . . . . 91

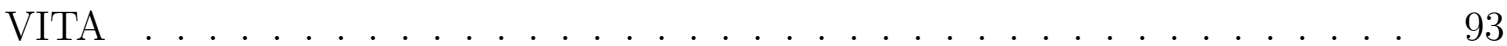




\section{LIST OF TABLES}

TABLE $\quad$ Page

I Average power with full and no regenerative braking for different

drive cycles . . . . . . . . . . . . . . . . . . . . . . . . . . . . . . . 31 


\section{LIST OF FIGURES}

FIGURE

$1 \quad$ Electric vehicle structure. A battery and an electric motor is what needed to make them. . . . . . . . . . . . . . . . . . 2

2 Common configuration for the series hybrid electric vehicles. . . . . . 5

3 Internal combustion engine optimal operating point. . . . . . . . . 6

4 Different controllers in series hybrid electric vehicle. . . . . . . . . . 7

$5 \quad$ Maximum state of charge control strategy for series hybrid electric vehicles. ...................... 8

$6 \quad$ Engine ON/OFF control strategy for series hybrid electric vehicles. . 10

7 Electric motor power and torque for different shaft speeds. . . . . . . 11

8 Effect of $x$-factor on the maximum torque of an electric motor. . . . . 12

$9 \quad$ Torque-speed profile for a single gear transmission electric motor with rolling resistance and aerodynamic drag. . . . . . . . . . . . . . 14

10 Torque-speed and power-speed profiles for an internal combustion engine. Both profiles are different than the ideal desired shapes. The figure also shows the fuel consumption goes up by getting away from the optimal operating speed of the engine. . . . . . . .

11 Torque-speed profile for an internal combustion engine with a multi gear transmission. The transmission helps the torque profile become closer to the ideal required shape. . . . . . . . . . . .

12 Torque-speed profile comparison for an internal combustion engine with a multi gear transmission and an electric motor with a single gear transmission. The electric motor profile matches the ideal torque requirement profile without need for multi gear transmission. . . . . . . . . . . . . . . . . . 
FIGURE

13 Torque, tractive effort and longitudinal speed of the vehiile. . . . . . 17

14 Tractive power versus time in an stop and go drive routine. . . . . 18

15 Tractive power versus time for urban and highway drive cycles. . . . 20

16 Battery charging and discharging efficiency at different SOC's. . . . . 21

17 Motor power and torque in different shaft speeds. . . . . . . . . . . 26

18 Acceleration time and distance for various vehicle speeds. . . . . . . 28

19 Vehicle tractive effort and road resistance for various vehicle speeds and road slope grades. . . . . . . . . . . . . . . . . 29

$20 \quad$ Gradeability for various vehicle speeds. . . . . . . . . . . . 30

21 Vehicle simulation for FTP 75 drive cycle and engine-on-off controller. From top to bottom: Vehicle speed or drive cycle, tractive effort generated by electric motor, engine on-off scheme with on-mode power, battery power, energy level change in battery (battery state of charge). . . . . . . . . . . . . . . 34

22 Snapshot of "design" interface of the proposed CAD tool. . . . . . . 38

23 Vehicle shape determined aerodynamic drag coefficient; battery technology determines its charging characteristics and mass. . . . . . 39

24 Choosing which variables to be 'known'. . . . . . . . . . . 39

25 A range of variation is entered for known variables. . . . . . . . . . 40

26 Solution space could be squeezed by additional constraints. . . . . . . 41

27 Simulation resolution impacts precision of the solution space. . . . . 41

28 Solution space shown as ranges for variables. . . . . . . . . . . . . . 42

29 Snapshot of "Simulation for Performance" interface. . . . . . . . . . 43

30 Any point in solution space represents a vehicle that could be simulated. 44 
31 Gradeability as function of vehicle speed for chosen vehicle. . . . . .

32 Acceleration time and distance as function of vehicle speed for the chosen vehicle. . . . . . . . . . . . . . . . . .

33 Required engine power as function of vehicle speed for the chosen vehicle. . . . . . . . . . . . . . . . .

34 Snapshot of "Graphs" interface for 2D and 3D representations of the vehicle variables. . . . . . . . . . . . . . . . 46

35 Snapshot of "Simulation with Drive Cycle and Controller" interface. 48

36 Driving pattern and engine controller determines how engine charges

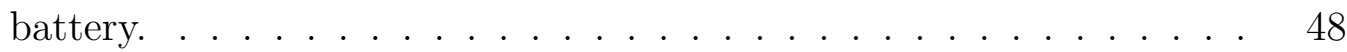

37 It is best to operate engine at its optimum operating speed. . . . . . 49

38 Standard drive cycles are available; new ones could be added. . . . . 49

39 The instantaneous and average required power to run the vehicle. . . 50

40 Engine turns on and off at the moments and by the power commanded by controller. . . . . . . . . . . . . . . 50

41 Battery receives or delivers power based on engine operation. . . . . 50

42 Engine operation increases the SOC of battery. . . . . . . . . . . 51

43 Structure of series hybrid electric vehicles. . . . . . . . . . . 52

$44 \quad$ Known variables are determined for the series hybrid electric vehicle. 54

45 Ranges for known variables are determined. . . . . . . . . . . . 55

46 The vehicle performance is verified against design criteria. . . . . . . 56

47 The vehicle is simulated here in different drive cycles using various battery/engine management controllers. . . . . . . . . . 58

48 Major components of a plug-in series hybrid electric vehicle. . . . . . 59 
$50 \quad$ Vehicle shape and battery technology selection. . . . . . . . . 65

$51 \quad$ Selecting known variables. . . . . . . . . . . . . . . 66

52 Entering the varying range for known variables. . . . . . . . . . . 67

53 Additional constraints could be defined as inequalities to be forced on the solution space. . . . . . . . . . . . . . . . 68

54 Defining calculation resolution for the solution space. A higher number indicates more number of points considered in determining the solution space. . . . . . . . . . . . . . . . 68

$55 \quad$ Feasible ranges for the variables in the solution space. . . . . . . . 69

56 "Simulation for Performance" interface. . . . . . . . . . . . . . 70

$57 \quad$ Choosing a single vehicle from the solution space to be simulated. . . 70

$58 \quad$ Gradeability at different speeds. . . . . . . . . . . . . 71

$59 \quad$ Acceleration time and distance at different speeds. . . . . . . . . . 71

$60 \quad$ Required engine power at different speeds. . . . . . . . . . . . . . 72

61 "Graphs" interface . . . . . . . . . . . . . . . . 73

62 "Simulation with Drive Cycle and Controller" interface. . . . . . . . 75

63 Choosing a drive cycle and an engine controller. . . . . . . . . . . 75

64 Determining the throttle angle and engine speed for simulation. . . . 76

65 The drive cycle used for simulation. . . . . . . . . . . . . . . 76

66 The power required to run the vehicle: instantaneous, average with and average without regenerative braking. . . . . . . . . . . . . 77

$67 \quad$ Engine operation. . . . . . . . . . . . . . 77

$68 \quad$ Power sent to the battery. . . . . . . . . . . . . . 77 
69 Battery state of charge. . . . . . . . . . . . . 78

$70 \quad$ Major components of an electric vehicle. . . . . . . . . . . . 79

71 'Design' interface is used to specify the known variables and set the values for them. . . . . . . . . . . . . . . . . . . 80

72 The battery type and the vehicle shape is entered here. . . . . . . . 80

73 The vehicle mass, maximum speed and acceleration will be entered here. 81

$74 \quad$ The initial simulation for performance will be done in this interface. . 82

$752 \mathrm{D}$ and 3D plots of the possible ranges for any two or three selected variables in the vehicle. ................ 83

76 Major components of a series hybrid electric vehicle. . . . . . . . 85

$77 \quad$ Specifying known variables. . . . . . . . . . . . . . 87

78 Determining variable ranges. . . . . . . . . . . . 87

79 Initial simulation for performance . . . . . . . . . . . . . . . . 90

80 Simulation for different drive cycles and controllers. . . . . . . . . . 91

81 Structure of plug-in series hybrid electric vehicles. . . . . . . . . . 92 


\section{CHAPTER I}

\section{INTRODUCTION}

\section{A. History}

Electric vehicles were first designed and created long before internal combustion engines were developed. This was mainly because of the simplicity of design for these cars. Figure 1 shows the general structure of electric vehicles. As could be seen, there is simply an electric motor, connected to the wheels through usually a single gear transmission. Despite its simplicity, these vehicles have unique advantages. Because there is no fossil fuel being burned in the vehicle, the pollution by them is almost zero. They use the electricity which in the worst case has been produced from fossil fuel, but still, burning fossil fuel in the utility is much more efficient than in an ICE [1]. The other advantage of these vehicles is their great performance. The torque-speed characteristics of an electric motor looks much more like the ideal traction profile needed for a vehicle.

Beside all these advantages, there were difficulties also that pushed electric cars out of attention when gasoline engine cars came in. The most important problems came from the limitations on the amount of available on-board energy storage [2]. The entire energy storage of an electric vehicle is being done by the batteries. The existing battery technology had serious limitations on the energy capacity and power capacity. Long charging and discharging time was also another problem with the current battery technology. All these problems caused the electric vehicles to have short drive range per full charge, long charge time and the large volume of batteries which cause limitations on the payload they can carry. Needless to say that most of

The journal model is IEEE Transactions on Automatic Control. 


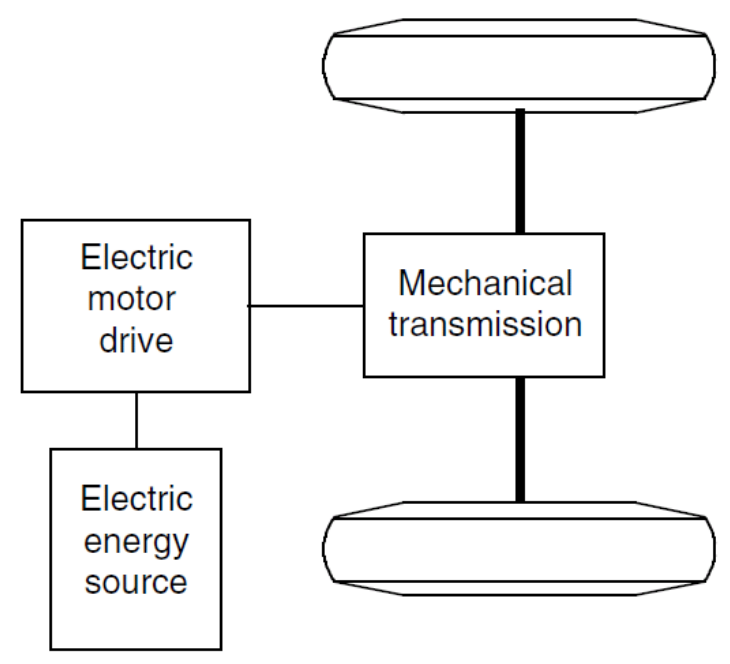

Fig. 1. Electric vehicle structure. A battery and an electric motor is what needed to make them.

these problems still exist because there is still not a good storage technology available for electrical energy.

Different solutions have been thought of to get around mentioned problems in EV's. The solution that caught the most attention was introducing the concept of hybrid electric vehicles.

\section{B. Dissertation Outline}

In the next chapter the theory and fundamentals of electric vehicles, hybrid electric vehicles and plug-in hybrid electric vehicles will be discussed. It will be concluded that series hybrid electric vehicles are fundamentally similar to electric vehicles with the only difference that they have an internal combustion engine as well to charge the battery when needed in order to increase the operation range of the vehicle. Furthermore it will be discussed that plug-in hybrid vehicles are fundamentally the exact same copy of series hybrid electric vehicles with mere difference that their 
battery does not need to be charged by the internal combustion engine / generator; they could be directly plugged to an external electric power source to be charged.

In Chapter III the series hybrid electric vehicles will be studied in more detail and various components and their characteristics will be covered. Chapter IV will continue on series HEV's and will illustrate in detail how to design such a vehicle using conventional design methods by hand. A design example will be examined thoroughly.

Chapter V will explain the concept of Computer Aided Design (CAD) tools and specifically their application in automotive industry and vehicle design. The revolution of computer aided design tools will be covered and the new CAD design/simulation tool that is the subject of this research will be explored. Further, the details of the new tool will be explained. Chapter VI will demonstrate several case studies and examples of vehicle design using the proposed tool and Chapter VII will talk about limitations of the new tool and will recommendations for future research. 


\section{CHAPTER II}

\section{ELECTRIC, HYBRID ELECTRIC, PLUG-IN HYBRID ELECTRIC AND SERIES HYBRID ELECTRIC VEHICLES}

\section{A. Introduction}

The first attempts to abandon the cars burning fossil fuels started by electric vehicles. The idea of hybrid electric cars is developed short after that because of the close similarities between the structure of electric and series hybrid electric vehicles [3]. Figure 1 shows the configurations of an electric vehicle and Figure 2 the latter. This similarity also makes it very easy to use the same design application for all these types of vehicles with small tunings.

\section{B. Vehicle Structure Configurations}

Figure 2 shows the most common configuration for the series hybrid vehicles. As could be seen in this figure, the vehicle wheels are driven directly by the electric traction motor connected to a mechanical transmission. Since the electric motor has the ideal torque-speed profile for the best traction, the transmission is usually a single-gear gear box. Motor controller controls the traction motor to output the required amount of power in the form of speed or torque. Traction motor receives its energy from the battery through the DC/DC converter. at the same time the battery is being charged by the reverse line from the motor when the vehicle is in braking mode using the vehicle inertia.

Engine uses the fuel tank as the energy source to propel the generator. The generator output is fed to both the traction motor to energize it when battery does not have enough charge, and to the battery to charge it when the state of charge 


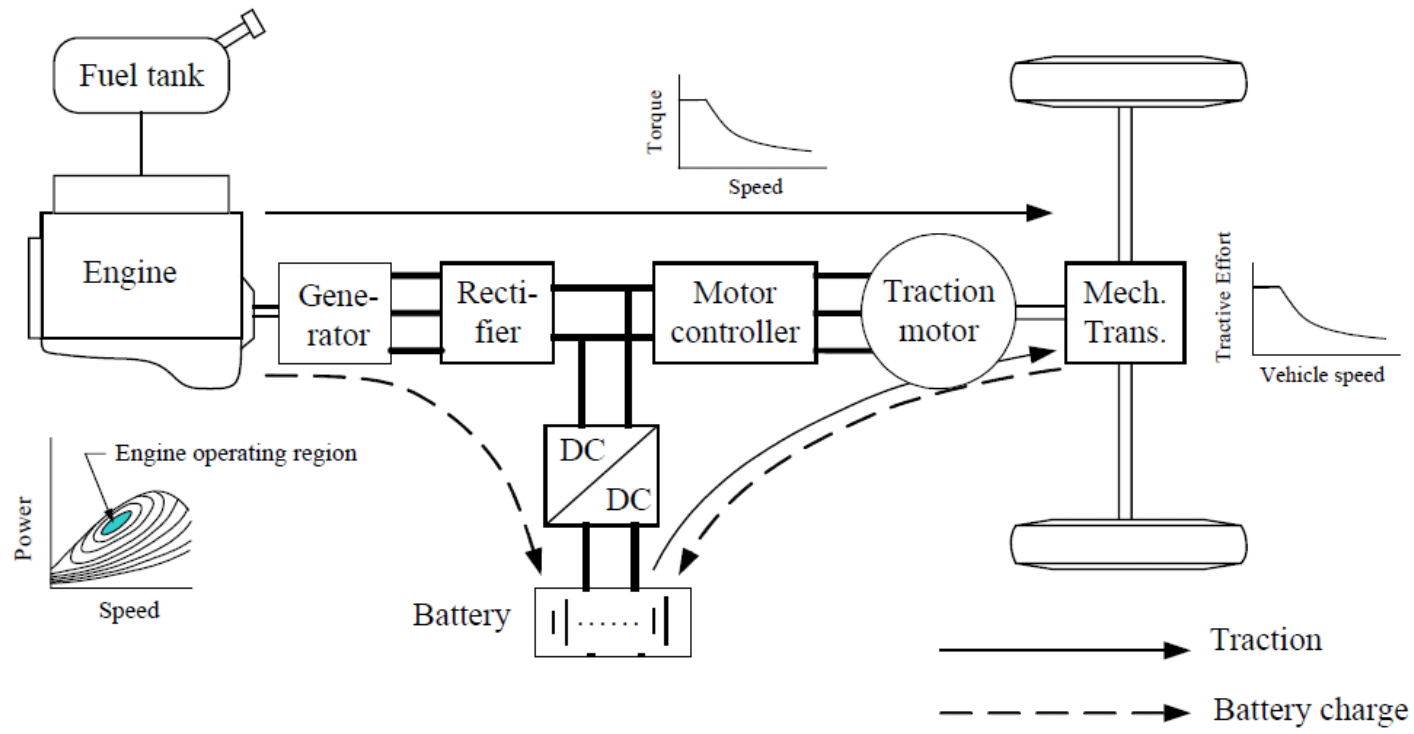

Fig. 2. Common configuration for the series hybrid electric vehicles.

on it is too low. Since the energy transfer from engine to the battery and motor is bidirectional, the engine is turned on only when its energy is needed and is off the rest of the time.

\section{Engine Operation}

As explained in Figure 2 the traction motor is mechanically coupled with the vehicle wheels through the transmission, but the engine is mechanically decoupled from both traction motor and the wheels. This is the greatest advantage of series hybrid configuration, because it gives the internal combustion engine the freedom to be used at any operating point [4]. Figure 3 shows the engine maximum output power curves versus its shaft speed for different fuel consumption rates. It is demonstrated in this figure that the engine should be operated at a specific output power and speed to 


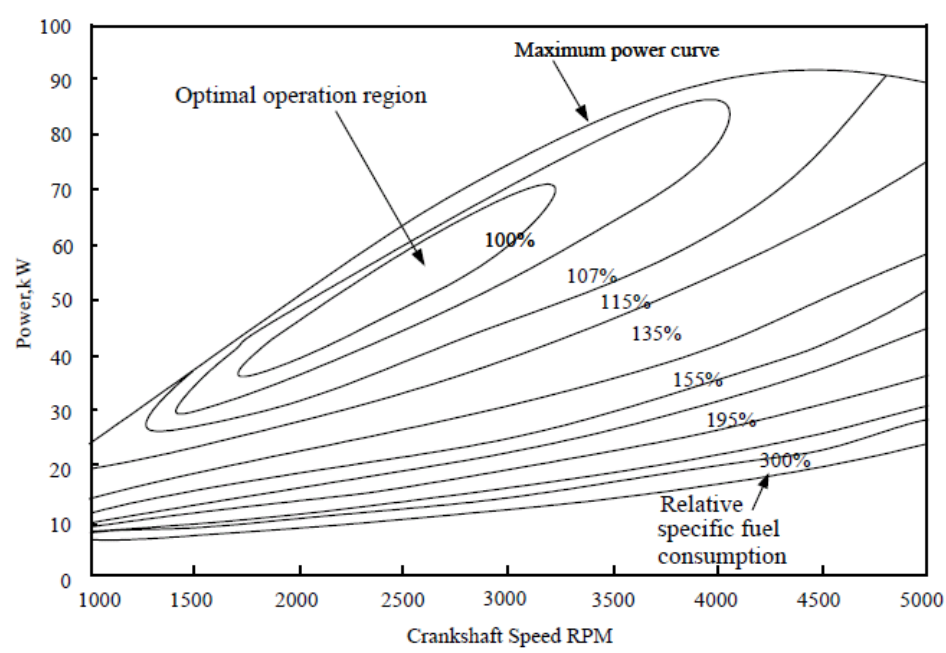

Fig. 3. Internal combustion engine optimal operating point.

deliver the minimum fuel consumption. This region is called the engine optimum operating point.

Since in series hybrid electric vehicles there is no limitation on engine shaft speed, we can always control it to operate at its optimum region when it is on to get the best fuel economy and shut it down when not needed. Based on this scheme and the responsibility of the engine as explained earlier to both drive the traction motor and charge the battery, several operation modes could be imagined for the vehicle. These modes are explained in more detail in [5].

\section{Controllers}

Several controllers are applied in a series hybrid electric vehicle as shown in Figure 4 to ensure that different components of the vehicle operate at their best possible condition and that the vehicle delivers the best performance it could. There are controllers for the electric motor, the brakes, the engine and all are supervised by the main vehicle controller. All these controllers receive commands and data from the 


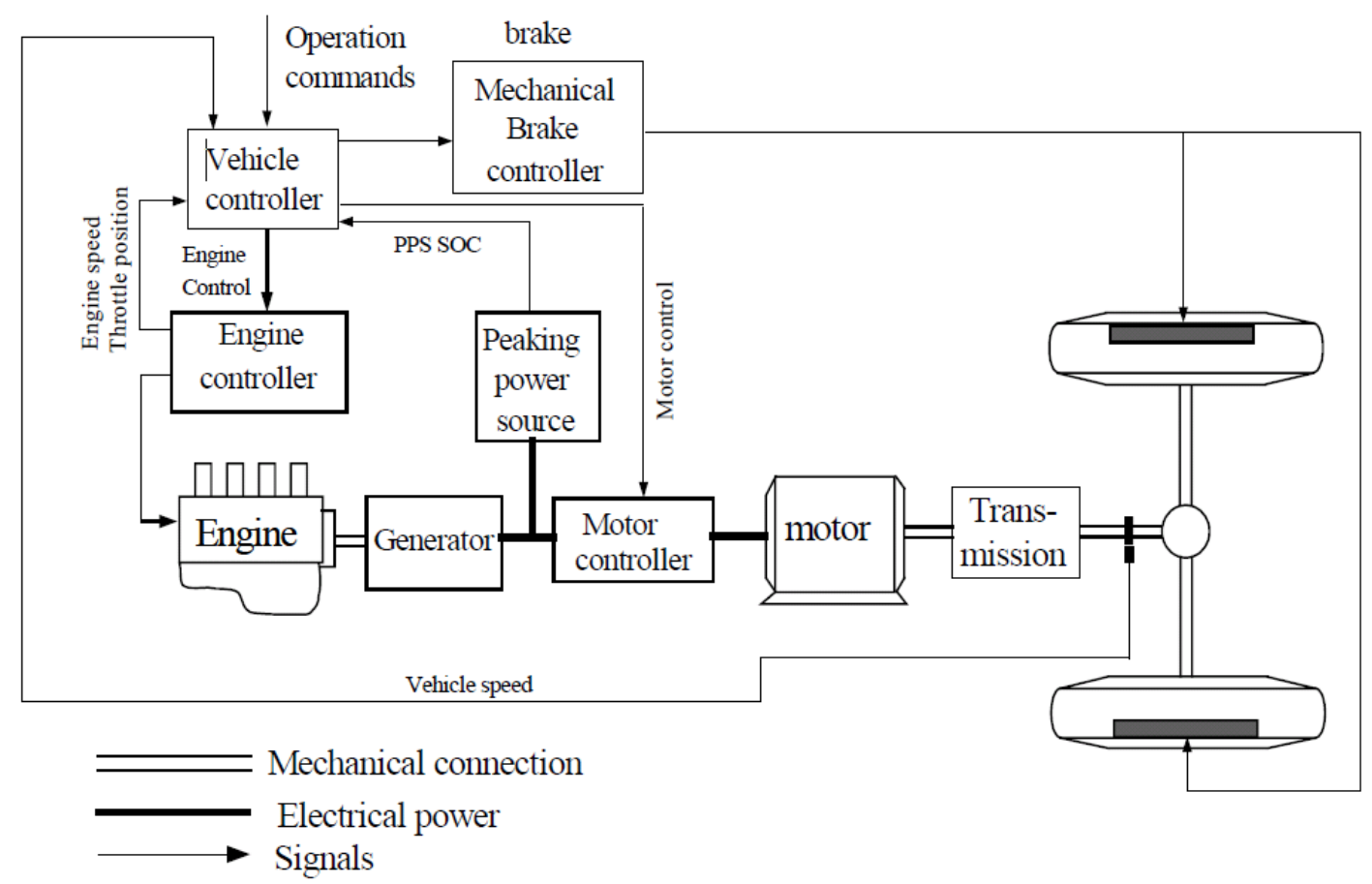

Fig. 4. Different controllers in series hybrid electric vehicle.

driver, the sensors, the road condition and their supervising controller.

There are two strategies that are common for the controller systems to follow, which are as follows:

\section{Maximum State of Charge for the Peaking Power Source}

This strategy is based on maintaining the state of charge of the peaking power source (battery) at its maximum throughout the drive cycle the vehicle is operating at. The important point to notice in this strategy is that the engine should always generate enough power to keep the battery fully charged. Any other power requirement from the traction motor should also be supplied by the engine. Considering this, four different operating situations could occur that are shown in in Figure 5. Points A, B, $\mathrm{C}$ and $\mathrm{D}$ are referring to these operating situations: 


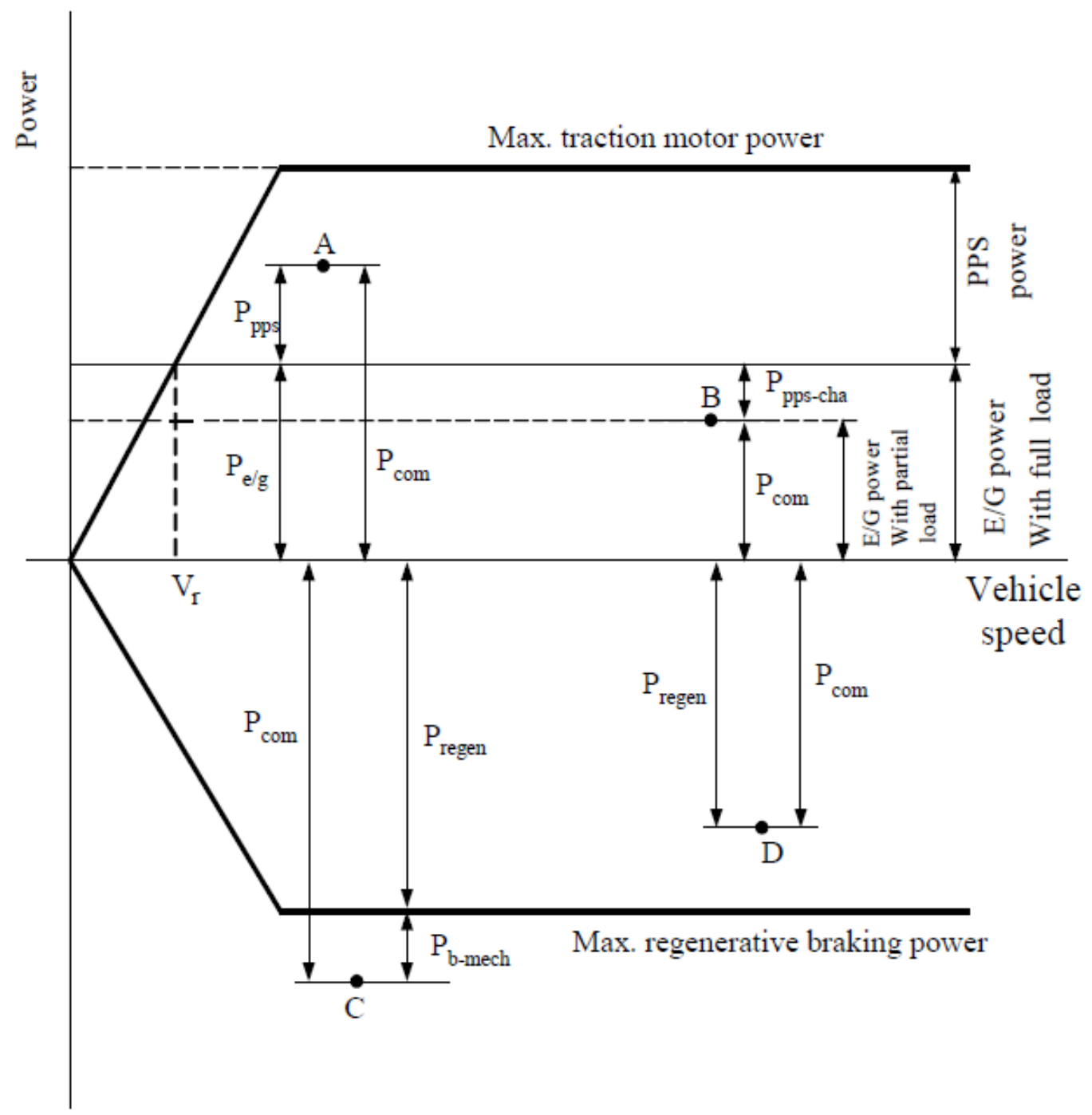

Fig. 5. Maximum state of charge control strategy for series hybrid electric vehicles. 
- A: Hybrid Traction Mode

Point A shows the mode that the load power is greater than what the engine/generator can support by itself. Therefore, the traction motor is supported by both the engine/generator and the battery.

- B: Engine/Generator Alone Traction Mode

Point B shows the vehicle in the mode that the engine/generator supplies more power than what the traction motor needs. Therefore, not only the traction motor receives its needed power from the engine, the battery is also being charged by the excess of the power that the engine generates. This lets the engine to operate at its optimal point. If the battery is charged enough and should not receive more power, while the traction motor still demands more power than what the battery can supply by itself, the engine will be forced to operate at a sub-optimal point.

\section{- C: Hybrid Braking Mode}

At this point, the braking power by the traction motor is not enough to stop the vehicle, so mechanical brake power is also applied.

- D: Regenerative Braking Mode

In this mode, the power from the traction motor is more than enough to stop the vehicle. Only regenerative braking is used in this point.

\section{Engine turn on/off}

Point B in Figure 5 reveals a hidden point that if the vehicle is to be used in a highway drive cycle for most of the time, the battery can get charged in the beginning and leave the engine operate at a sub-optimal region for the rest of the trip. This will result in a very high fuel consumption. To avoid this situation a new control strategy 
should be developed that is based on keeping the engine at its optimal operating point as much as possible with a compromise on the battery state of charge. For this purpose, an acceptable minimum and maximum margin could be defined for the SOC such that the controller tries to keep the SOC within the boundaries by operating the engine at its optimal point. This is shown in Figure 6. This figure shows the timing between the engine operation and battery charging/discharging function.

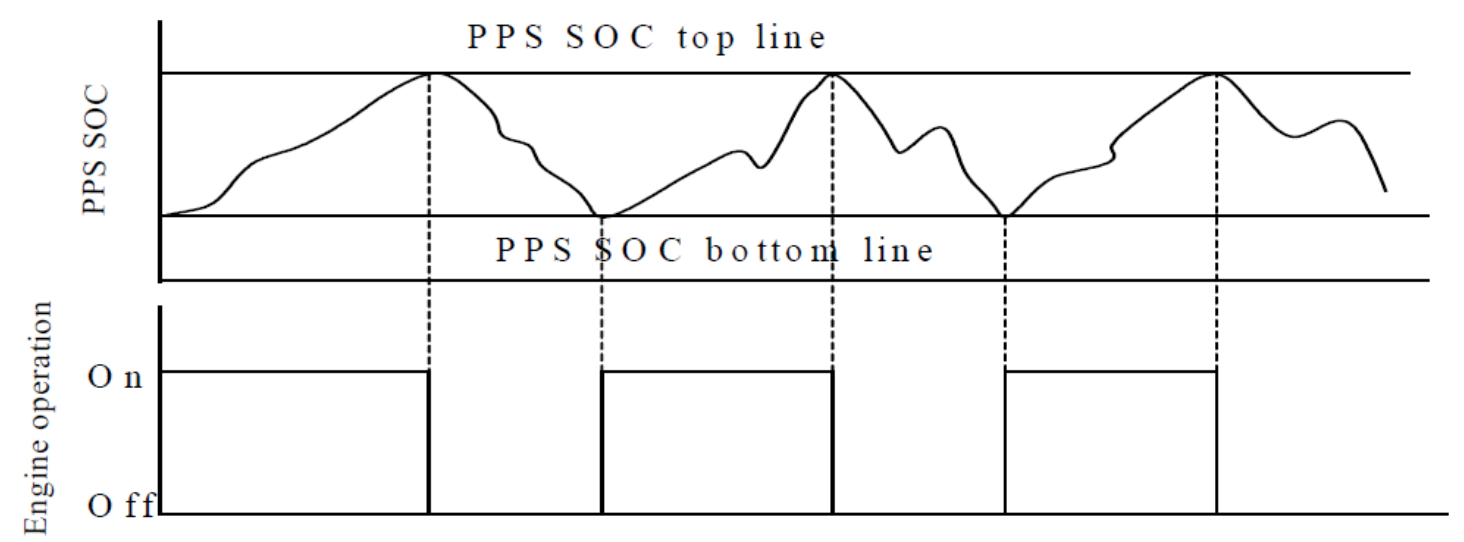

Fig. 6. Engine ON/OFF control strategy for series hybrid electric vehicles.

\section{E. Physical Equations Describing Different Components in the Vehicle}

The vehicle design procedure is all about sizing different components in the vehicle so that they build a car that meets specific performance characteristics and this is possible by defining every component by physical models and mathematical equations. In this section the physical models governing the behavior of each component in the vehicle will be discussed and their relationship with performance measures will be established. Details of vehicle dynamics, electric motors and converters, engine models and other technical information are used in this discussion that could be found in more depth in references [6], [7] and [8] respectively. 


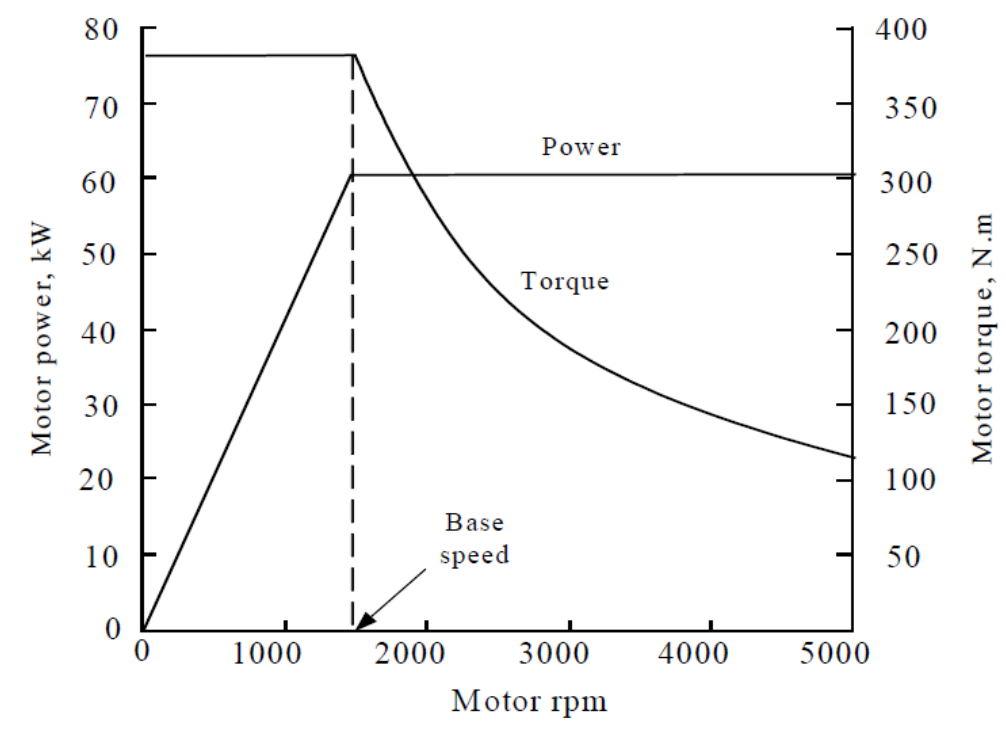

Fig. 7. Electric motor power and torque for different shaft speeds.

\section{Electric Motor}

The torque-speed and power-speed characteristics of a typical electric motor are shown in Figure 7. The output torque of the motor is constant from zero speed until its base speed. After the base speed motor enters a constant power phase. The 'x-factor' of an electric motor is defined as the ratio of motor maximum speed to its base speed:

$$
x=\frac{\text { Motor maximum speed }}{\text { Motor base speed }}
$$

Increasing the $\mathrm{x}$-factor at a fixed power will result in a reduction in the base speed and this will make the maximum torque of the motor larger. This is shown in Figure 8. Higher maximum torque brings better acceleration performance, better gradeability and easier transmission design.

Since in all types of electric vehicles and in the series hybrid electric vehicles the electric motor is the direct propulsion source for the wheels through transmission, its characteristics determine the acceleration and gradeability performance. Therefore, 


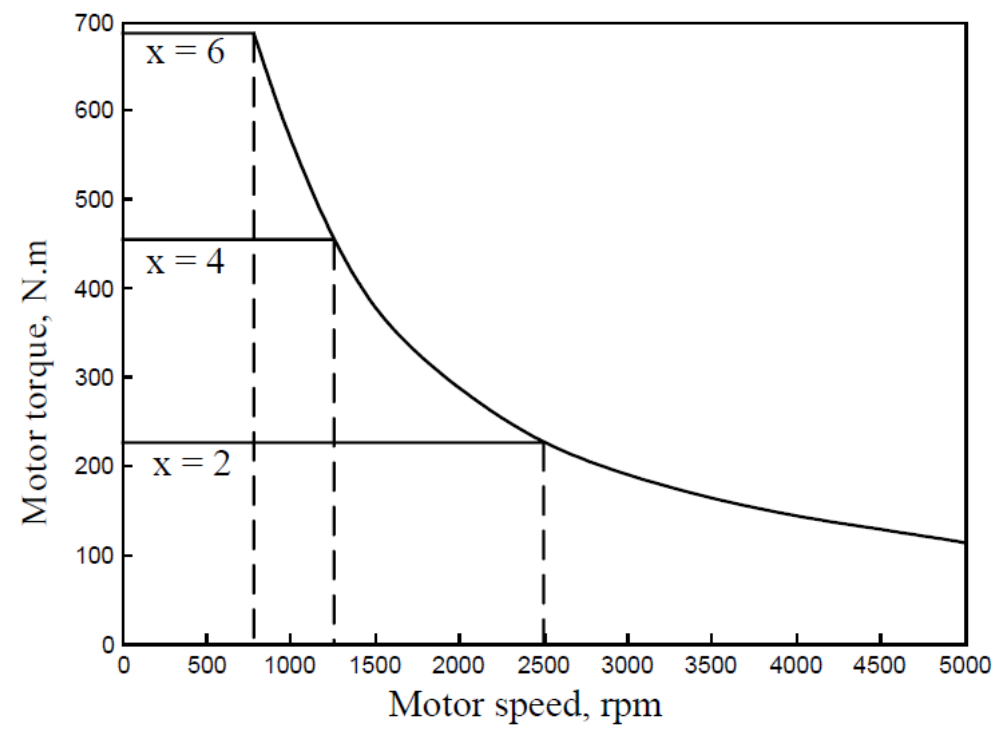

Fig. 8. Effect of x-factor on the maximum torque of an electric motor.

the electric motor ratings are determined by the mentioned performance requirements, and transmission characteristics. The factors involved in electric motor power determination are:

- Power needed to accelerate the vehicle mass from the speed of $V_{b}$ to $V_{f}$. This will be calculated as:

$$
P_{a c c}=\frac{\delta M}{2 t_{a}}\left(V_{f}^{2}+V_{b}^{2}\right)
$$

where

$$
\begin{aligned}
P_{a c c} & =\text { Power needed to accelerate vehicle from } V_{b} \text { to } V_{f} \\
M & =\text { Vehicle mass } \\
t_{a} & =\text { Acceleration time } \\
V_{f} & =\text { Final speed of the vehicle }(\mathrm{m} / \mathrm{s}) \\
V_{b} & =\text { Vehicle base speed }(\mathrm{m} / \mathrm{s})
\end{aligned}
$$

- Power needed to overcome the friction between the road and the wheels - rolling 
resistance:

$$
P_{r r}=\frac{2}{3} M_{v} g f_{r} V_{f}
$$

where

$$
\begin{aligned}
& P_{r r} \quad=\text { Power needed to overcome the wheel rolling resistance } \\
& g \quad=\text { Gravitational acceleration } \\
& f_{r} \quad=\text { Tire rolling resistance coefficient }
\end{aligned}
$$

- Power required to overcome the aerodynamic drag force at any speed:

$$
P_{\text {aero }}=\frac{1}{5} \rho_{a} C_{D} A_{f} V_{f}^{3}
$$

where

$$
\begin{aligned}
& P_{\text {aero }}=\text { Power needed to overcome the aerodynamic drag force } \\
& \rho_{a} \quad=\text { Air density factor }=1.202 \mathrm{~kg} / \mathrm{m}^{3} \\
& C_{D} \quad=\text { Aerodynamic drag coefficient } \\
& A_{f} \quad=\text { Vehicle front area }\left(\mathrm{m}^{2}\right)
\end{aligned}
$$

The summation of these three powers will give the total traction effort that the electric motor should deliver:

$$
P_{t}=\frac{\delta M}{2 t_{a}}\left(V_{f}^{2}+V_{b}^{2}\right)+\frac{2}{3} M_{v} g f_{r} V_{f}+\frac{1}{5} \rho_{a} C_{D} A_{f} V_{f}^{3}
$$

\section{Transmission}

As was discussed earlier, the traction power to the wheels in a series hybrid electric vehicle is provided directly by the electric motor. The torque-speed characteristics of an electric motor as shown in Figure 7 and 9 is well suited for the torque requirements of a vehicle: at the constant power region it provides high torque at low speeds and lower torque for higher speeds. This is not true for an internal combustion engine 
though. The torque-speed characteristics of an ICE is shown in Figure 10 and it is observable that by deviating from the optimum operating speed of the engine the fuel consumption grows exponentially but the supplied torque decreases.

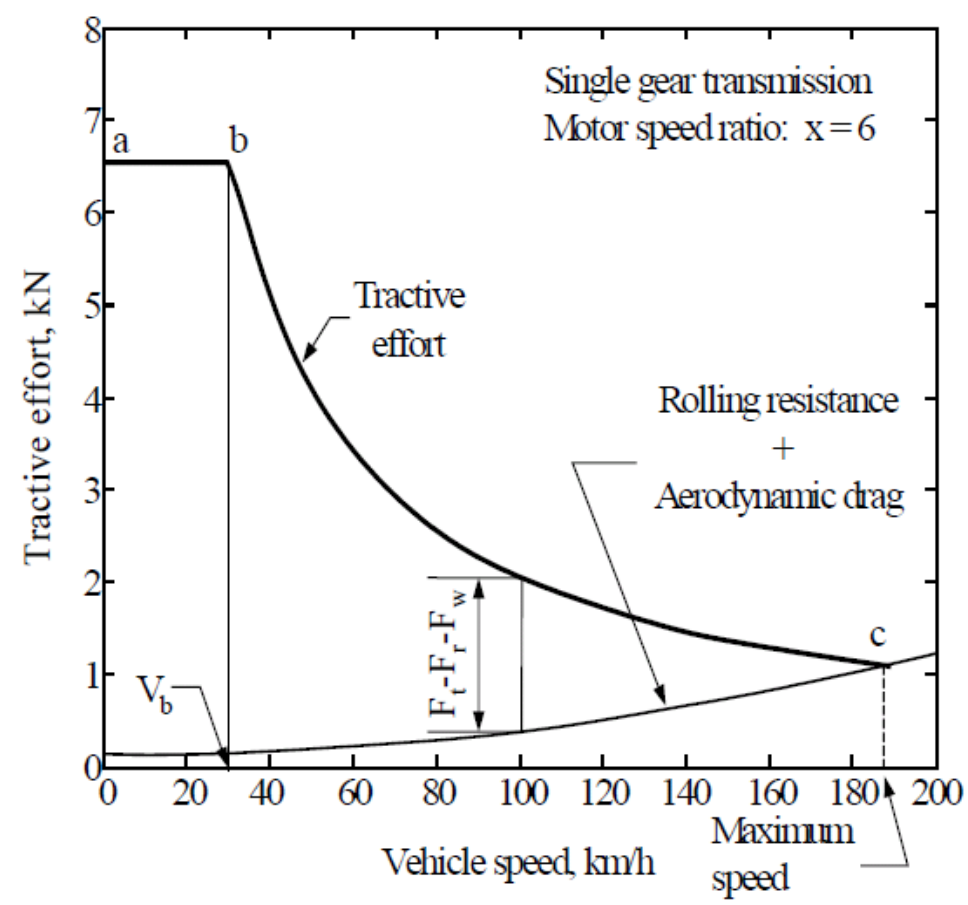

Fig. 9. Torque-speed profile for a single gear transmission electric motor with rolling resistance and aerodynamic drag.

To fix this problem in the gasoline engine vehicles, several gears are used in the gearbox to be able to move the good portion of the ICE torque-speed profile to different speeds by different gears and maintain a semi-optimal operation of the engine all the time. Figure 11 shows how we can get close to the ideal torque characteristics by adding multiple gears.

Figure 12 compares the torque-speed profile of an ICE with multiple gears and an electric motor with only one gear to the ideal desired profile. The single gear transmission in the series HEV's is to map the maximum speed of the motor to the 


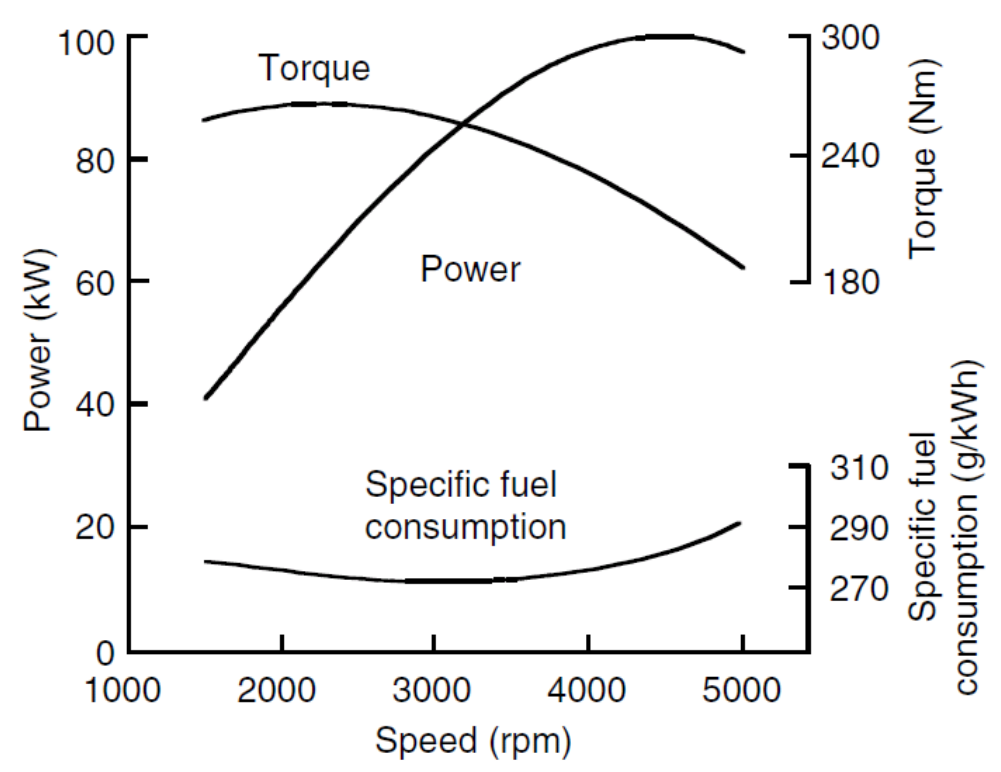

Fig. 10. Torque-speed and power-speed profiles for an internal combustion engine. Both profiles are different than the ideal desired shapes. The figure also shows the fuel consumption goes up by getting away from the optimal operating speed of the engine.

desired maximum speed of the vehicle by the wheels. From Figure 13 one can calculate this relationship at follows:

$$
F_{t}=\frac{T_{p} i_{g} \eta_{t}}{r_{d}}
$$

where

$$
\begin{aligned}
F_{t} & =\text { Tractive effort } \\
i_{g} & =\text { Gear ratio } \\
\eta_{t} & =\text { Transmission efficiency } \\
r_{d} & =\text { Tire radius }
\end{aligned}
$$

The gear ratio is designed such that the vehicle reaches its maximum speed at the maximum speed of the electric motor. Therefore the gear ratio, $i_{g}$ will be calculated 


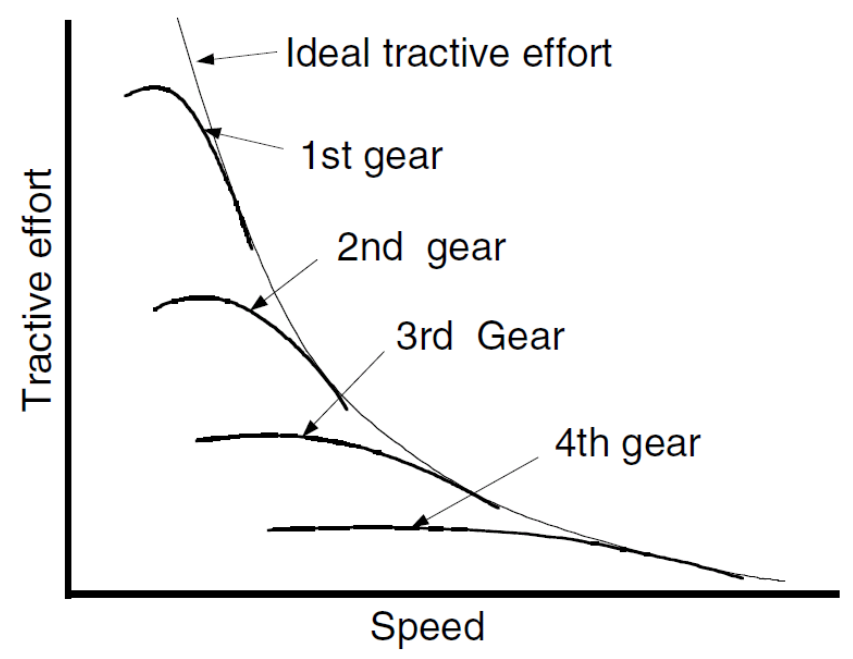

Fig. 11. Torque-speed profile for an internal combustion engine with a multi gear transmission. The transmission helps the torque profile become closer to the ideal required shape.

as follows:

$$
i_{g}=\frac{\pi n_{\max } r_{d}}{30 V_{\max }}
$$

where

$$
\begin{array}{ll}
i_{g} & =\text { Gear ratio } \\
n_{m, \max } & =\text { Maximum speed of electric motor } \\
n_{\max } & =\text { Maximum speed of vehicle }(\mathrm{m} / \mathrm{s}) \\
r_{d} & =\text { Tire radius }(\mathrm{m})
\end{array}
$$

\section{Engine}

The role of the engine and generator in the series hybrid vehicle is to supply electric charge both to the electric motor when the battery does not have enough power to feed to the motor, and to the battery to keep it charged. To design an engine to play these roles in the best way, we need to take two different scenarios into account: 


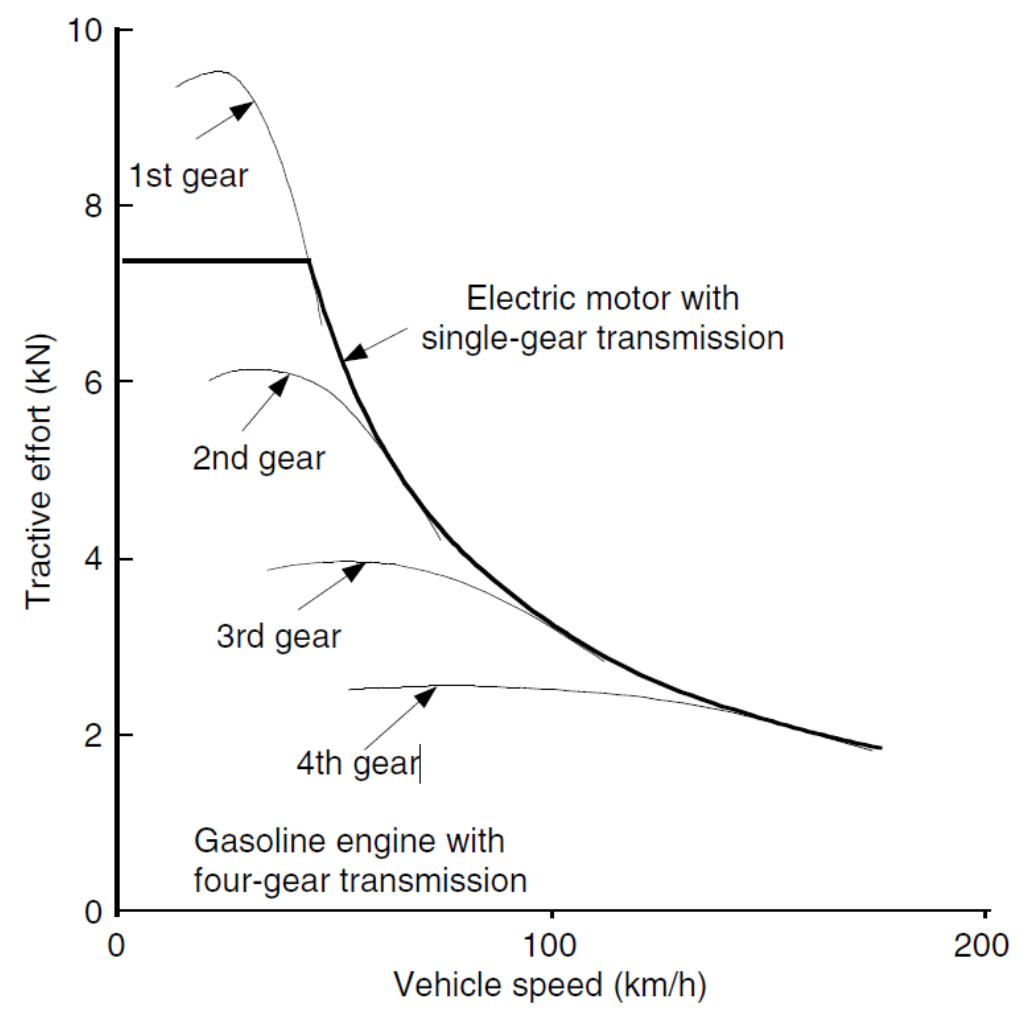

Fig. 12. Torque-speed profile comparison for an internal combustion engine with a multi gear transmission and an electric motor with a single gear transmission. The electric motor profile matches the ideal torque requirement profile without need for multi gear transmission.

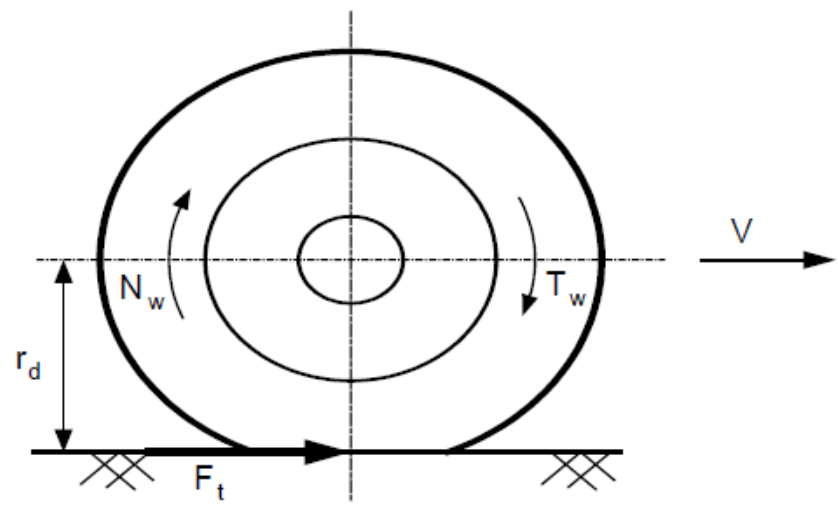

Fig. 13. Torque, tractive effort and longitudinal speed of the vehicle. 


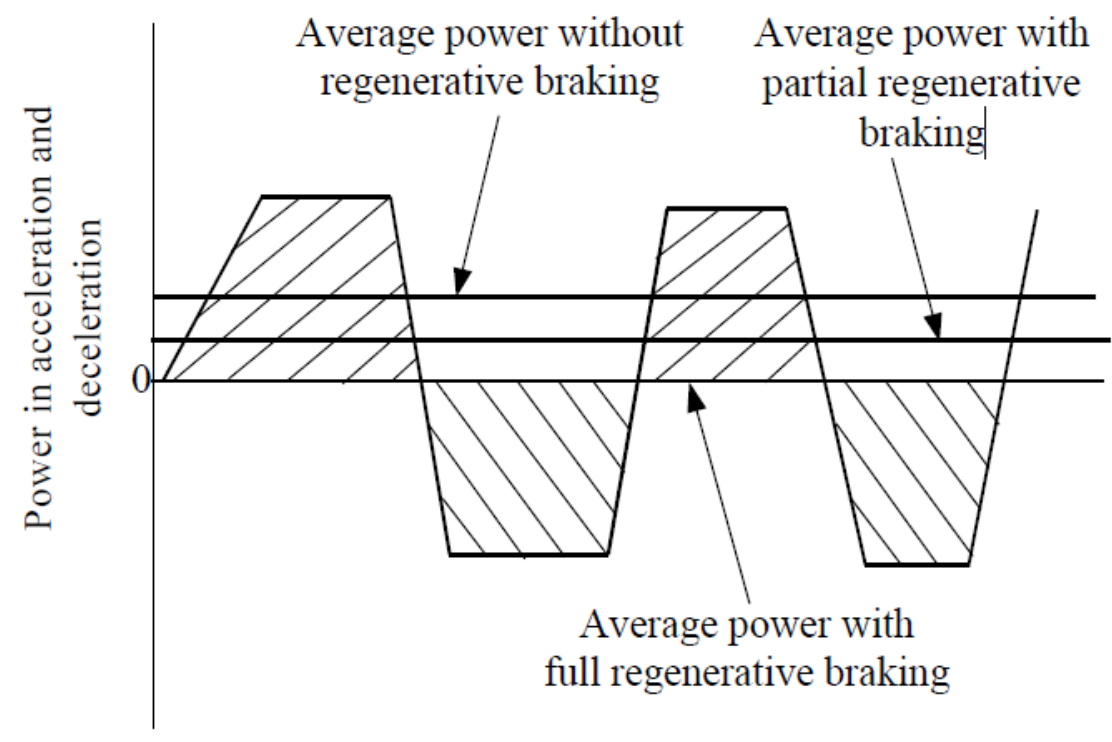

Fig. 14. Tractive power versus time in an stop and go drive routine.

- designing the engine for driving the vehicle at a constant cruise speed for a long distance. In this case the engine must have enough power to move the vehicle without needing any other energy source. This means that the engine power should compensate for the power needed to move the vehicle mass and the power needed to overcome the air resistance against vehicle's movement. The minimum power needed for this task in a constant cruise speed is calculated as follows:

$$
P_{\text {cruise }}=\frac{V}{1000 \eta_{t} \eta_{m}}\left(M g f_{r}+\frac{1}{2} \rho_{a} C_{D} A_{f} V^{2}\right)
$$

where $\eta_{t}$ and $\eta_{m}$ are transmission and electric motor drive efficiencies respectively.

- designing the engine to operate the vehicle in an urban stop-and-go profile. In this scenario as could be seen in Figure 14 the engine should be able to provide enough average power to keep the vehicle moving for a limited period of time, 
$T$, at a varying speed profile, and also to provide enough power to accelerate the vehicle from stop to a constant speed. The required power for this purpose could be calculated as follows:

$$
P_{\text {avg }}=\int_{0}^{T}\left(M g f_{r}+\frac{1}{2} \rho_{a} C_{D} A_{f} V^{2}\right) \cdot V d t+\frac{1}{T} \int_{0}^{T} \delta M \frac{d V}{d t} d t \quad(k W)
$$

This power is needed to maintain an acceptable amount of charge in the battery. Also, since $P_{\text {avg }}$ is calculated for stop-and-go profiles, it is dependent on the drive cycle that is being followed.

\section{Peaking Power Source - Battery}

The peaking power source or the battery, together with the engine supply the required power to the electric motor. The obvious result of this statement would be that the total power that the engine and the battery can supply should be greater than what the electric motor needs. If $P_{m, \max }$ is the rated power of the electric motor, $P_{\text {eng }}$ the power provided by the engine and $P_{P P S}$ the power provided by the battery, the following equation must stand true:

$$
P_{P P S} \geq \frac{P_{m, \max }}{\eta_{m}}-P_{e n g}
$$

where $P_{b}$ is the power capacity of the battery.

\section{Battery Energy Capacity}

In the internal combustion engine, the energy is measured in the physical unit of gasoline volume per unit distance. The most common unit is the liter per $100 \mathrm{~km}$. In U.S. the common energy measure is the number of miles per gallon of fuel or $m p g$. In the case of electric vehicles though, the energy is stored in the batteries and 

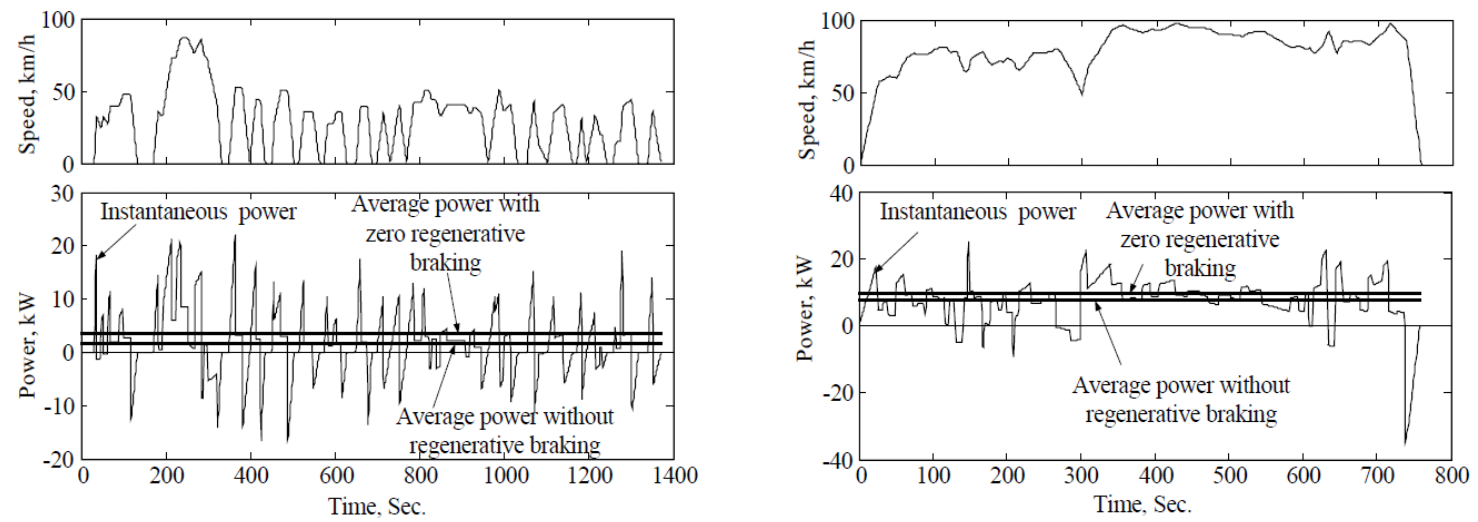

Fig. 15. Tractive power versus time for urban and highway drive cycles.

so a proper energy measure could be $k W h$. The driving range for these vehicles could also be measured by the number of miles the vehicle can travel on one full charge of the batteries.

The energy that the battery supplies could be calculated by integrating the instantaneous power that it provides to move the vehicle on its drive cycle:

$$
\Delta E=\int_{0}^{T} P_{p p s} d t
$$




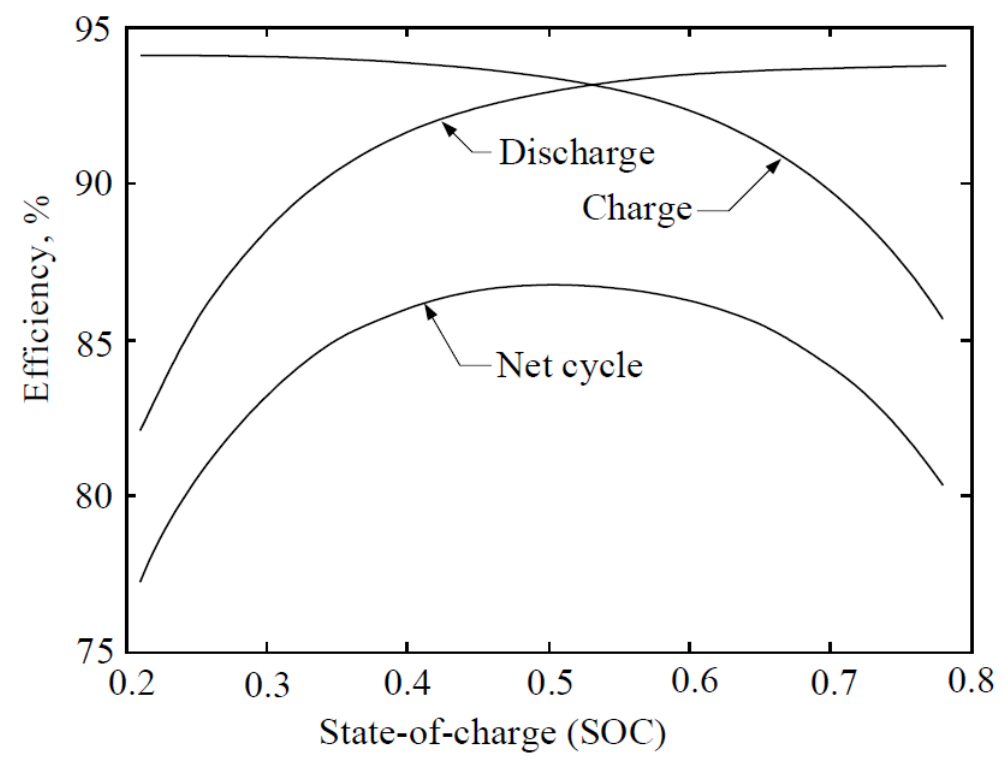

Fig. 16. Battery charging and discharging efficiency at different SOC's.

Figure 15 shows two very common drive cycles, an urban and a high way cycle and the instantaneous power needed for a vehicle to move on them. Positive power means the power that the battery gives to the vehicle, and the negative one means the power the vehicle gives to the battery to charge it up.

State of charge of a battery is defined as:

$$
\text { Battery state of charge }=\frac{\text { Present charge of the battery }}{\text { Maximum charge that can be stored in the battery }}
$$

which is 1 for a fully charged battery and zero for a fully drained out one. The battery has different charging and discharging efficiencies as shown in Figure 16

The energy capacity of the battery could be calculated from the maximum energy change in the battery $\left(\Delta E_{\max }\right)$ which is dictated by the controller, and its maximum and minimum state of charge:

$$
E_{c a p}=\frac{\Delta E_{\text {max }}}{S O C_{t o p}-S O C_{b o t t}}
$$


where

$=$ Energy capacity of the battery.

$=$ Maximum variation in battery energy over the drive cycle.

$=$ Maximum SOC of the battery.

$=$ Minimum SOC of the battery. 


\section{CHAPTER III}

\section{CONVENTIONAL METHOD OF SERIES HYBRID ELECTRIC VEHICLE DESIGN}

\section{A. Introduction}

The conventional design consists of specifying the characteristics of all the building components of a vehicle from a set of given performance criteria and some other fix known parameters. The building components of a hybrid electric vehicle include the electric motor, internal combustion engine, generator, gearbox, battery and etc. Some examples of performance criteria include acceleration time and distance, gradeability, vehicle maximum speed and so forth. The physical equations relating the components to the performance measures which were discussed in the previous chapter are used in performing the vehicle design by the conventional method. A design example by this method will be demonstrated in the following in order for the reader to have a better picture of the concept and to be able to compare it later with the proposed method of this research.

\section{B. Design Question}

The vehicle that is going to be designed here should meet the following performance requirements:

$$
\begin{array}{ll}
\text { Acceleration time }(0-100 \mathrm{~km} / \mathrm{h}) & 10 \mathrm{sec} \\
\text { Minimum gradeability } & 5 \% @ 100 \mathrm{~km} / \mathrm{h} \\
\text { Maximum speed } & 160 \mathrm{Km} / \mathrm{h}
\end{array}
$$

This vehicle also has the following given parameters: 
Vehicle mass

Single gear transmission efficiency

Vehicle front area $\left(A_{f}\right)$

Electrical motor and drive efficiency $\quad 85 \%$

Generator efficiency

Aerodynamic drag coefficient $\left(C_{D}\right)$

Rolling resistance coefficient $\left(f_{r}\right)$

Tire radius

$\operatorname{Air} \operatorname{density}\left(\rho_{a}\right)$
$1500 \mathrm{Kg}$

$90 \%$

$2.0 \mathrm{~m}^{2}$

90

0.3

0.01

$0.3 m$

$1.202 \mathrm{Kg} / \mathrm{m}^{2}$

\section{Traction Motor}

The traction motor should be strong enough to make the vehicle overcome all resistive forces against it as well as to enable it accelerate fast enough. The following equation states the traction motor power in order as summation of the power needed to accelerate the vehicle from an initial speed $\mathrm{Vb}$ to a final speed $\mathrm{Vf}$, the power needed to overcome the rolling resistance of the tires with the road and the required power to overcome the aerodynamic drag against the vehicle movement.

$$
P_{t}=\frac{\delta M}{2 t_{a}}\left(V_{f}^{2}+V_{b}^{2}\right)+\frac{2}{3} M_{v} g f_{r} V_{f}+\frac{1}{5} \rho_{a} C_{D} A_{f} V_{f}^{3}
$$

We are also interested in calculating the maximum torque that the electric motor yields. The motor torque is defined as:

$$
\text { Motortorque }=\frac{\text { Motor Power }}{\text { Motor Base Speed }}
$$


To start with the design procedure we know that

$M_{v}=$ Vehicle mass $(K g)=1500 K g$

$t_{a}=$ Acceleration time in $\sec =10 \mathrm{sec}$

$V_{f}=$ Final speed of the vehicle in $\mathrm{m} / \mathrm{s}=160 \mathrm{~km} / \mathrm{h}=44.44 \mathrm{~m} / \mathrm{s}$

$V_{b}=$ Vehicle speed at electric motor's base speed in $\mathrm{m} / \mathrm{s}=11.11 \mathrm{~m} / \mathrm{s}$

The motor base speed and maximum speed are related to each other by an $x$-factor defined as:

$$
x=\frac{\text { Motor maximum speed }}{\text { Motor base speed }}
$$

$V_{f}$ and $V_{b}$ are also related to each other by the same equation:

$$
x=\frac{V_{f}}{V_{b}}
$$

The value of the $x$-factor depends on the type of motor the designer chooses to use and here is assumed to be 4 . We also choose the motor maximum speed to be $5000 \mathrm{rpm}$ which will yield the motor base speed as $1250 \mathrm{rpm}$.

Plugging the given parameters and speed measures into the equation will yield a net load power of $82.5 \mathrm{~kW}$. Therefore the electric motor should have a minimum of $82.5 \mathrm{~kW}$ to overcome this load and further move the vehicle. The motor torque is also calculated as:

$$
\text { Motor torque }=\frac{82500}{1250}=66 \mathrm{Nm}
$$

Therefore, the following specifications are designed for the electric motor: 
Motor power

Motor rated torque

Motor base speed

Motor maximum speed 5000 rpm
$82.5 \mathrm{~kW}$

$63 \mathrm{Nm}$

$1250 \mathrm{rpm}$

The motor power and torque are dependent to the speed at which the motor is rotating at. These profiles are demonstrated in Figure 17.

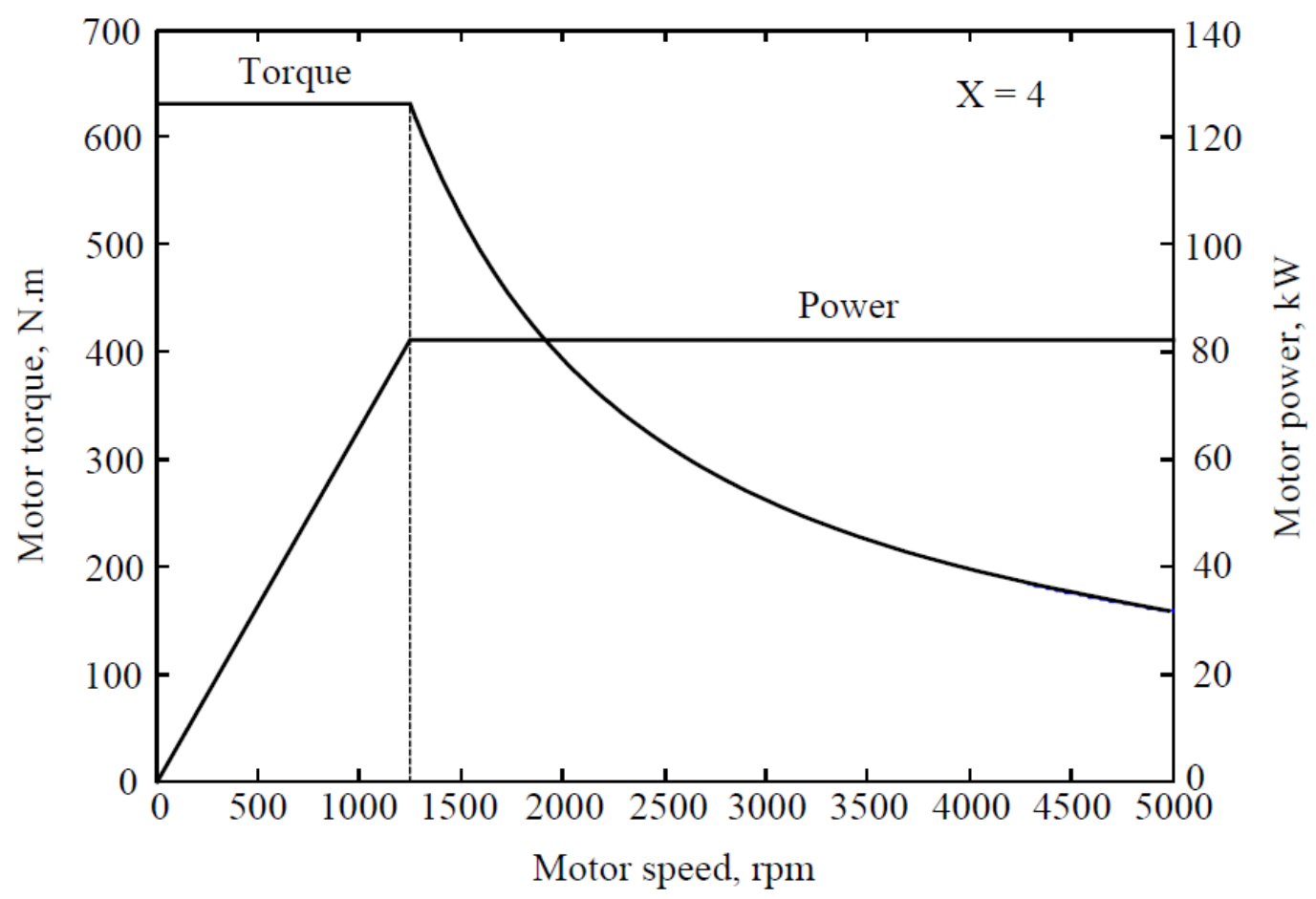

Fig. 17. Motor power and torque in different shaft speeds.

\section{Gear Ratio}

The electric motor is the main drive train that moves a hybrid vehicle. Vehicles with internal combustion engine have a multi-gear transmission between the wheels and the engine, to obtain the speed-torque characteristic that generates the best traction. 
Since the speed-torque profile of an electric motor is the ideal shape for this purpose, there is usually a single gear transmission used in hybrid electric and plug-in hybrid electric vehicles. The purpose of the single gear is to map the maximum rotational speed of the motor to the maximum longitudinal speed of the vehicle. This relationship is shown here:

$$
i_{g}=\frac{\pi n_{m, \max } r}{30 V_{\max }}
$$

where

$n_{m, \max }=$ Motor maximum speed in $\mathrm{rpm}=5000 \mathrm{rpm}$

$r=$ Tire radius $=0.3 \mathrm{~m}$

$V_{\max }=160 \mathrm{~km} / \mathrm{h}$

The calculated gear ratio is 3.29 .

E. Gradeability and Acceleration Performance Verification

Acceleration performance and gradeability are performance measures that are completely dependent on the electric motor characteristics. There are mathematical methods including what has been discussed in [9] to calculate the acceleration time and distance and the gradeability from the electric motor specifications. The following equations describe this in detail:

$$
\begin{aligned}
t_{a} & =\int_{V_{1}}^{V_{2}} \frac{M \delta}{\left(T_{p} i_{g} \eta_{t} / r_{d}\right)-M g f_{r}-(1 / 2) \rho_{a} C_{D} A_{f} V^{2}} \\
S_{a} & =\int_{V_{1}}^{V_{2}} \frac{M \delta V}{\left(T_{p} i_{g} \eta_{t} / r_{d}\right)-M g f_{r}-(1 / 2) \rho_{a} C_{D} A_{f} V^{2}}
\end{aligned}
$$


where $t_{a}$ is the acceleration time and $S_{a}$ is the acceleration distance. Using these equations, $t_{a}$ and $S_{a}$ are plotted for different vehicle speeds in Figure 18. This graph is used to verify that the vehicle meets the minimum acceleration requirements at the speed of $100 \mathrm{~km} / \mathrm{h}$.

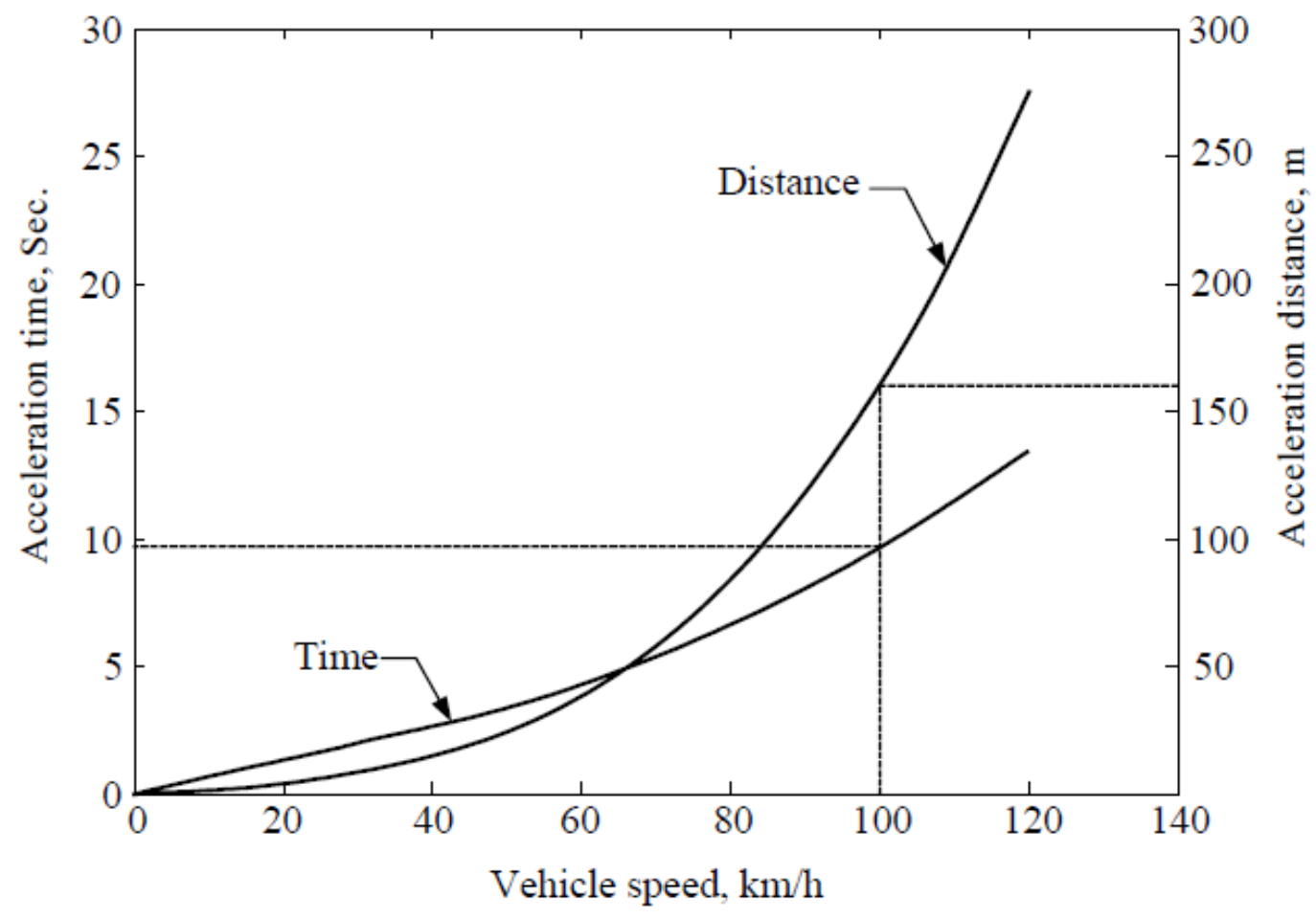

Fig. 18. Acceleration time and distance for various vehicle speeds.

The other performance requirement to be checked is the gradeability. We need to make sure that the vehicle has enough traction to overcome the required slope grade of the road. In this design question, we need the vehicle to be able to run at the speed of $100 \mathrm{~km} / \mathrm{h}$ on the grade of $5 \%$. For this purpose, we need to plot the tractive effort profile of the vehicle and the road resistance profiles for different slope grades on the same plot. The tractive effort of the vehicle could be calculated as $T_{p}$ from the following equation: 


$$
\frac{T_{p} i_{g} \eta_{t}}{r_{d}}=M g f_{r}+\frac{1}{2} \rho_{a} C_{D} A_{f} V^{2}+M g i
$$

The tractive effort has been plotted against vehicle speed in Figure 19. The grade value that the vehicle can support at the speed of $100 \mathrm{~km} / \mathrm{h}$ could be found out from this graph.

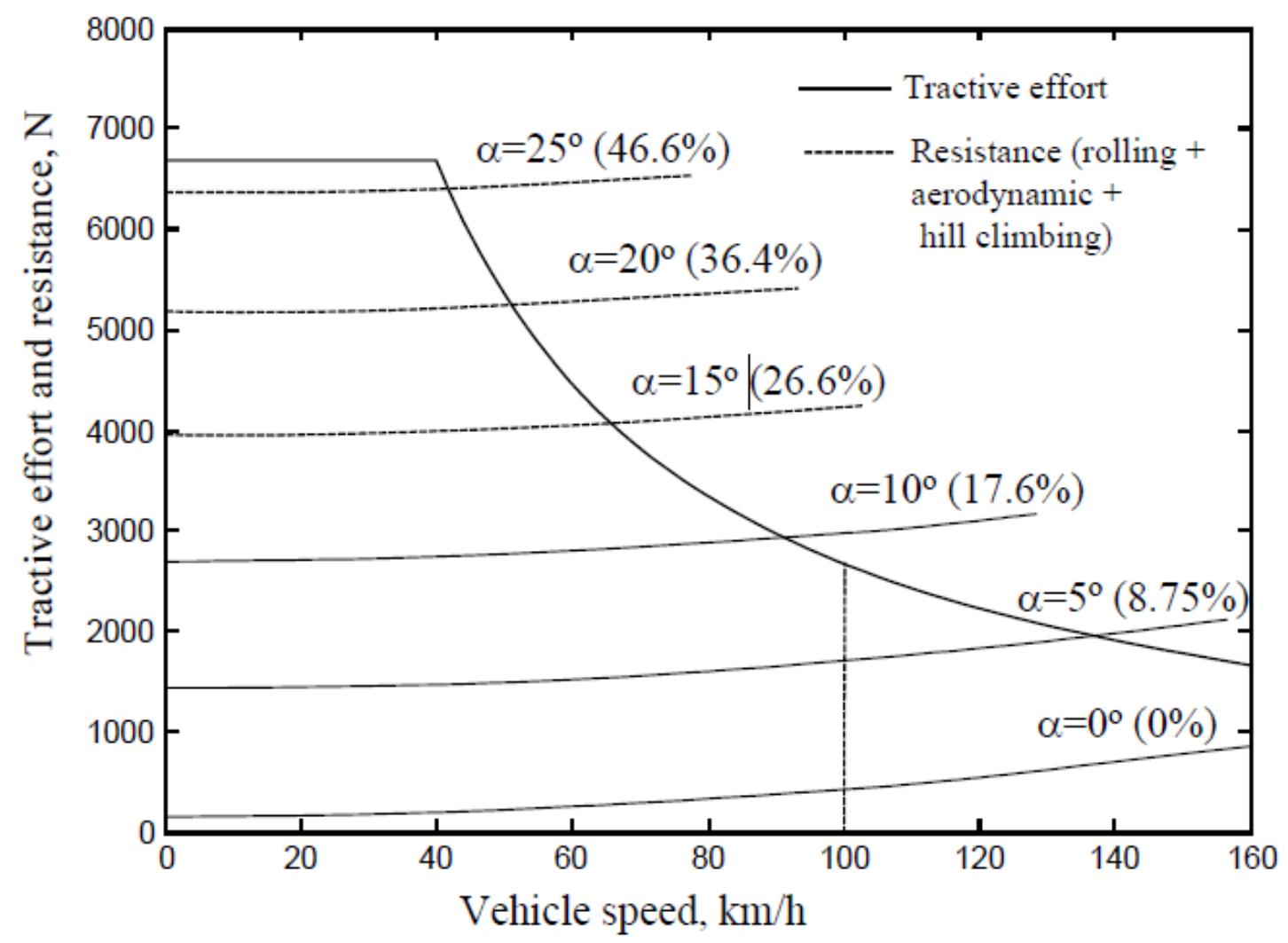

Fig. 19. Vehicle tractive effort and road resistance for various vehicle speeds and road slope grades.

Another useful graph is shown in Figure 20 that shows the calculated gradeability of the vehicle for different vehicle speeds. As could be seen in the graph, the designed vehicle achieves the minimum gradeability requirement of $5 \%$ at the speed 
of $100 \mathrm{~km} / \mathrm{h}$.

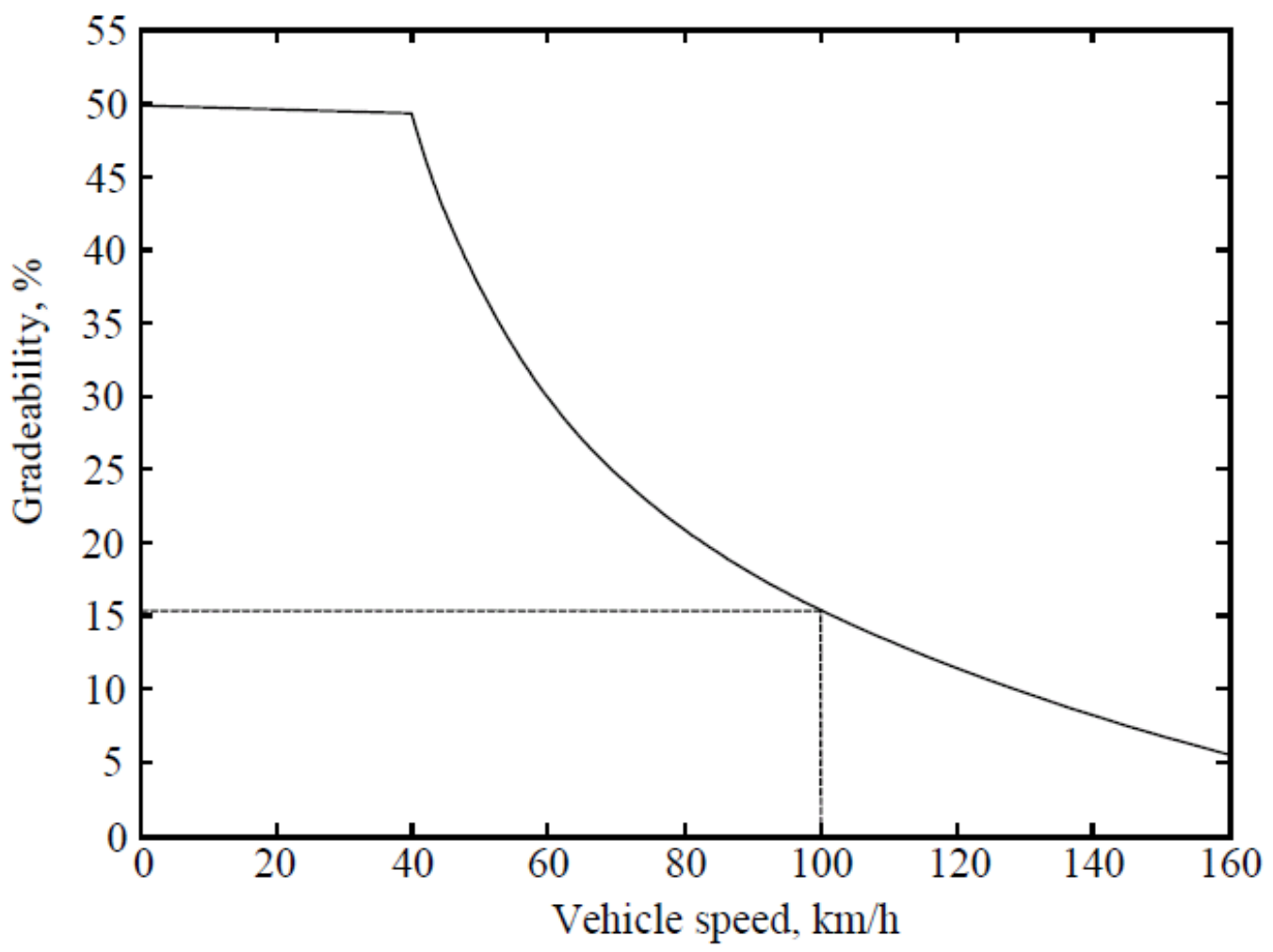

Fig. 20. Gradeability for various vehicle speeds.

\section{F. Engine}

To design the engine, we need to take two different scenarios into account:

- designing the engine for driving the vehicle at a constant cruise speed for a long distance. In this situation the engine is supposed to have enough power to move the vehicle without needing any other energy source. This means that the engine power should compensate for the power needed to move the vehicle mass and the power needed to overcome the air resistance against vehicle's movement. 
Table I. Average power with full and no regenerative braking for different drive cycles

\begin{tabular}{|l|l|l|l|ll|}
\hline & $\begin{array}{l}\text { Max. } \\
\text { Speed }\end{array}$ & $\begin{array}{l}\text { Average Average Power } \\
\text { Speed }\end{array}$ & Average Power \\
& $(k m / h)$ & $(\mathrm{km} / \mathrm{h})$ & Braking $(\mathrm{kW})$ & Braking $(\mathrm{kW})$ \\
\hline FTP75 Urban & 86.4 & 27.9 & 3.76 & 4.97 \\
FTP75 Highway & 97.7 & 79.6 & 12.6 & 14.1 \\
US06 & 128 & 77.4 & 18.3 & 23.0 \\
ECE-1 & 120 & 49.8 & 7.89 & 9.32 \\
\hline
\end{tabular}

The minimum power needed for this task is calculated as follows:

$$
P_{\text {cruise }}=\frac{V}{1000 \eta_{t} \eta_{m}}\left(M g f_{r}+\frac{1}{2} \rho_{a} C_{D} A_{f} V^{2}\right) \quad(k W)
$$

where $\eta_{t}$ and $\eta_{m}$ are transmission and electric motor drive efficiencies respectively.

- designing the engine to operate the vehicle in an urban stop-and-go profile. In this scenario the engine should be able to provide enough average power to keep the vehicle moving for a limited period of time, $T$, at a varying speed profile, and also to provide enough power to accelerate the vehicle from stop to a constant speed. The required power for this purpose could be calculated as follows:

$$
P_{a v g}=\int_{0}^{T}\left(M g f_{r}+\frac{1}{2} \rho_{a} C_{D} A_{f} V^{2}\right) \cdot V d t+\frac{1}{T} \int_{0}^{T} \delta M \frac{d V}{d t} d t \quad(k W)
$$

This power is needed to maintain an acceptable amount of charge in the battery. Also, since $P_{a v g}$ is calculated for stop-and-go profiles, it is dependent on the drive cycle that is being followed. Table I demonstrates the average power needed for some famous drive cycles. 
The minimum engine power should be greater than the power calculated from both scenarios. However, driving for a long time at cruise speed usually takes more power and therefore, usually $P_{\text {cruise }}$ is a good estimate of required engine power. By choosing $\eta_{t}=90 \%, \eta_{m}=84 \%$ and taking 80 miles $/ \mathrm{hr}$ as the highway cruise speed, the required engine power will be calculated as $32.5 \mathrm{~kW}$.

\section{G. Peaking Power Source}

The peaking power source or battery is the immediate direct source that drives the electrical motor in the series hybrid and electric vehicles. On the other hand, the battery is charged by the engine/generator.

There are two different factors that need to be designed for the battery:

\section{- power capacity}

The summation of total power stored in the battery and the power generated by the engine at any given time should be greater than or equal to the power that the electric motor needs as the only power consumer in the vehicle. This is stated in the following equation:

$$
P_{b} \geq \frac{P_{m, \max }}{\eta_{m}}-P_{e / g}
$$

where $P_{b}$ is the power capacity of the battery. From this equation, $P_{b}$ is calculated to be $67.8 \mathrm{~kW}$.

\section{- Energy capacity}

The energy capacity of the battery will determine how long the battery will support the vehicle under different driving conditions. Therefore, the drive cycle that the vehicle is traveling at and the engine management controller that 
determines when to turn the engine on or off to charge the battery are required to determine the minimum required energy capacity for the battery. For this purpose, we need to simulate the vehicle in a drive cycle using a controller. This has been demonstrated in the next section.

\section{H. Simulation with Drive Cycle and Controller}

As explained in the previous section the simulation with drive cycle and controller is used to determine the battery energy capacity. Different drive cycles could be used and here the FTP 75 is chosen. It could be seen in Figure 21. The controller that is used to manage the engine is based on engine-on-off strategy which is meant to keep the battery state of charge between a maximum and minimum level. These levels are decided to be 0.6 and 0.4 respectively. Therefore $S O C_{t o p}-S O C_{\text {bott }}=0.2$.

The total variation of the energy in battery turn out to be between $1.5 \mathrm{kWh}$ and $1 \mathrm{kWh}$ from simulation which gives the total energy variation of the battery as $\Delta E_{\max }=0.5 \mathrm{kWh}$. This yields the energy capacity of the battery as

$$
E_{p p s}=\frac{\Delta E_{\max }}{\Delta S O C}=\frac{0.5}{0.2}=2.5 \mathrm{kWh}
$$

Figure 21 shows the tractive effort needed for the drive cycle, the engine control command to turn on and off at the specified output power level, power to or from the battery and finally the state of charge of the battery in different times.

\section{Summary}

These were the steps to specify the major components of a series hybrid vehicle. The point to notice is that if at any time the designer wishes to change any of the design parameters or performance criteria, they have to start over and take all the mentioned 


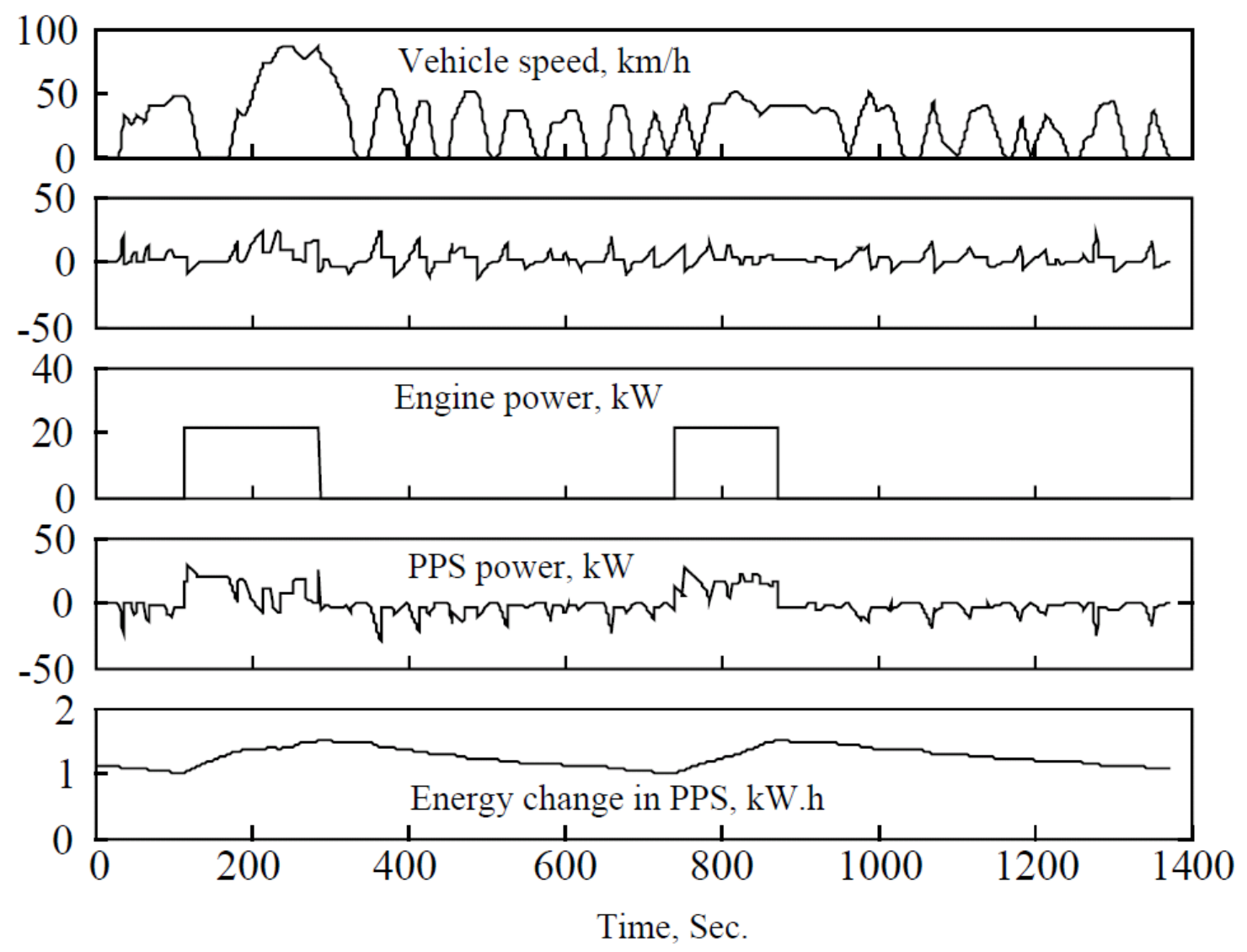

Fig. 21. Vehicle simulation for FTP 75 drive cycle and engine-on-off controller. From top to bottom: Vehicle speed or drive cycle, tractive effort generated by electric motor, engine on-off scheme with on-mode power, battery power, energy level change in battery (battery state of charge).

steps again in order to achieve the new design. More important than that is the fact that it is almost impossible in this method to start and do the design by a set of known parameters other than what are expected in this specific routine. All these problems are addressed in the new proposed method which is going to be explained next. 


\section{CHAPTER IV}

\section{THE NEW CAD/SIMULATION TOOL FOR VEHICLE DESIGN}

A. Concept of CAD/Simulation Tools for Vehicle Design, Their Evolution and Shortcomings

\section{Concept and Evolution}

Design of a vehicle in general is a very complicated and time consuming process because of its several different components and sophisticated relationships in their operations. It is both very risky and costly to do a full vehicle design completely by hand and to hope that it is going to meet all the desired design requirements. This was the main reason for appearing the very first versions of vehicle simulation applications.

A simulation applications is a piece of software that would get the designed values for all of the variables in the vehicle and runs them through the physics laws and vehicle dynamics equations implemented in the computer. They would plot some simple graphs to ease the analysis and verification of performance by the designer as well.

This was a good progress at the time in the sense that these simulation packages would eliminate the need to build an actual vehicle based on a design to be able to check if it meets certain requirements. But there was still need for more. Designers were still struggling in achieving the optimum design as well as keeping the costs down. Trial and error was still necessary; this time in simulation which costs less than building an actual copy.

The next generation of packages were simulation tools that would use modular models for different components of the vehicle. There were computer models for the 
engine, electric motor, battery and other components. Researchers and scientists could develop new models and the designers only needed to tweak the variables and tune them for their application. Advisor is a famous example of such an application.

All of the packages developed until this time were simulation only. They were not helping the vehicle designer through the design process; they were checking the designed vehicle against certain measurements. The next generation of applications aimed at the ways they could help the design process itself.

\section{Shortcomings}

There have always been shortcomings with either the simulation or design packages. One of the most important difficulties is that as mentioned before, the designer needs to perform multiple trials with the changes he is making in his design until he finds a relatively good solution which is not necessarily the best all the time. In the other word, there is not a way available in any application to guide the designer intelligently through the design process to get to the optimum choice he needs. Obviously this wastes a lot of time and effort with no guaranteed solution. The other problem is that in the conventional design method, if the designer decides to change a parameter or a performance criterion, he would need to redo the entire process as if he is designing a new vehicle. This will cause a large amount of time to be wasted. Another problem is that it is impossible in the conventional method to design a vehicle around a specific component for any reason like cost, shape or so forth other than going through trial and error. The same situation is when the designer needs to do a sensitivity analysis based on a small change in one of the designed variables. This is a difficult and extremely time-consuming process in the conventional method. The biggest disadvantage of all about the conventional method however is in the fact that it gives the designer a single solution for his design problem and leaves him blind of all other 
possible options that could be used and might be even better in other aspects.

The new concept that has been presented in this research answers all the mentioned problems using a new approach to design a vehicle. The following summarizes the advantages of the proposed tool over conventional design tools:

1. The proposed tool allows the designer to choose any arbitrary set of variable to be known and leave the rest as the ones to be solved for, either they are vehicle component characteristic variables or performance measures. This provides a great amount of flexibility and success in designing a vehicle from any available information about it.

2. Instead of starting from single values, the new tool can work with a range of possible values for the known variables and suggest range of feasible values for the unknown variables. This provides the capability of refining the design even further and performing sensitivity analysis.

3. The proposed tool is a package that offers both design and simulation capabilities. It includes analytical performance simulation as well as simulation with arbitrary drive cycles and engine controllers.

4. It provides the capability of $2 \mathrm{D}$ and $3 \mathrm{D}$ representation of any arbitrary set of design variables in the solution space.

\section{B. The New Design/Simulation Tool}

In the following different sections of the proposed CAD tool are introduced and their function has been explained. 


\section{Design}

The "Design" interface is where the known variables of the vehicle as well as the fix parameters are entered as inputs and an initial range of possible solutions for the vehicle design question will be provided. Figure 22 is a snapshot of this interface which will be further explained in the following.

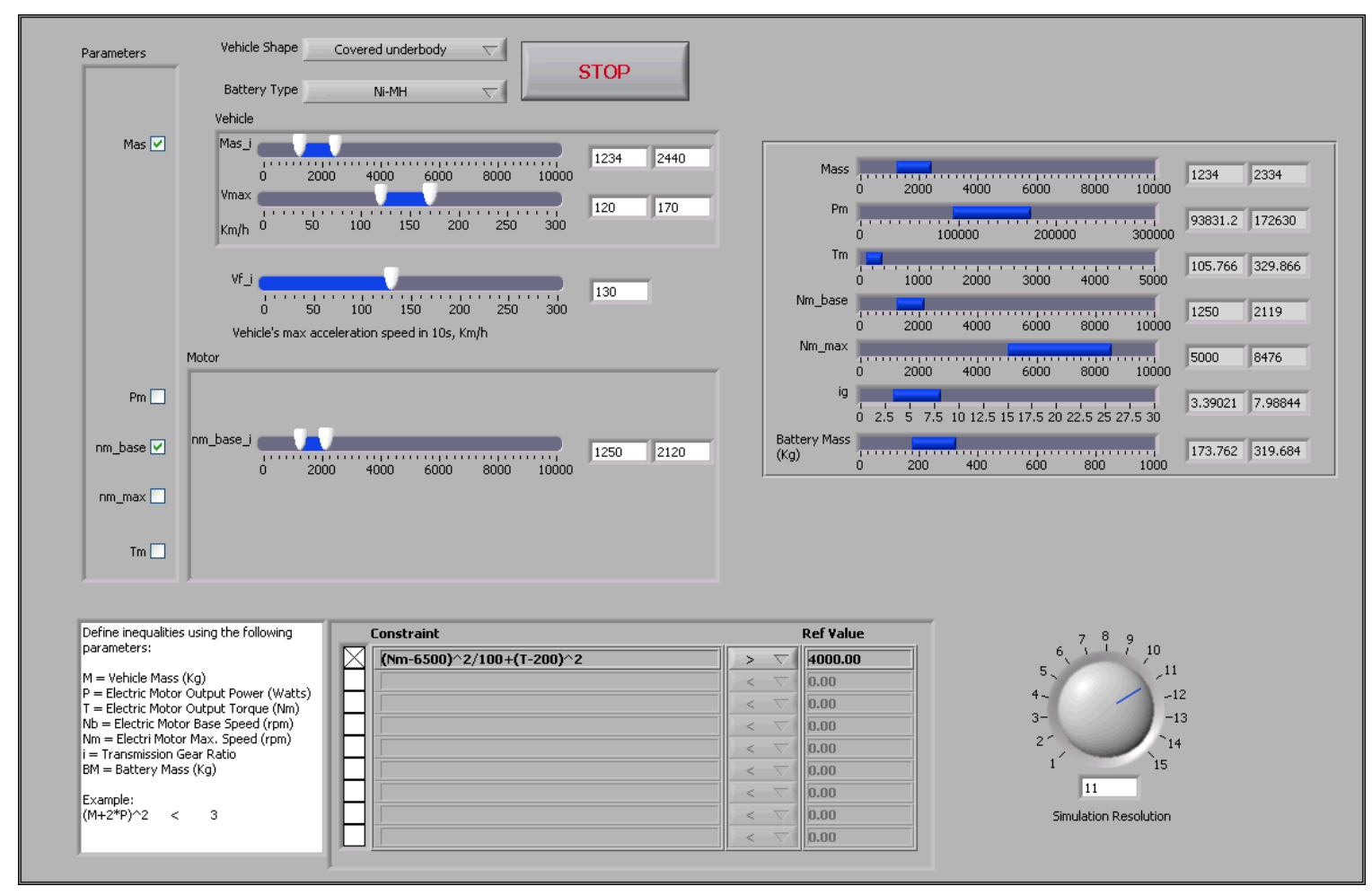

Fig. 22. Snapshot of "design" interface of the proposed CAD tool.

At the top of the interface, there is a scroll down option that helps the designer choose the shape of the vehicle as well as the battery technology to be used in the vehicle. This menu is shown in Figure 50. The vehicle shape determines the aerodynamic drag coefficient, $C_{D}$. The battery technology is important in calculating the volume and weight of the battery based on the required power and energy capacity.

In the very left side of the interface the designer can select which variables to 


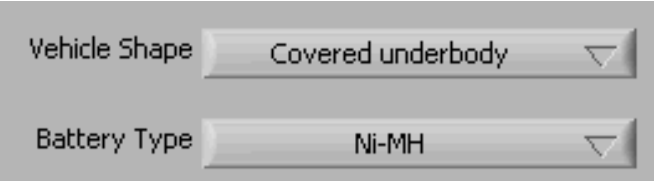

Fig. 23. Vehicle shape determined aerodynamic drag coefficient; battery technology determines its charging characteristics and mass.

be considered as knowns and which ones as unknown int the design process. This is shown in Figure 51. By checking the box for any variable, it is selected as known and the designer will have to determine its variation range.

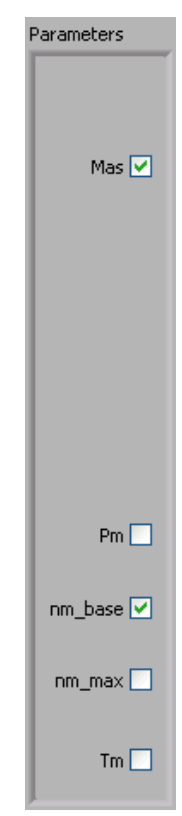

Fig. 24. Choosing which variables to be 'known'.

In the right side of the variable selection check boxes, the designer can enter the acceptable range for each variable. A minimum and a maximum is to be entered for any variable chosen earlier. This is shown in Figure 52. Vehicle's maximum acceleration speed in a limited time (10 seconds here) is a variable that is always required to be known. If a variable is not checked as input, the range lever will not show up for that specific variable. 


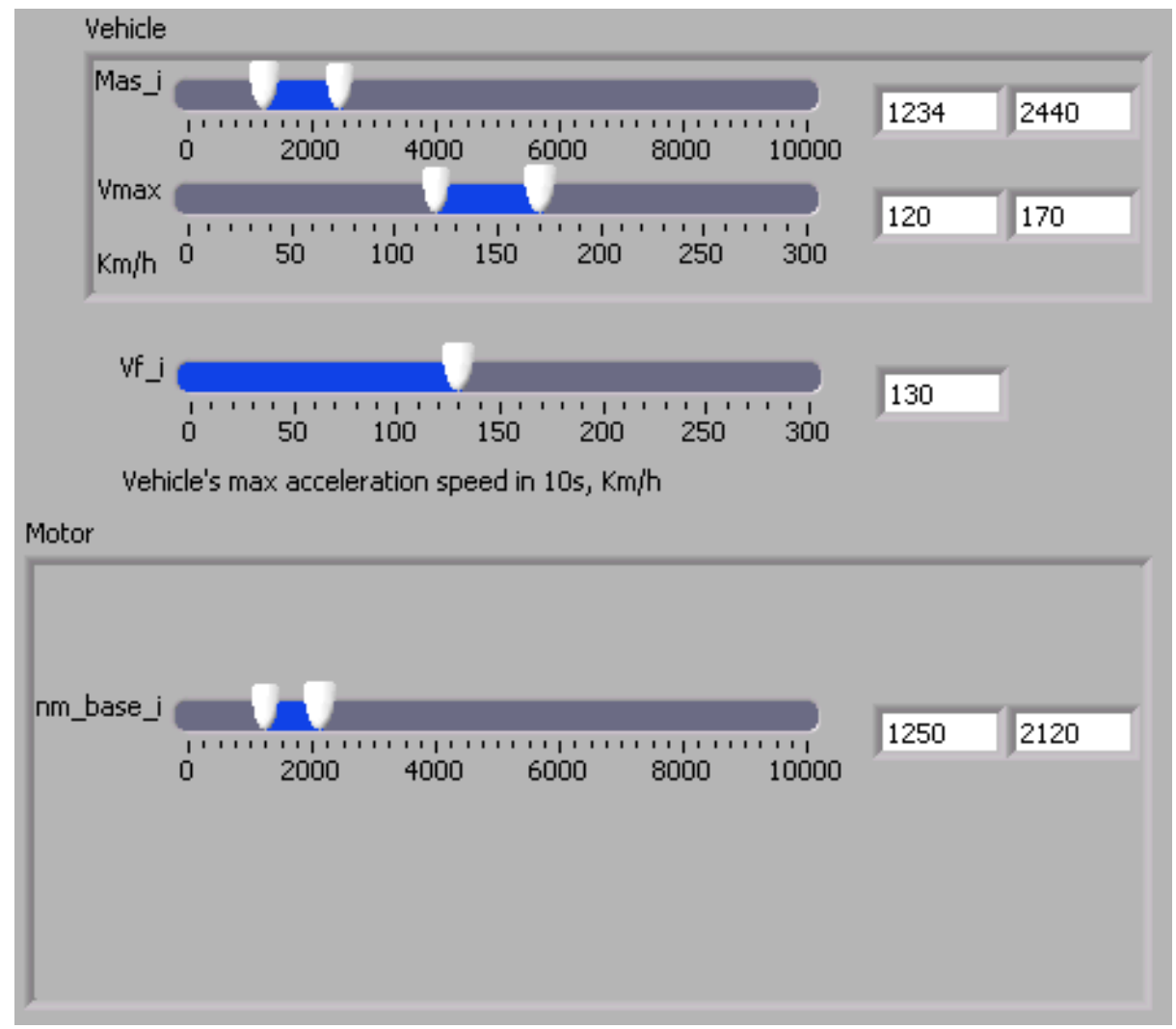

Fig. 25. A range of variation is entered for known variables.

There are times that the designer needs to manually force some limitations on some variables, because of occasional constraints. This might have various reasons from availability of a component only with a specific characteristic, to price preference in using an specific component. All these additional constraints could be added to the design in the box provided at the bottom of the interface. This section is shown in detail in Figure 53. The constraints have to be defined in the form of inequalities using the symbols defined for each variable.

The final input by the designer in this level is the calculation resolution. It is shown in Figure 54. A higher resolution number results in considering more points in the solution space, providing smoother and more accurate solution space. Obviously higher resolution will make it longer for the software to calculate the results. 


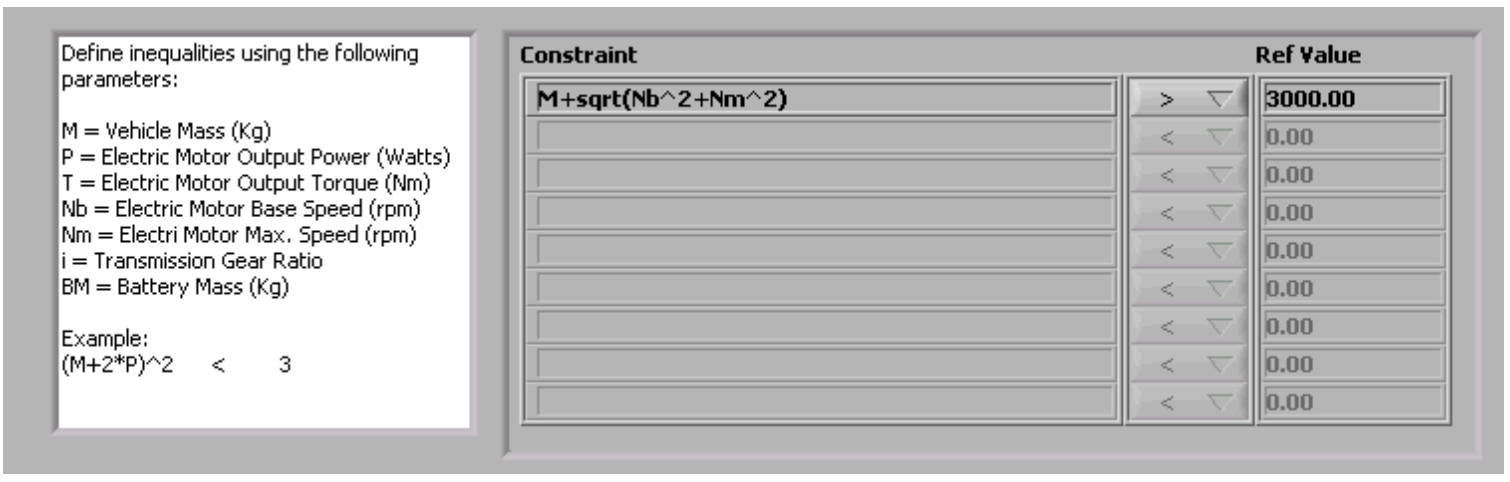

Fig. 26. Solution space could be squeezed by additional constraints.

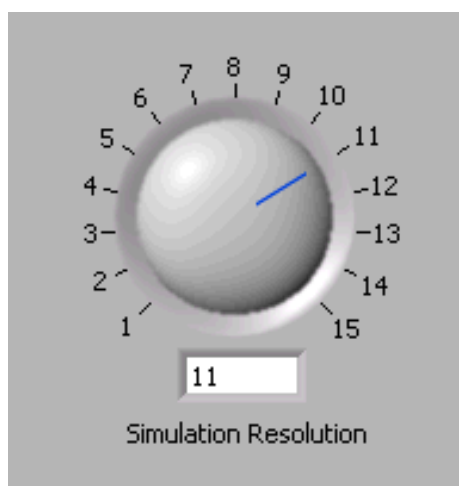

Fig. 27. Simulation resolution impacts precision of the solution space.

The last section of the "Design" interface is the outputs which could be found at the right side of the screen. It is shown in Figure 55 in detail. This section provides the results of the solution space calculations. It provides a range for every variable in the design such that all these ranges together form a closed solution space; every point in this space will represent one possible vehicle that meets all the predefined design requirements.

It should be noted that the conventional design leads to one single solution vehicle which is a single point in the so-called solution space in the new CAD tool. Having all these possible points as option opens the designer's hand in narrowing the space for other concerns than what could be taken into the game in a conventional design. 


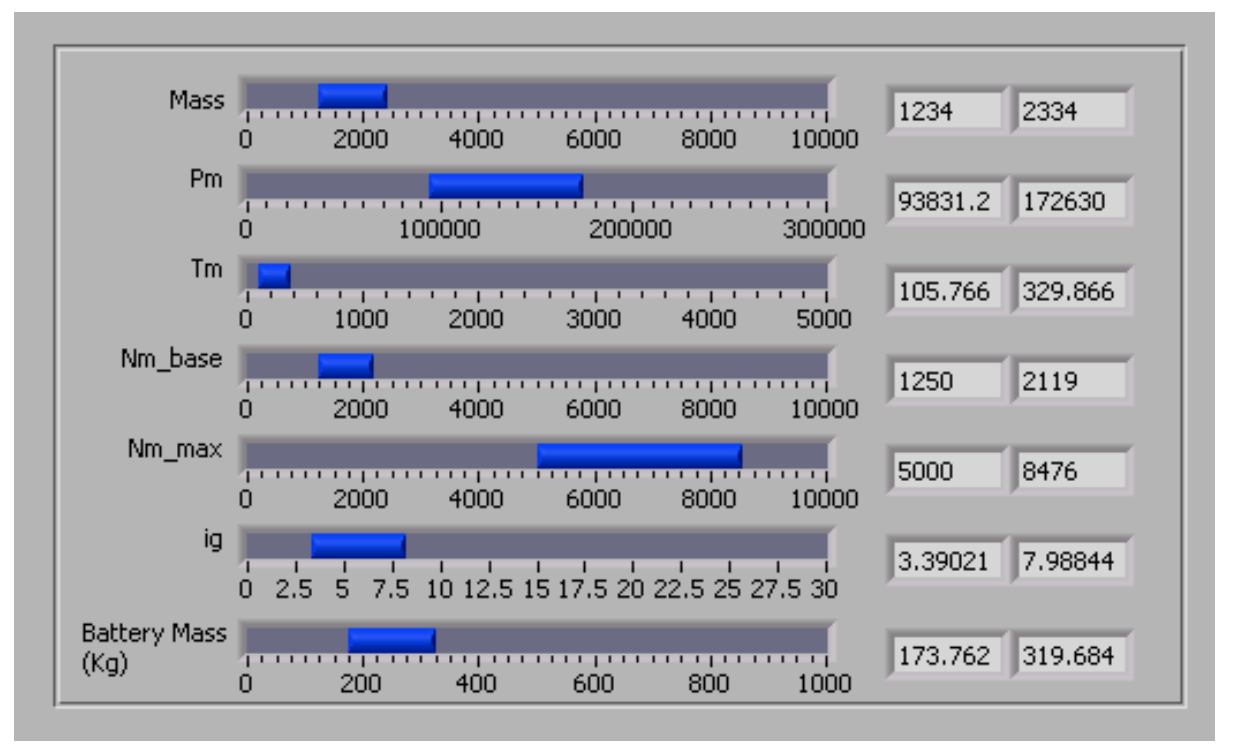

Fig. 28. Solution space shown as ranges for variables.

\section{Simulation for Performance}

Once an acceptable range is determined for each variable in the "Design" interface, those points need to be simulated for performance characteristics and be verified that they meet performance requirements, or have a minimum desired safety margins. For that purpose the "Simulation for Performance" interface is provided which would be running in parallel with other sections of the tool. This interface is shown in Figure 56.

Since a simulation by definition is the exercise of applying specific conditions to a specific system and observe its functionality and output, the designer needs to choose a single specific vehicle from the millions of options in the feasible range. Therefore, all the feasible solution ranges will be copies from "Design" to "Simulation for Performance" which are represented in the left side of the screen. The designer could choose single points from the ranges to specify a single vehicle for simulation. This is shown in detail in Figure 57. 


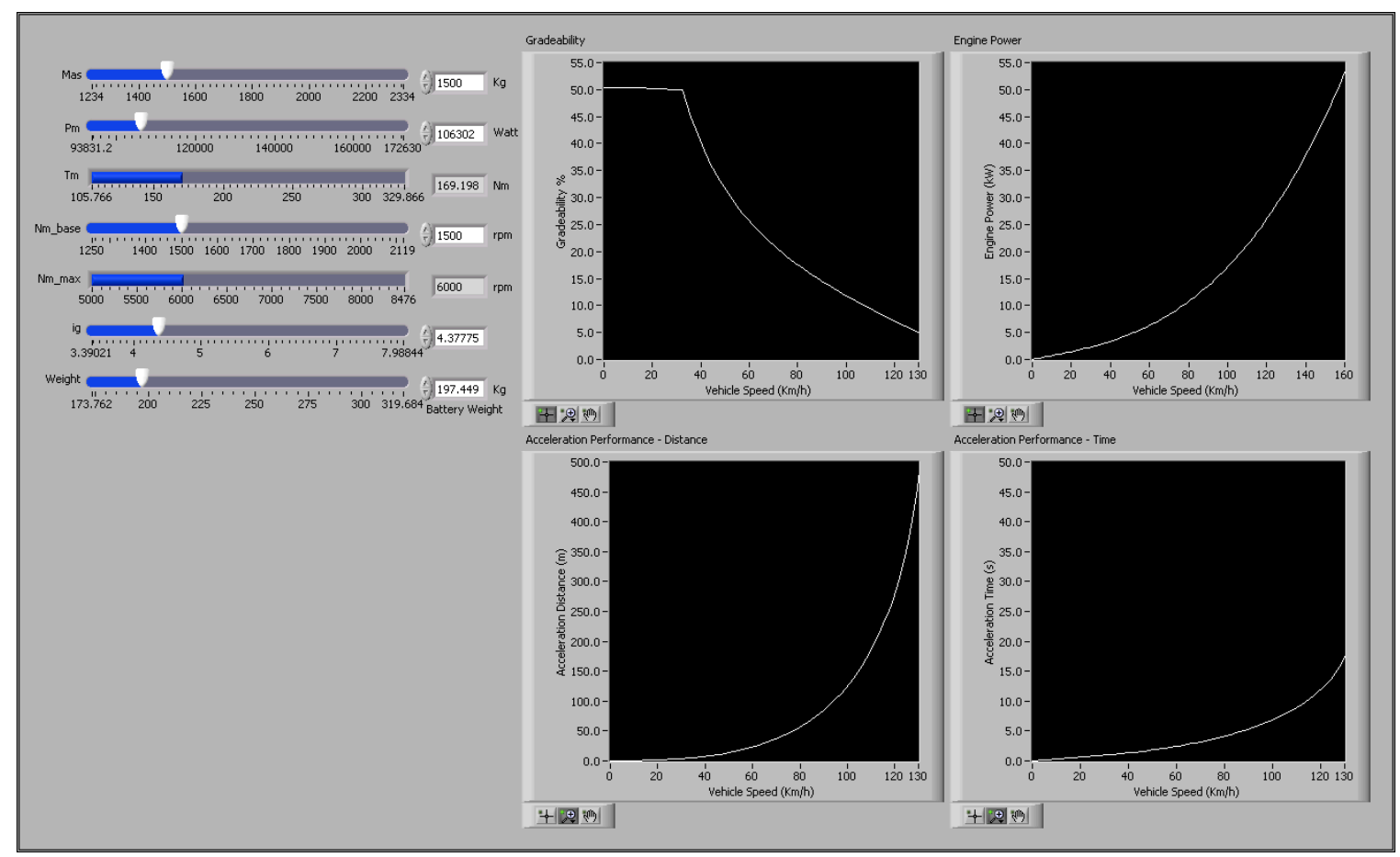

Fig. 29. Snapshot of "Simulation for Performance" interface.

Once a vehicle is identified, it will be simulated for different performance measures to be verified. All these simulation results are plotted in the right side of the screen.

Figure 58 shows the gradeability results for different speeds. Figure 59 shows the acceleration time and distance for different speeds. Figure 60 shows the required power of the vehicle engine at different speeds. 


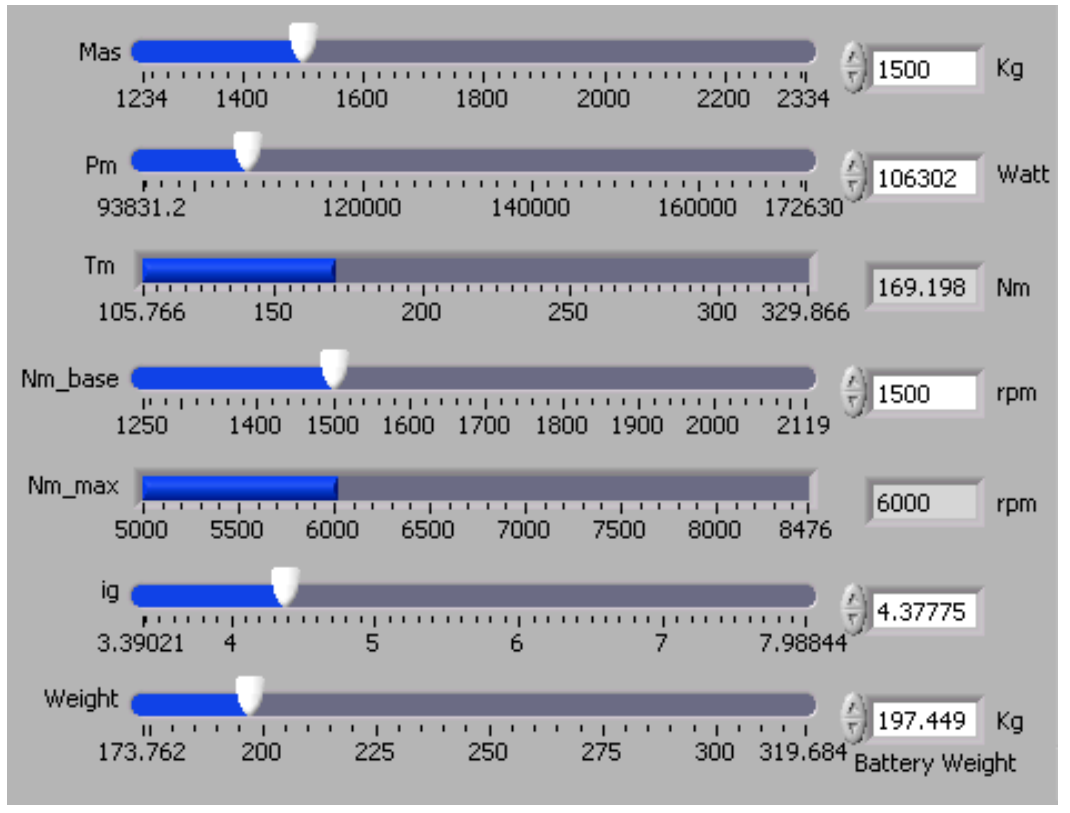

Fig. 30. Any point in solution space represents a vehicle that could be simulated.

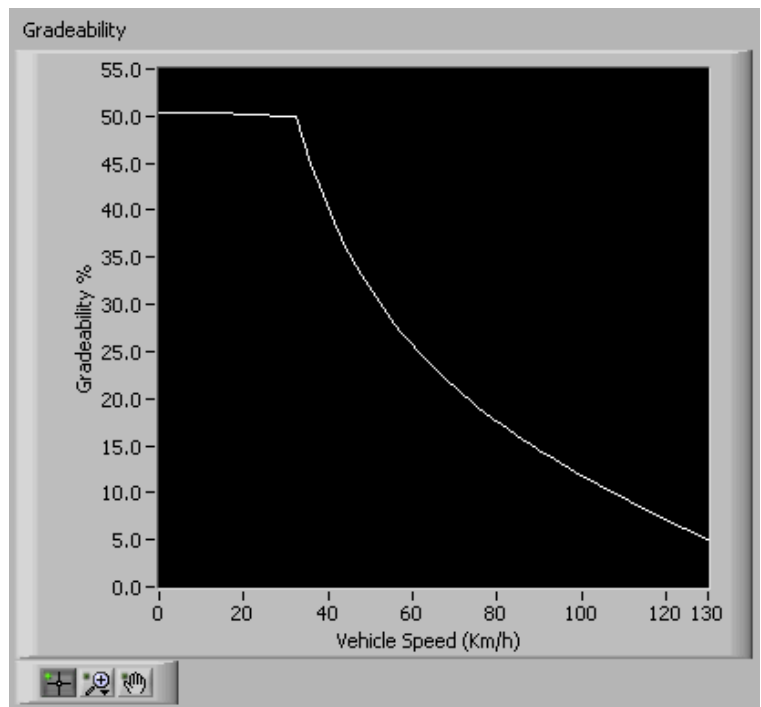

Fig. 31. Gradeability as function of vehicle speed for chosen vehicle. 


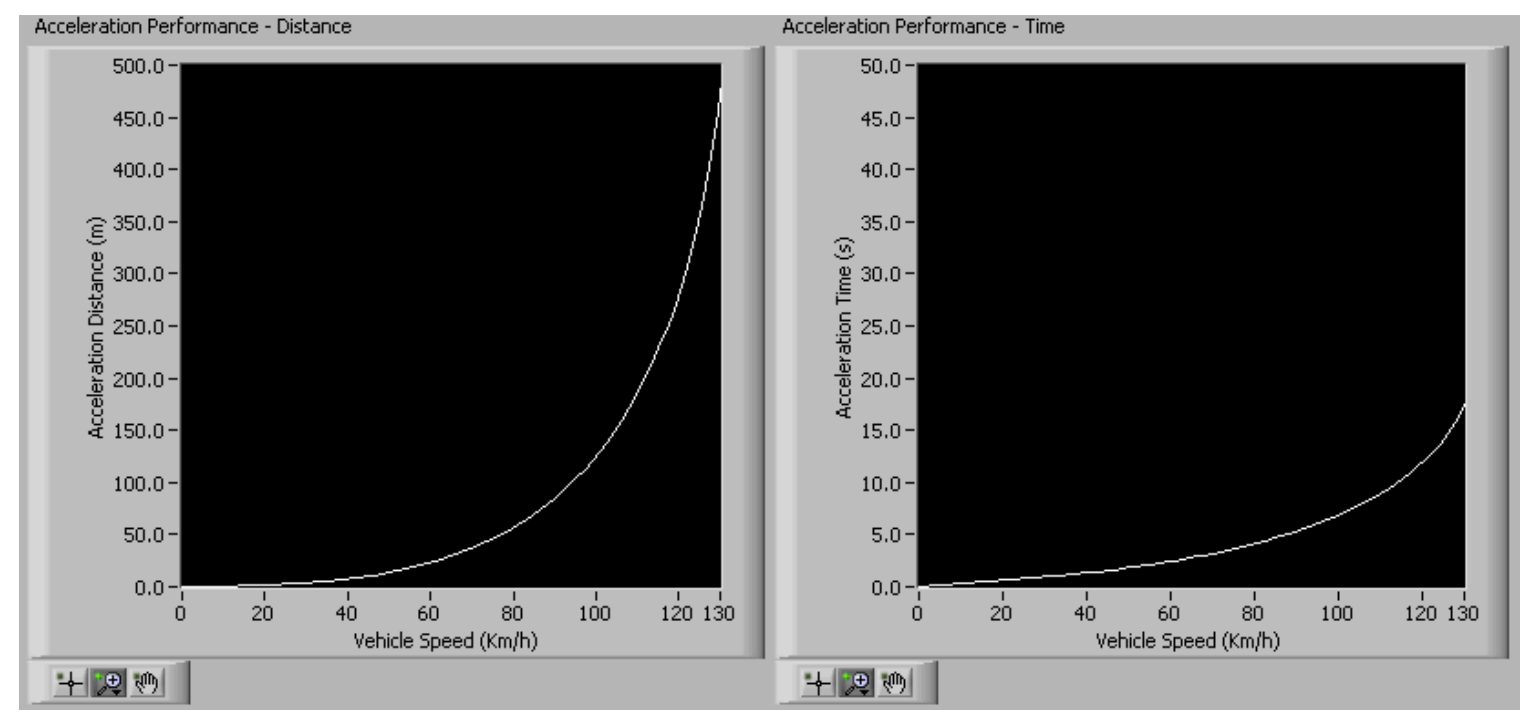

Fig. 32. Acceleration time and distance as function of vehicle speed for the chosen vehicle.

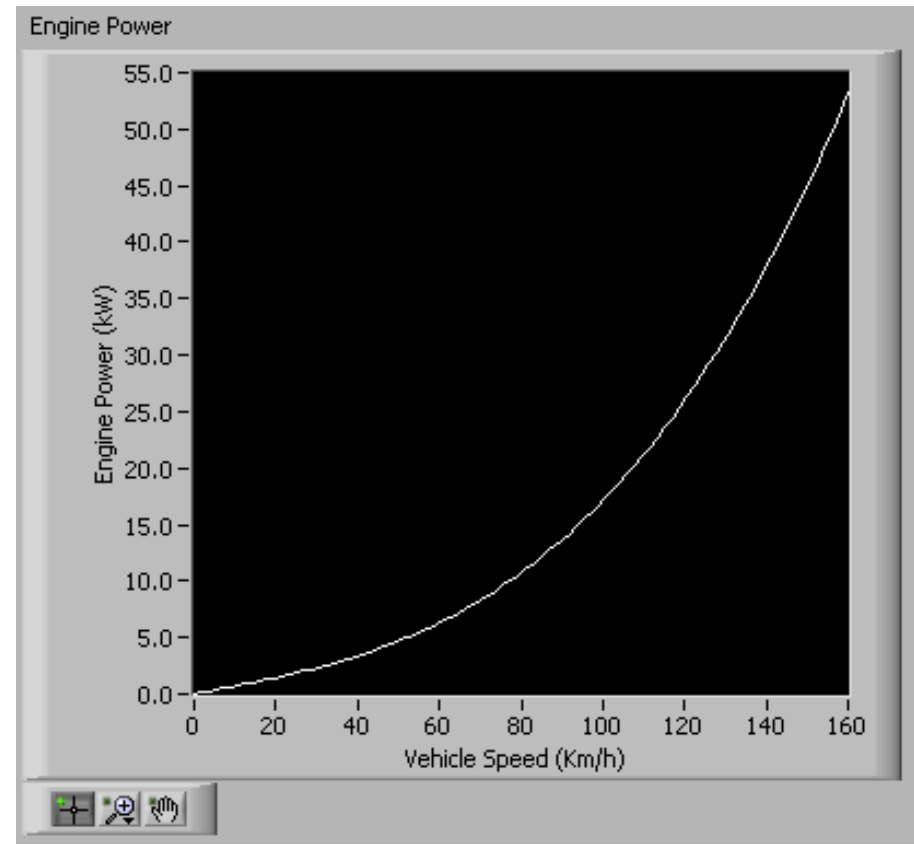

Fig. 33. Required engine power as function of vehicle speed for the chosen vehicle. 


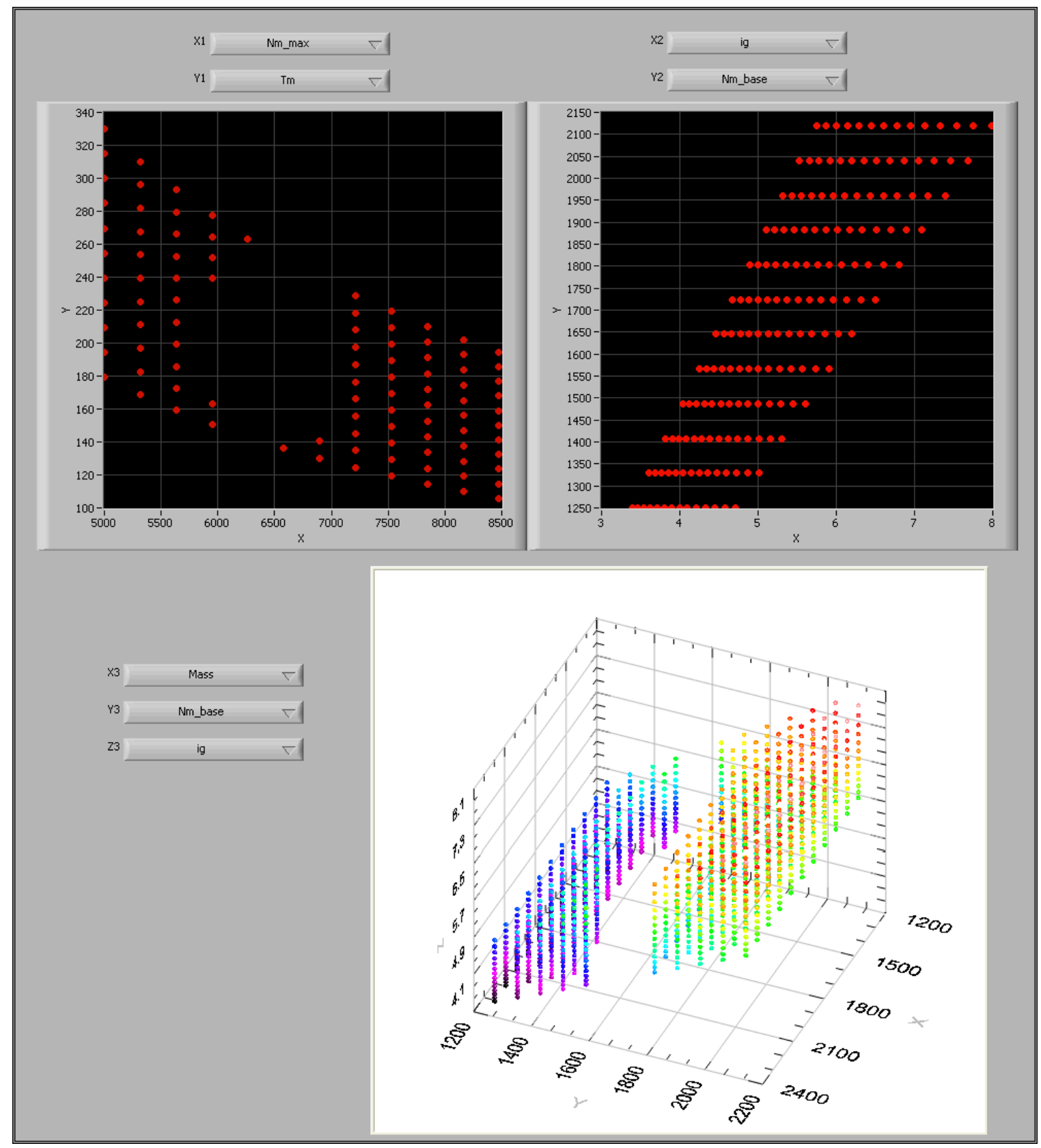

Fig. 34. Snapshot of "Graphs" interface for 2D and 3D representations of the vehicle variables. 


\section{Graphs}

The number of dimensions of the solution space depends on the number of variables included in the design process, but is always more than three. Therefore it is never possible to represent the whole space in a graphical mode. However, it is always beneficial to be able to graphically see the two or three dimensional representations of different variables against each other. For this purpose, the "Graphs" interface is also provided which is again working in parallel with the whole system and the graphs are constantly being updated by the latest design results. This interface is shown in Figure 61 . There are two 2D graphs are provided at the top, as well as a 3D graph at the bottom. The variables to be displayed could be chosen from the drop-down boxes by the graphs.

\section{Simulation with Drive Cycle and Controller}

Once the vehicle is simulated and its performance characteristics are verified, it is needed to be simulated on a drive cycle. This is necessary to be able to specify the battery specifications since the battery will be discharged along the way in the drive cycle and its charging/discharging pattern is important in determining its size as well as in controlling the engine. For this purpose, the "Simulation with Drive Cycle and Controller" interface is also running in parallel with the whole system to complete whatever is needed to completely design and simulate a vehicle. This interface is shown in Figure 62.

The first step in using this interface is choosing a drive cycle. A library of different common drive cycles are provided in the drop down block at the top left of the interface. This is shown in Figure 63. More drive cycles could also be simply added to this library. 


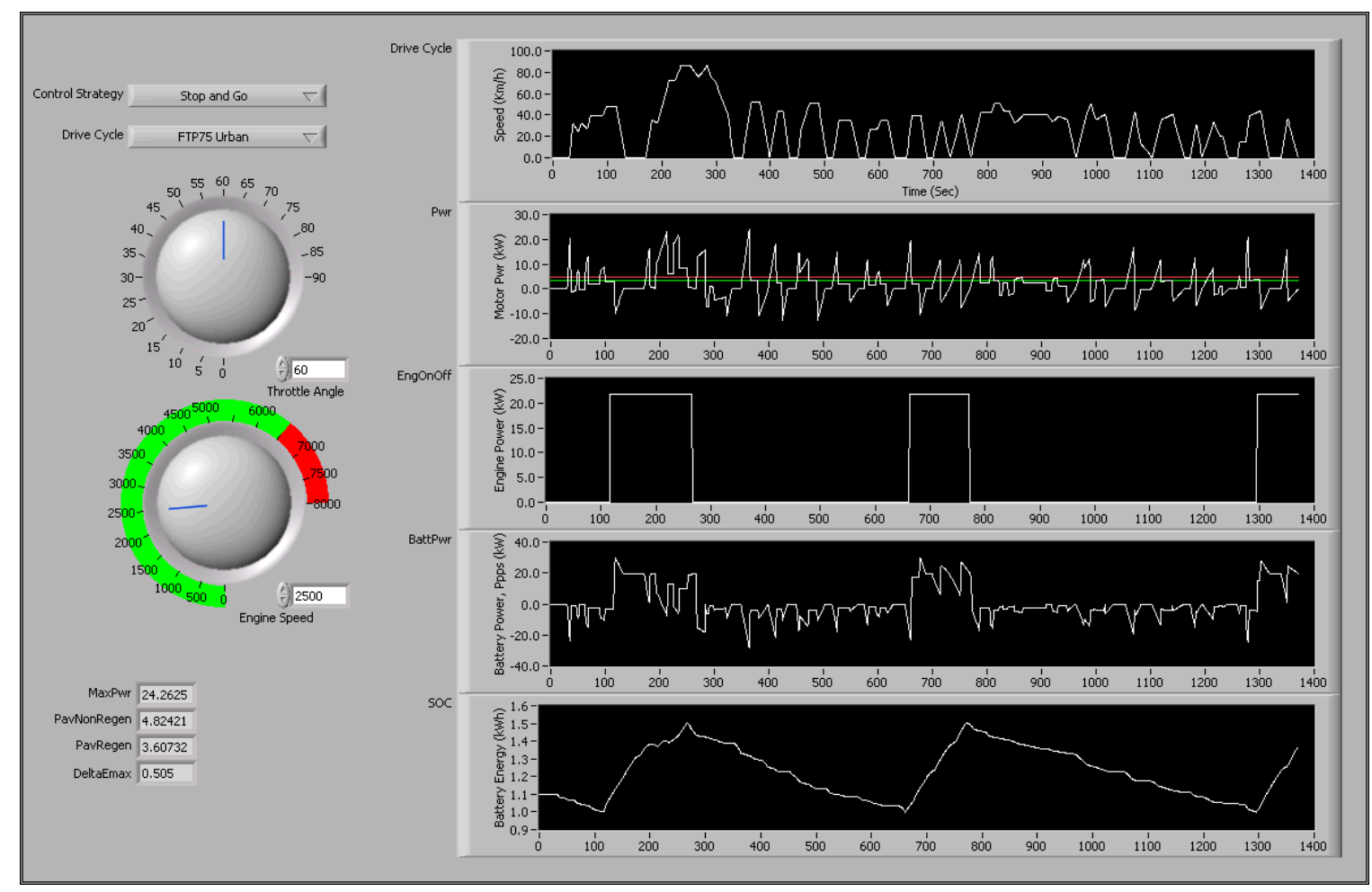

Fig. 35. Snapshot of "Simulation with Drive Cycle and Controller" interface.

\begin{tabular}{rlr} 
Control Strategy & Stop and Go & \\
\cline { 2 - 3 } Drive Cycle & FTP75 Urban & -1 \\
\hline
\end{tabular}

Fig. 36. Driving pattern and engine controller determines how engine charges battery.

The next step is to choose a controller for the engine. As discussed before, the controller decides when and at how much power to turn the engine on and when to shut it down to maintain a good state of charge on the battery. A controller could be chosen from the drop down block shown in Figure 63.

Another useful option in accurately simulating the vehicle is to determine the throttle angle and engine speed of the vehicle. These options are also provided in the left side of the interface and could be seen in Figure 64.

Once all these inputs are determined, the simulation will run and the results will 


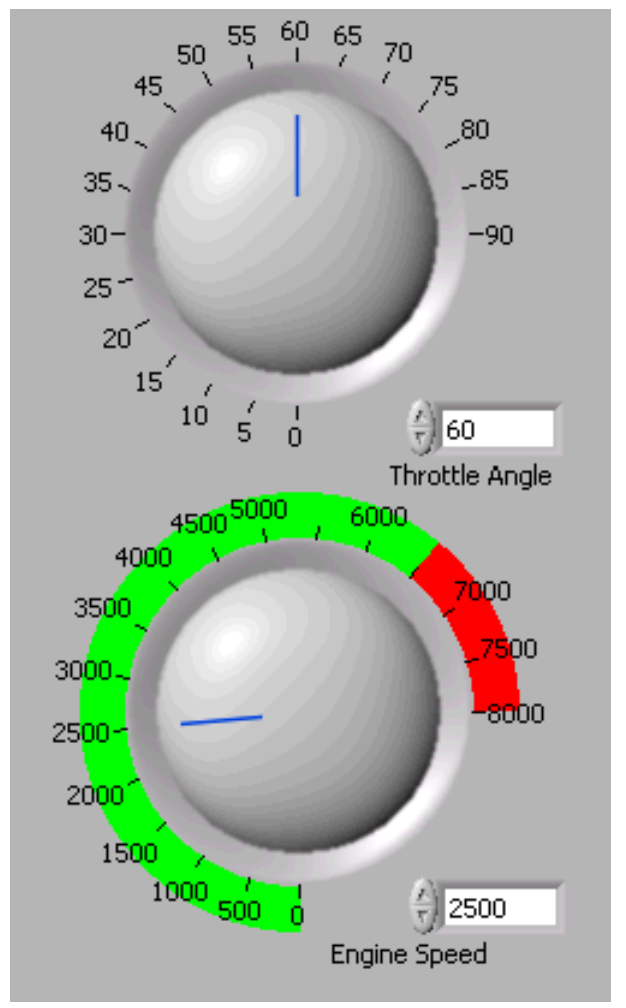

Fig. 37. It is best to operate engine at its optimum operating speed.

be demonstrated in the right side of the interface. Figure 65 shows the drive cycle that has been used for the simulation and Figure 66 shows the instantaneous power needed to be provided by the vehicle to run it at the chosen drive cycle. This figure also shows the average required power in both cases of applying and not applying the regenerative braking.

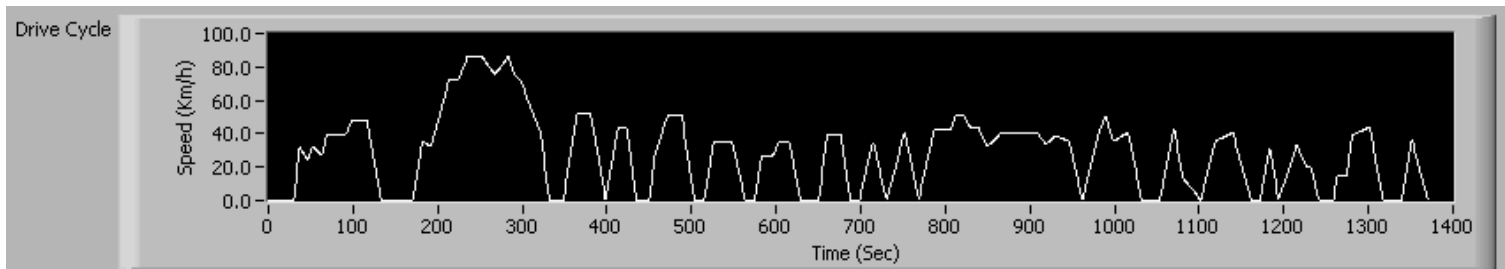

Fig. 38. Standard drive cycles are available; new ones could be added.

Figure 67 shows the engine operation; i.e. the instances that the engine is turned 


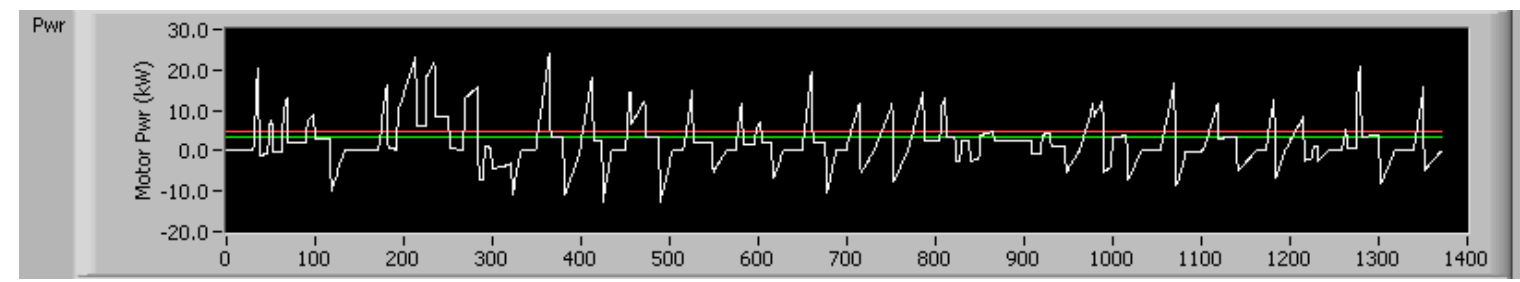

Fig. 39. The instantaneous and average required power to run the vehicle.

on and the power that the engine will operate at when on. Figure 68 shows the power received by the battery. When the engine is on, this power will be positive, meaning that the battery is being charged and when the engine is off it will be negative meaning that the battery is supplying power to the vehicle.

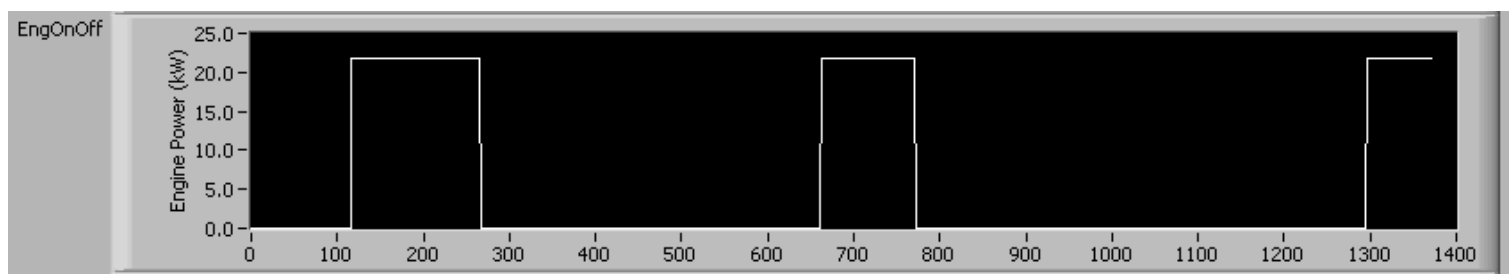

Fig. 40. Engine turns on and off at the moments and by the power commanded by controller.

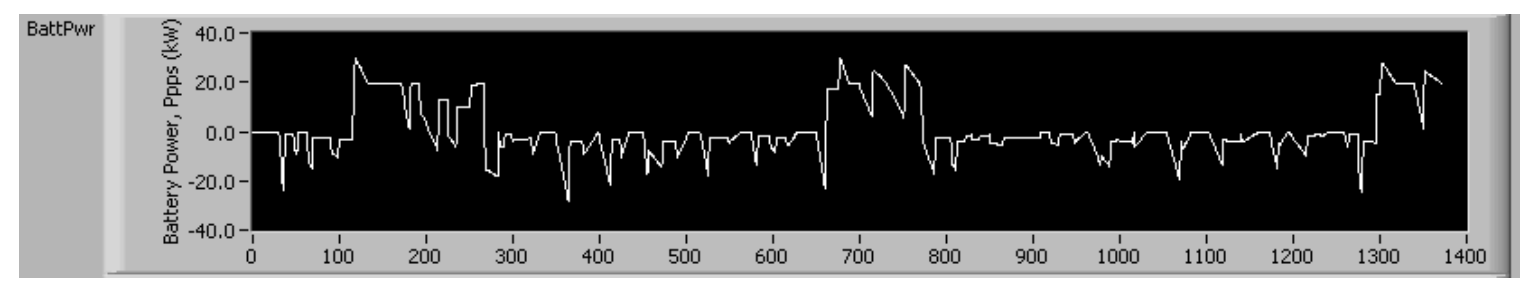

Fig. 41. Battery receives or delivers power based on engine operation. 


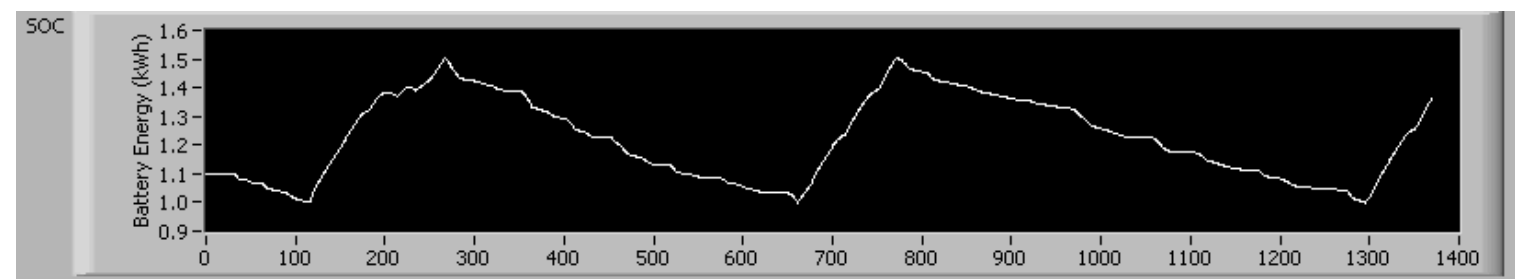

Fig. 42. Engine operation increases the SOC of battery.

Finally, Figure 69 shows the state of charge of the battery. This is indeed the energy level of the battery varying by time. 


\section{CHAPTER V}

\section{DESIGN EXAMPLES BY THE PROPOSED TOOL}

\section{A. Introduction}

In this chapter the design process for series hybrid electric vehicle will be gone through and simulated using the new proposed CAD tool. Examples are chosen such that they explain all different configurations that this package could help with designing. Appendix A includes more examples including pure electric and plug-in hybrid electric vehicle design using the proposed package as well.

\section{B. Series Hybrid Electric Vehicle Design}

A series hybrid electric vehicle has 4 main components that are going to be addressed: electric motor, internal combustion engine, single gear transmission and battery. The construction of such a vehicle is shown is Figure 76 .

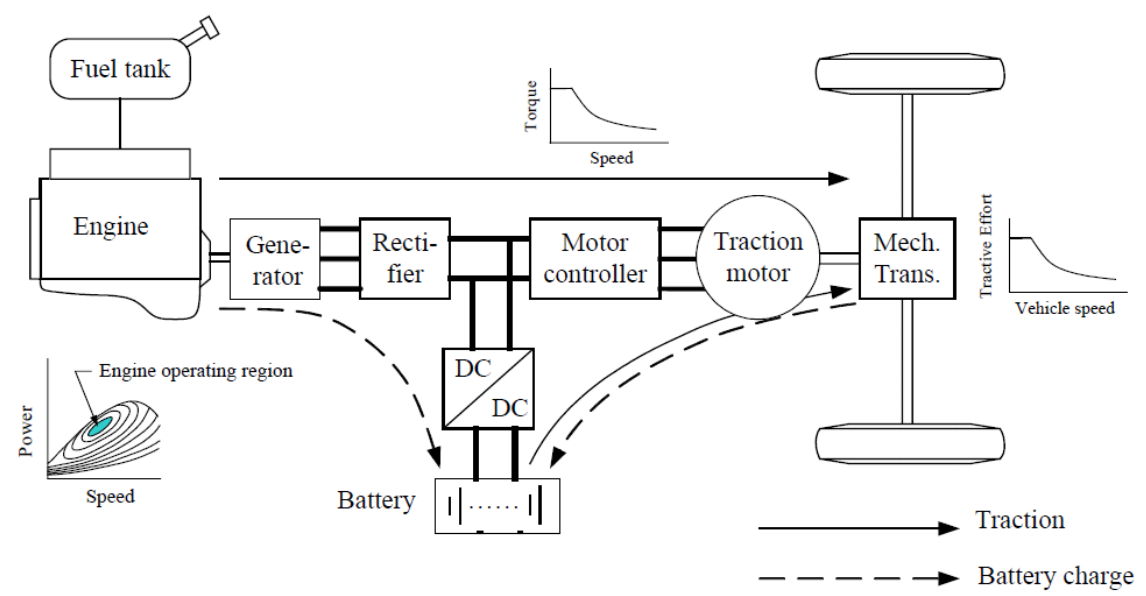

Fig. 43. Structure of series hybrid electric vehicles. 


\section{Design Question}

The vehicle that is going to be designed here should meet the performance requirements same as the electric vehicle example designed in the previous section:

$\begin{array}{ll}\text { Acceleration time }(0-100 \mathrm{~km} / \mathrm{h}) & 10 \mathrm{sec} \\ \text { Minimum gradeability } & 5 \% @ 100 \mathrm{~km} / \mathrm{h} \\ \text { Maximum speed } & 160 \mathrm{Km} / \mathrm{h}\end{array}$

This vehicle also has the following given parameters:

Vehicle mass

Single gear transmission efficiency

Vehicle front area $\left(A_{f}\right)$

Electrical motor and drive efficiency $\quad 85 \%$

Generator efficiency

Aerodynamic drag coefficient $\left(C_{D}\right)$

Rolling resistance coefficient $\left(f_{r}\right)$

Tire radius

$\operatorname{Air} \operatorname{density}\left(\rho_{a}\right)$
$1500 \mathrm{Kg}$

$90 \%$

$2.0 \mathrm{~m}^{2}$

90

0.3

0.01

$0.3 \mathrm{~m}$

$1.202 \mathrm{Kg} / \mathrm{m}^{2}$

\section{Design Using the Proposed Tool}

The first step is to understand what components exist in the vehicle that is going to be designed. As explained earlier in this chapter, a series hybrid electric vehicle has an electric motor, a battery to power the motor, an engine to maintain the state of charge on the battery and a single gear transmission to transfer the torque from the electric motor to the wheels. 
From the design question we understand that our known variables are vehicle mass, acceleration time and the vehicle's maximum speed. The first interface that should be used is the 'Design' that is shown in Figure 77.

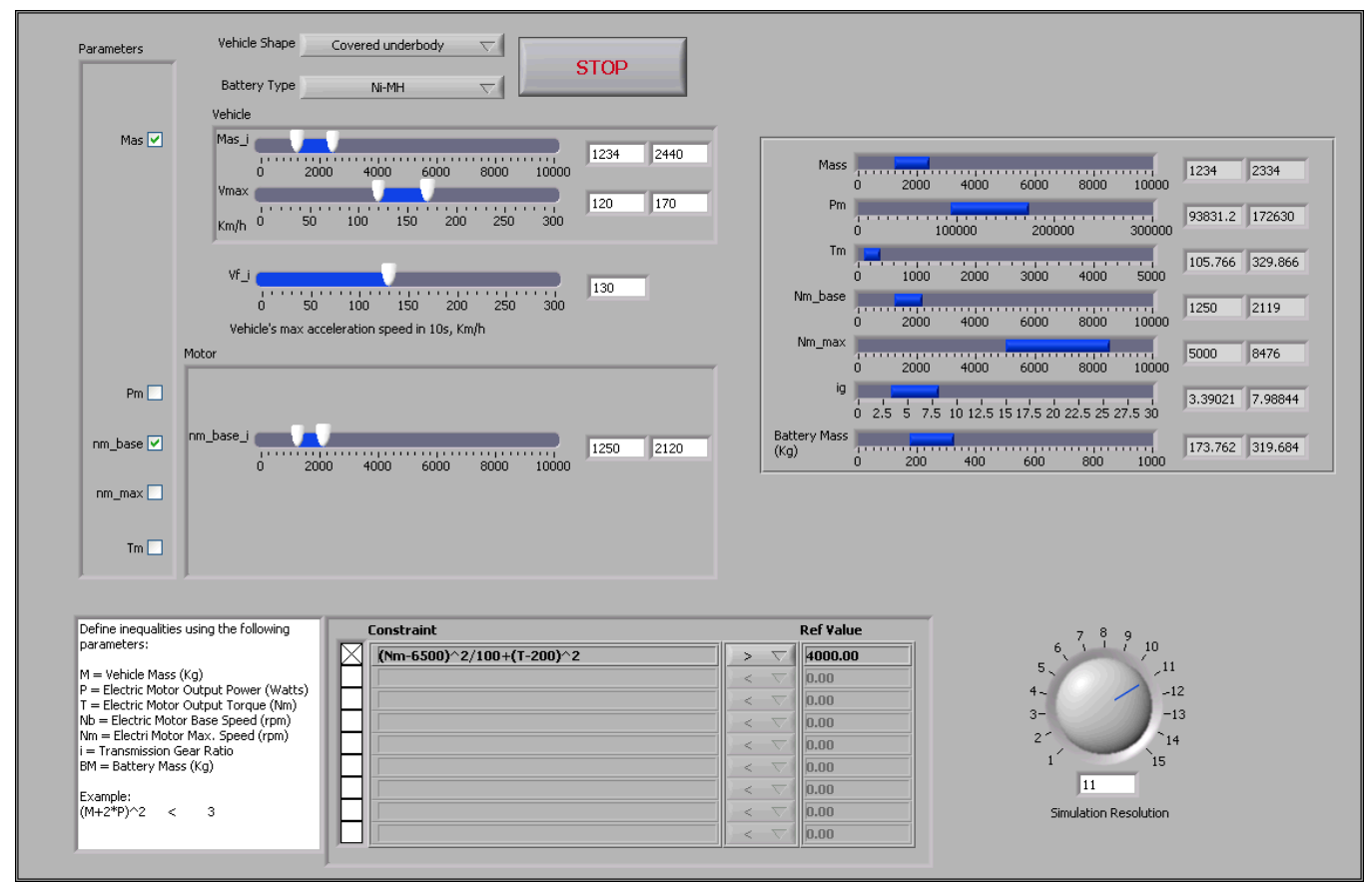

Fig. 44. Known variables are determined for the series hybrid electric vehicle.

From the left hand side, we need to enter the vehicle shape and the battery type. We need to choose the battery type as Ni-MH and an arbitrary shape for the vehicle. We can assume that we are designing a 'Covered Underbody' shape vehicle.

The next step is to enter the vehicle mass and its maximum speed, as well as the acceleration. This could be done in the top left side of the interface as is shown in Figure 78. The check marks in the left side of different variables determine which ones we wanna choose to be knowns and we would like to enter value ranges for. The application is going to solve for the rest of the variables. Keep in mind that there are two ways to express the acceleration of a vehicle: The time that it takes for a vehicle to from still to a certain speed or the speed that the vehicle can reach 
in a certain amount of time starting from still condition. The latter is used in the developed application. We may consider a mass range of 1234 to $2440 \mathrm{Kg}$ and the maximum vehicle speed of 120 to $170 \mathrm{Km} / \mathrm{h}$. We also need to choose a base speed for the electric motor but there is no specific guideline in the design question about it. So we just pick 1250 to $2120 \mathrm{rpm}$.

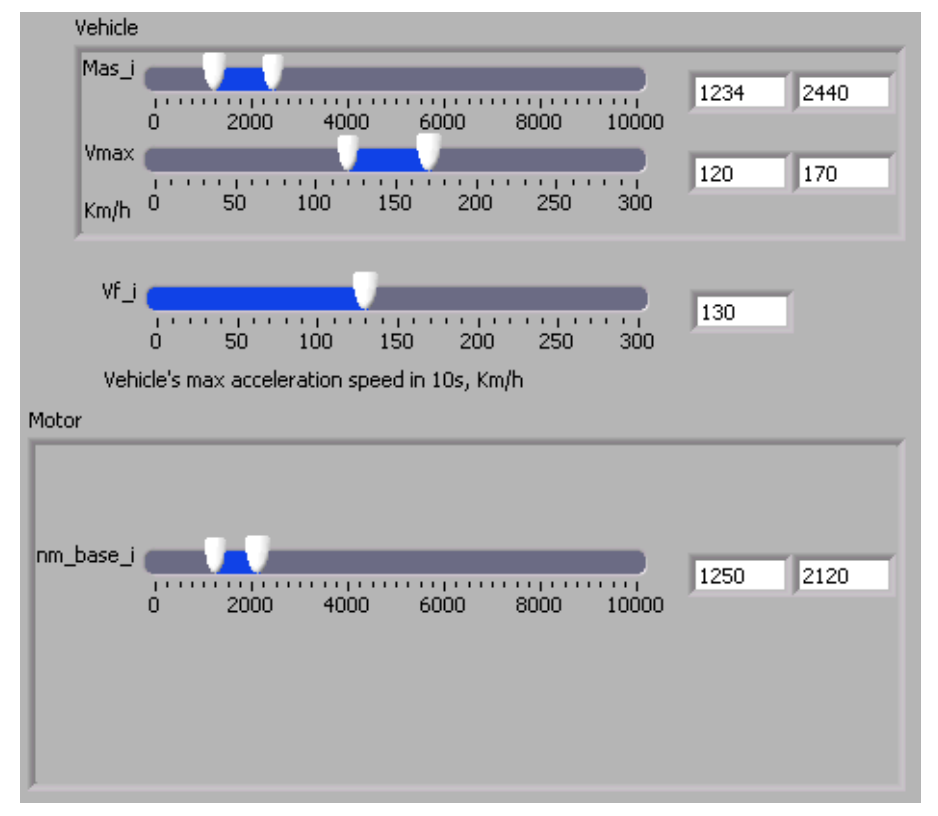

Fig. 45. Ranges for known variables are determined.

Just by determining the values for the variables in their lever markers the application is going to take them into effect and the results would be updated. So all the designer needs to do is to determine a minimum and maximum level for each known variable. The acceptable ranges for all the variables are going to be displayed in the right hand of the screen. These ranges simply mean that any point in those ranges is the representative of a separate vehicle that means the initial design specifications. At the bottom of the screen there is an option of impose more user defined restrictions but no such a restriction is needed in this design. Once the acceptable design ranges are determined we have an idea of different components of the vehicle we need, we 


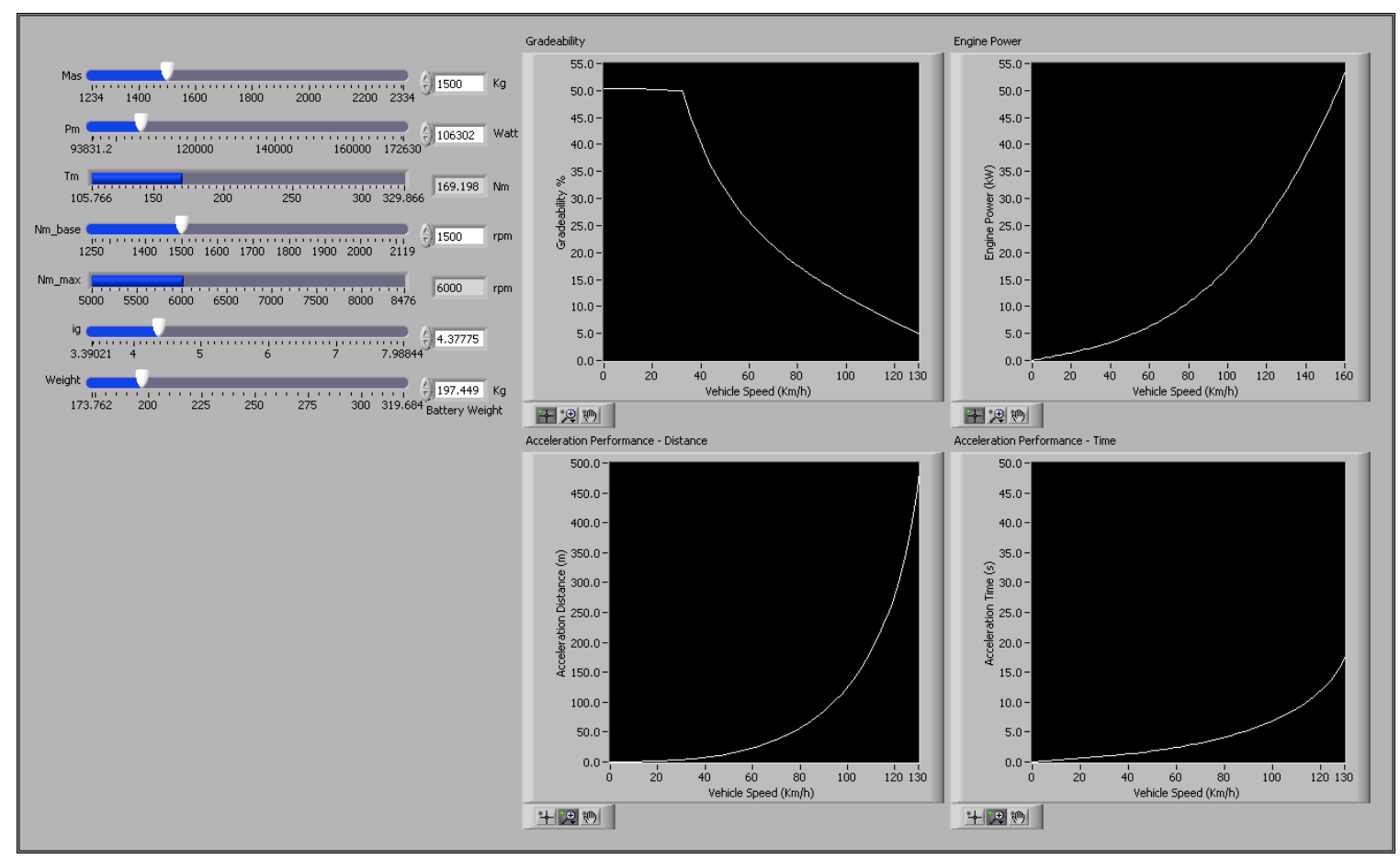

Fig. 46. The vehicle performance is verified against design criteria.

can start simulating the possible options and narrow down our design.

The initial simulation is done in the interface shown in Figure 79. All the possible ranges for all variables are displayed in the left side of the screen. Every combination of points represent a vehicle. By choosing different values we can select the resulting vehicle and evaluate its performance for acceleration, different grades and etc. From the $2 \mathrm{D}$ and $3 \mathrm{D}$ graphs we can make sure that the vehicle we are choosing is in the right spot with respect to all variables. The vehicle we choose is going to have the following characteristics: 
Mass

Electric motor power

Electric motor torque

Electric motor base speed

Electrical motor maximum speed

Gear ratio

Battery mass
$1500 \mathrm{Kg}$

$106302 W$

$169.2 \mathrm{Nm}$

$1500 \mathrm{rpm}$

$6000 \mathrm{rpm}$

4.38

$197.4 \mathrm{Kg}$

Simulation results are plotted in the right hand of the screen which are as follows:

Mass

Acceleration time @ $100 \mathrm{Km} / \mathrm{h}$

Acceleration distance for $100 \mathrm{Km} / \mathrm{h}$

Maximum Gradeability @ $100 \mathrm{Km} / \mathrm{h}$

Engine power needed at $100 \mathrm{Km} / \mathrm{h}$ cruising speed
$1500 \mathrm{Kg}$

$6.1 \mathrm{sec}$

$75 m$

11

$17.5 \mathrm{KW}$

The final step is to simulate the chosen vehicle in the road conditions! To do this we can use the DriveCycleSimulation interface which is shown in Figure 80.

In the top left side of this interface we can select the proper drive cycle to simulate the vehicle operation at. Also we can choose a controller to be used to manage the battery charging management and engine operation. Here we choose the StopandGo controller and the standard FTP-75 Urban drive cycle. There is also a control that the designer can use to choose a right amount of throttle angle and engine speed. Here we choose the 60 degree throttle angle and 2500 rpm of engine speed.

The results are shown in the ride side of the screen. As is shown here and also through the numbers at the bottom of the page, the maximum engine power needed is $24 K W$, with the average power equal to $4.8 \mathrm{KW}$ for cruising.

Once we have this information it will be easy to derive other needed details about 


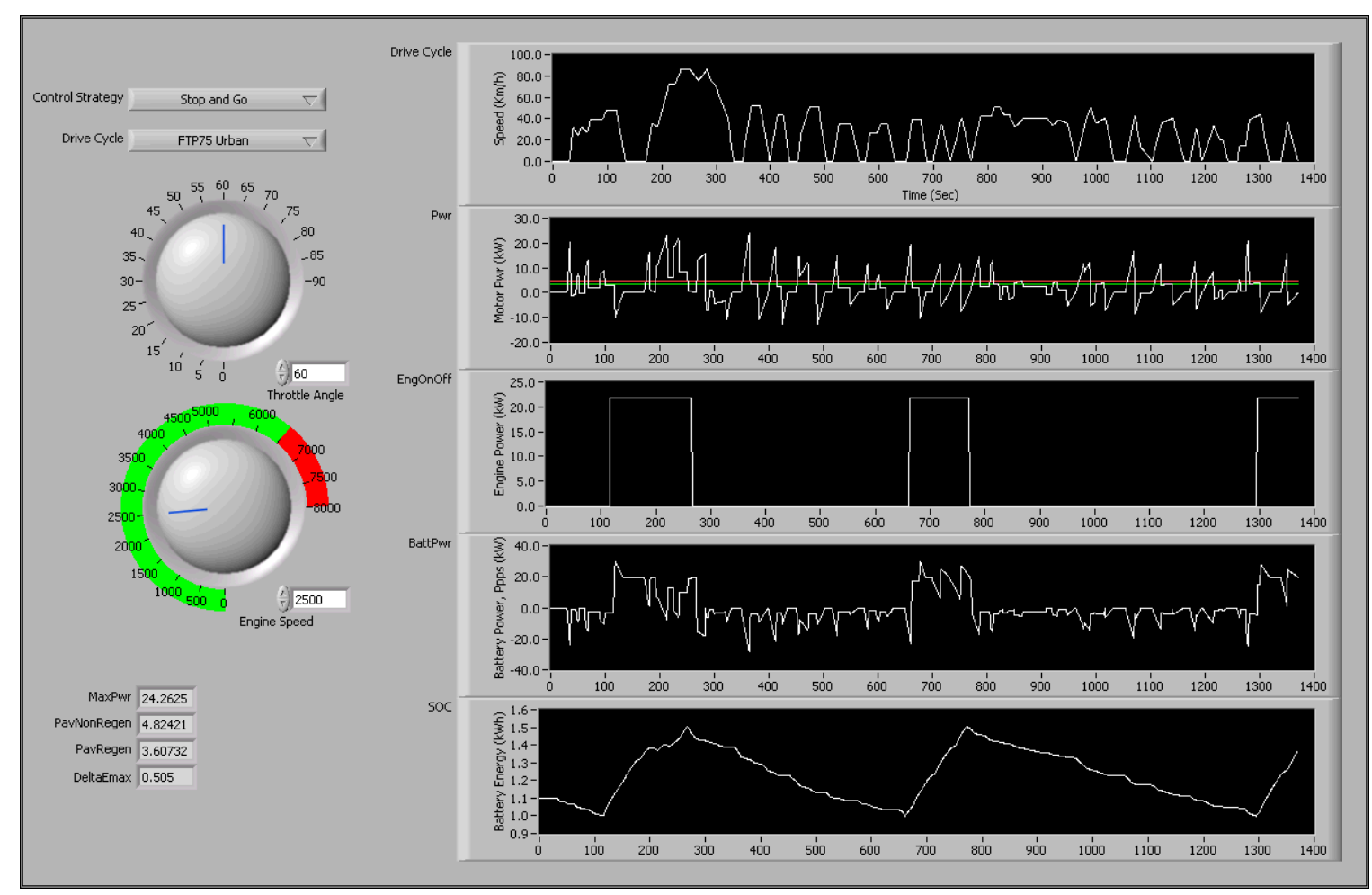

Fig. 47. The vehicle is simulated here in different drive cycles using various battery/engine management controllers.

the vehicle.

\section{Plug-in Series Hybrid Electric Vehicle Design}

A series plug-in hybrid electric vehicle has exact same components as the regular series hybrid electric vehicle except that its battery could also be charged directly by plugging the car to an external power source like the utility or a charging station. Remember that the regular series hybrid electric vehicle could only be charged by its internal combustion engine. The construction of a plug-in series hybrid electric vehicle is demonstrated in Figure 81. Because there is not any extra component in the plug-in hybrid electric vehicle than regular hybrid electric version, the deign process will be exactly the same and therefore the previous example could thoroughly explain 
the use of the new concept.

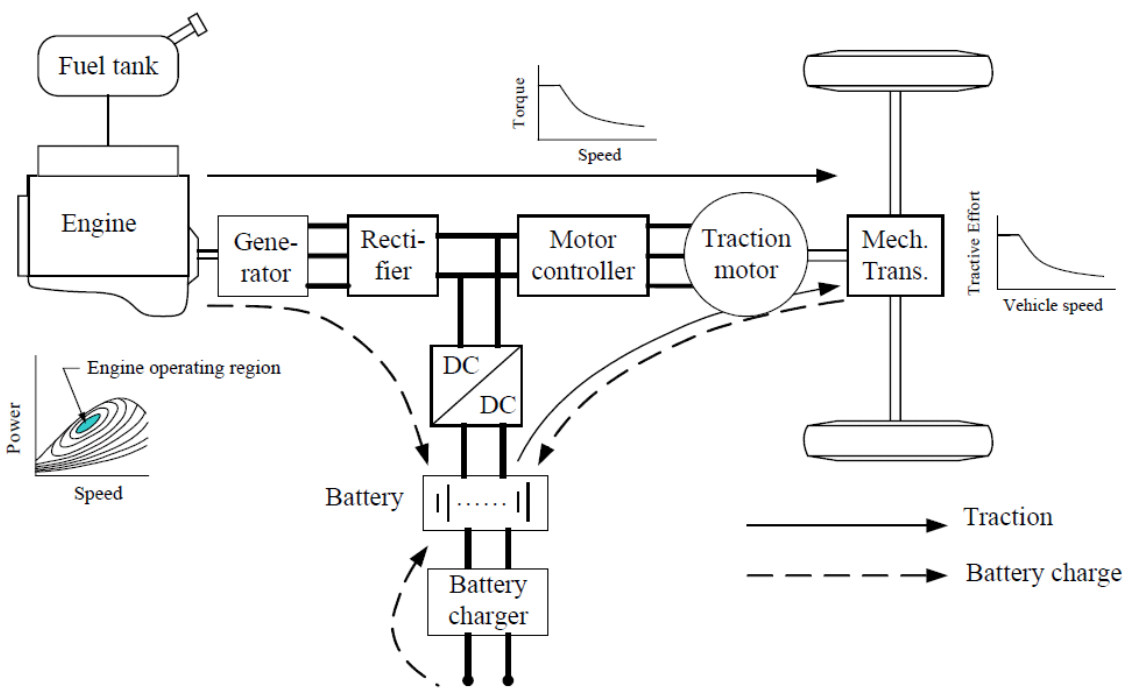

Fig. 48. Major components of a plug-in series hybrid electric vehicle. 


\section{CHAPTER VI}

\section{CONCLUSION AND FUTURE WORK}

\section{A. Conclusion}

In this research the problem of CAD tools for the application of designing electric, hybrid-electric and plug-in hybrid electric vehicles is addressed. After studying the available simulation and design tools for this purpose and understanding their shortcomings, new ideas for this application has been developed and implemented. These shortcomings are listed as the following:

- If the vehicle designer decides to change a parameter or a performance criterion in the conventional design method, he would need to redo the entire process as if he is designing a new vehicle. This will cause a large amount of wasted time.

- It is impossible in the conventional method to design a vehicle to use a specific component like an electric motor of certain power, other than doing trial and error.

- It is a difficult and timely process to do a sensitivity analysis based on a small change in one of the designed variables. The conventional methods do not offer any help in this regard.

- The most important of all, conventional methods give the designer a single solution for his design problem. It is obvious however that the same desired performance could be achieved by another configuration or even other components.

The outcome of the research is the concept of new generation of computer applications that has combined design and simulation process together with a special novel 
perspective towards the design process to address the above mentioned shortcomings.

- The proposed tool allows the designer to choose any arbitrary set of variable as known and leave the rest as the ones to be solved for, whether they are vehicle component characteristic variables or performance measures. This provides a great amount of flexibility and success in designing a vehicle from any available information about it.

- Instead of starting from single values, the new tool can work with a range of possible values for the known variables and suggest range of solution values for the unknown variables. This provides the capability of refining the design even further and performing sensitivity analysis.

- The proposed concept is a package that offers both design and simulation capabilities. It includes analytical performance simulation, simulation with arbitrary drive cycles and engine controllers and 2D or 3D representation of any arbitrary set of design variables in the solution space.

A pilot version of the new concept has been developed as a proof of concept.

\section{B. Future Work}

There are certain limitations with the proposed concept as explained below that could be further explored.

- Since designing a vehicle is a sophisticated process by itself, it is difficult to perform a thorough design in a computer application in general. Therefore the proposed concept is limited for a specific vehicle type when developing the application. It requires additional effort to customize the application to be able 
to analyze other types of vehicles. The prototype that has been developed in this research is able to handle electric, series hybrid electric and series plug-in hybrid electric vehicles. Separate packages or major modifications are required to have an application for parallel hybrid, fuel cell or other vehicle configurations.

- The design tool is developed considering the fundamental physical and dynamical laws governing motion of the vehicle. However, there are always engineering limitations in the design of a vehicle that need to be investigated and considered.

Also, there are certain capabilities as follows that could be added to the developed pilot version to turn it into an industrial version:

- Because of the nature of the problem this generation of vehicle CAD tools are solving, strong computational power is required to render such an application. Therefore, optimizing the application and exploring more efficient optimization theories would be needed.

- By problem definition, this generation is focused on modularity of the application. Various mathematical models for different components of the vehicle could be developed as computer models to be applied to the prototype in order to expand the precision of its design suggestions. 


\section{REFERENCES}

[1] N. Perrin, "Fill it up with what?," Country Journal, pp. 35-36, 1992.

[2] V. Wouk, "Hybrids: Then and now," IEEE Spectrum, pp. 16-21, 1995.

[3] C.C. Chan and K.T. Chau, Modern Electric Vehicle Technology, Oxford University Press, 2001.

[4] M.J. Ryan C.G. Hochgraf and H.L. Wiegman, "Engine control strategy for a series hybrid electric vehicle incorporating load-leveling and computer controlled energy management," Society of Automotive Engineers (SAE) Journal, 2002.

[5] Neeraj Shidore, "An omni-directional design tool for series hybrid electric vehicle design," M.S. thesis, Texas A\&M University, College Station, TX, December 2003.

[6] J.Y. Wong, Theory of Ground Vehicles, John Wiley \& Sons, 1978.

[7] T. Undeland N. Mohan and W. Robbins, Power Electronics - Converters, Application and Design, John Wiley \& Sons, 2nd edition.

[8] Y. Gao, "4 stroke spark plug ignition engine modelling for 2-elph simulation software package.," Annual report of the advanced vehicle system research program, Texas A\&M University, College Station, TX, 1999.

[9] Sebastien E. Gay Ali Emadi Mehrdad Ehsani, Yimin Gao, Modern Electric, Hybrid Electric, and Fuel Cell Vehicles, Fundamentals, Theory and Design, CRC Press, 1st edition, 2005. 


\section{APPENDIX A}

\section{USER'S MANUAL FOR THE PROPOSED TOOL}

In the following different sections of the new CAD tool are introduced and their function has been explained.

\section{A. Design}

The "Design" interface is where the known variables of the vehicle as well as the fix parameters are entered as inputs and an initial range of possible solutions for the vehicle design question will be provided. Figure 49 is a snapshot of this interface which will be further explained in the following.

At the top of the interface, there is a scroll down option that helps the designer choose the shape of the vehicle as well as the battery technology to be used in the vehicle. This menu is shown in figure 50. The vehicle shape determines the aerodynamic drag coefficient, $C_{D}$. The battery technology is important in calculating the volume and weight of the battery based on the required power and energy capacity.

In the very left side of the interface the designer can select which variables to be considered as knowns and which ones as unknown int the design process. This is shown in figure 51. By checking the box for any variable, it is selected as known and the designer will have to determine its variation range.

In the right side of the variable selection check boxes, the designer can enter the acceptable range for each variable. A minimum and a maximum is to be entered for any variable chosen earlier. This is shown in figure 52. Vehicle's maximum acceleration speed in a limited time (10 seconds here) is a variable that is always 


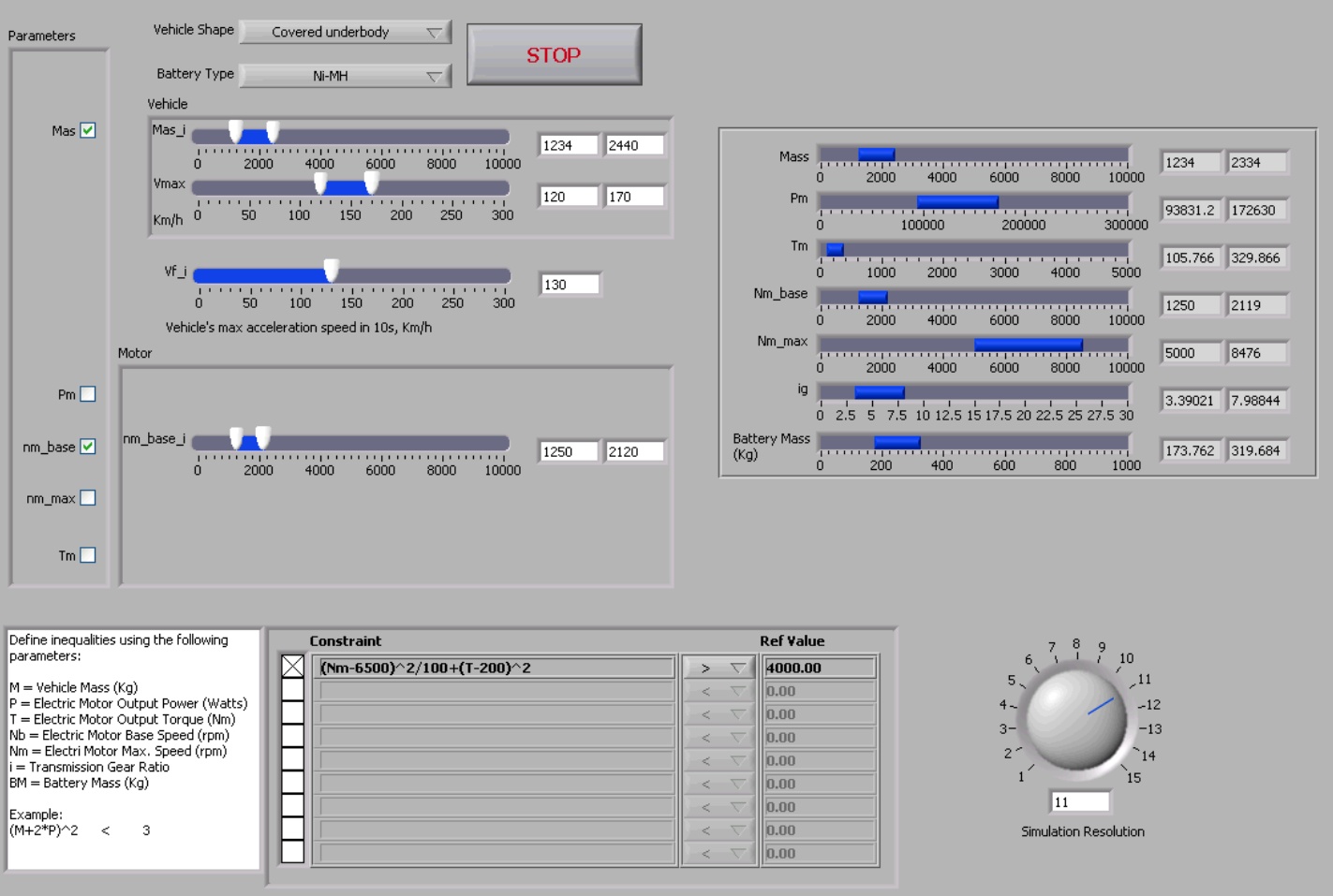

Fig. 49. "Design" interface.

\begin{tabular}{ccc} 
Vehicle Shape & Covered underbody & \\
\cline { 2 - 3 } Battery Type & $\mathrm{Ni-MH}$ & \\
\cline { 2 - 3 }
\end{tabular}

Fig. 50. Vehicle shape and battery technology selection.

required to be known. If a variable is not checked as input, the range lever will not show up for that specific variable.

There are times that the designer needs to manually force some limitations on some variables, because of occasional constraints. This might have various reasons from availability of a component only with a specific characteristic, to price preference in using an specific component. All these additional constraints could be added to the design in the box provided at the bottom of the interface. This section is shown 


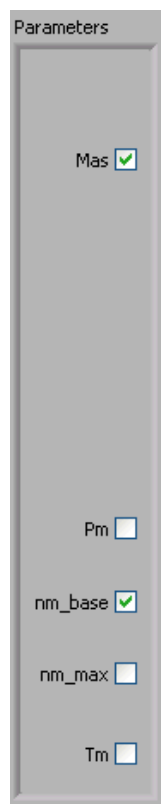

Fig. 51. Selecting known variables.

in detail in figure 53. The constraints have to be defined in the form of inequalities using the symbols defined for each variable.

The final input by the designer in this level is the calculation resolution. It is shown in figure 54. A higher resolution number results in considering more points in the solution space, providing smoother and more accurate solution space. Obviously higher resolution will make it longer for the software to calculate the results.

The last section of the "Design" interface is the outputs which could be found at the right side of the screen. It is shown in figure 55 in detail. This section provides the results of the solution space calculations. It provides a range for every variable in the design such that all these ranges together form a closed solution space; every point in this space will represent one possible vehicle that meets all the predefined design requirements.

It should be noted that the conventional design leads to one single solution vehicle which is a single point in the so-called solution space in the new CAD tool. Having 


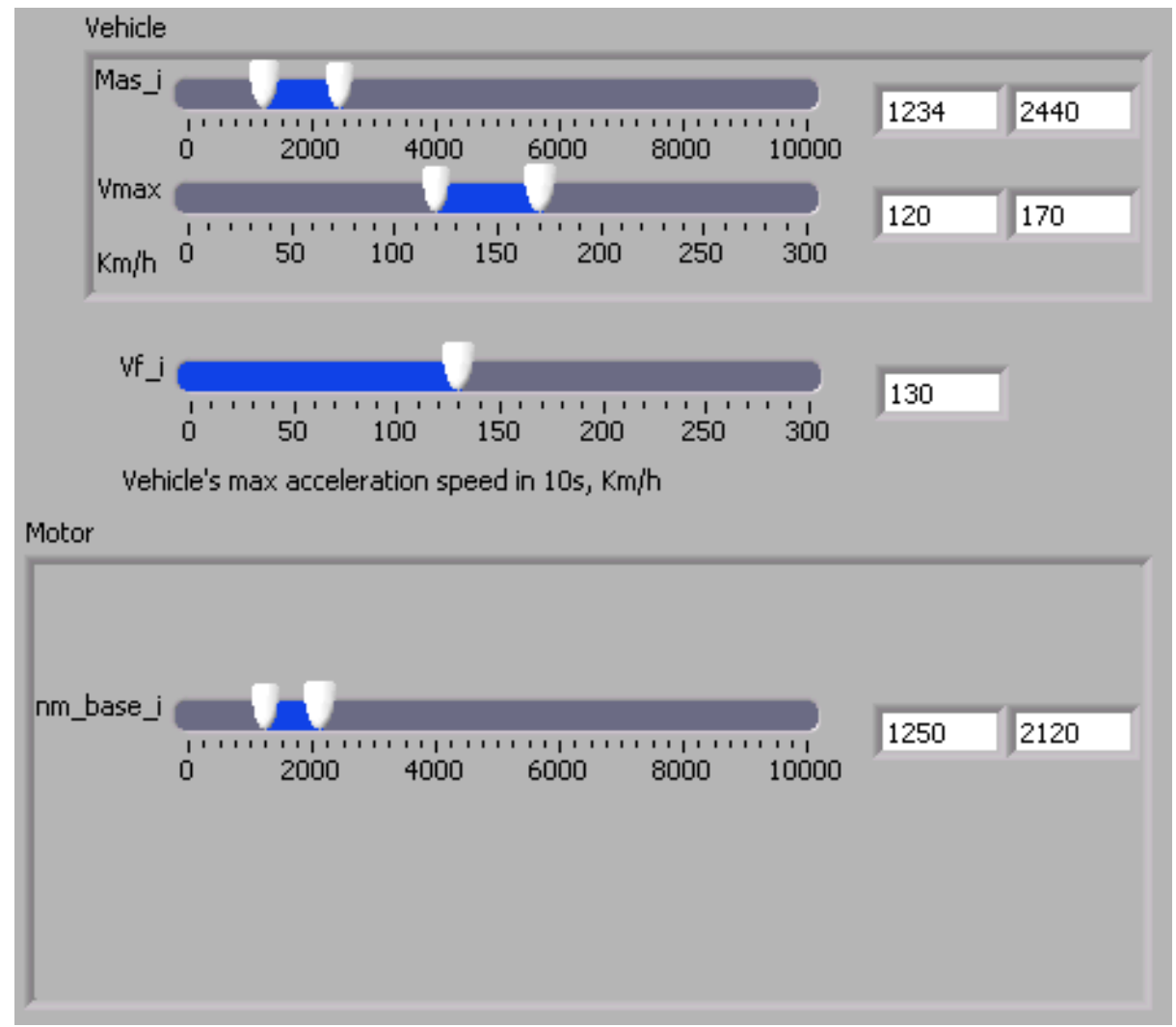

Fig. 52. Entering the varying range for known variables.

all these possible points as option opens the designer's hand in narrowing the space for other concerns than what could be taken into the game in a conventional design.

\section{B. Simulation for Performance}

Once an acceptable range is determined for each variable in the "Design" interface, those points need to be simulated for performance characteristics and be verified that they meet performance requirements, or have a minimum desired safety margins. For that purpose the "Simulation for Performance" interface is provided which would be running in parallel with other sections of the tool. This interface is shown in figure 56. 


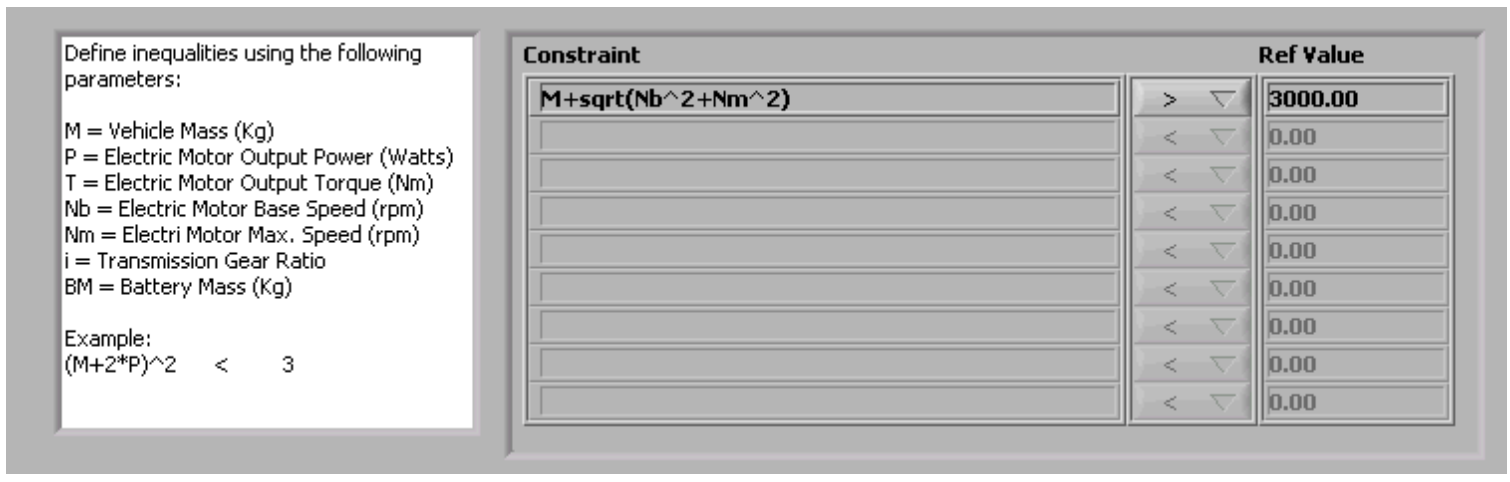

Fig. 53. Additional constraints could be defined as inequalities to be forced on the solution space.

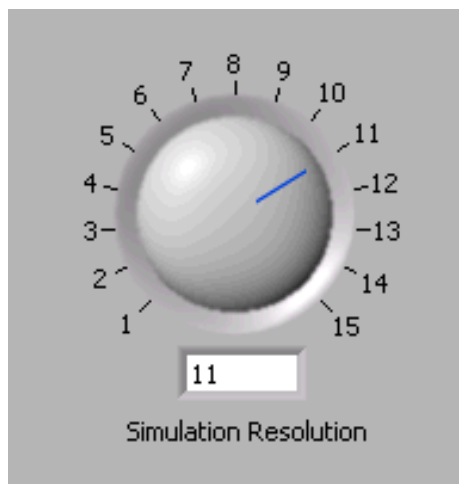

Fig. 54. Defining calculation resolution for the solution space. A higher number indicates more number of points considered in determining the solution space.

Since a simulation by definition is the exercise of applying specific conditions to a specific system and observe its functionality and output, the designer needs to choose a single specific vehicle from the millions of options in the feasible range. Therefore, all the feasible solution ranges will be copies from "Design" to "Simulation for Performance" which are represented in the left side of the screen. The designer could choose single points from the ranges to specify a single vehicle for simulation. This is shown in detail in figure 57.

Once a vehicle is identified, it will be simulated for different performance measures to be verified. All these simulation results are plotted in the right side of the 


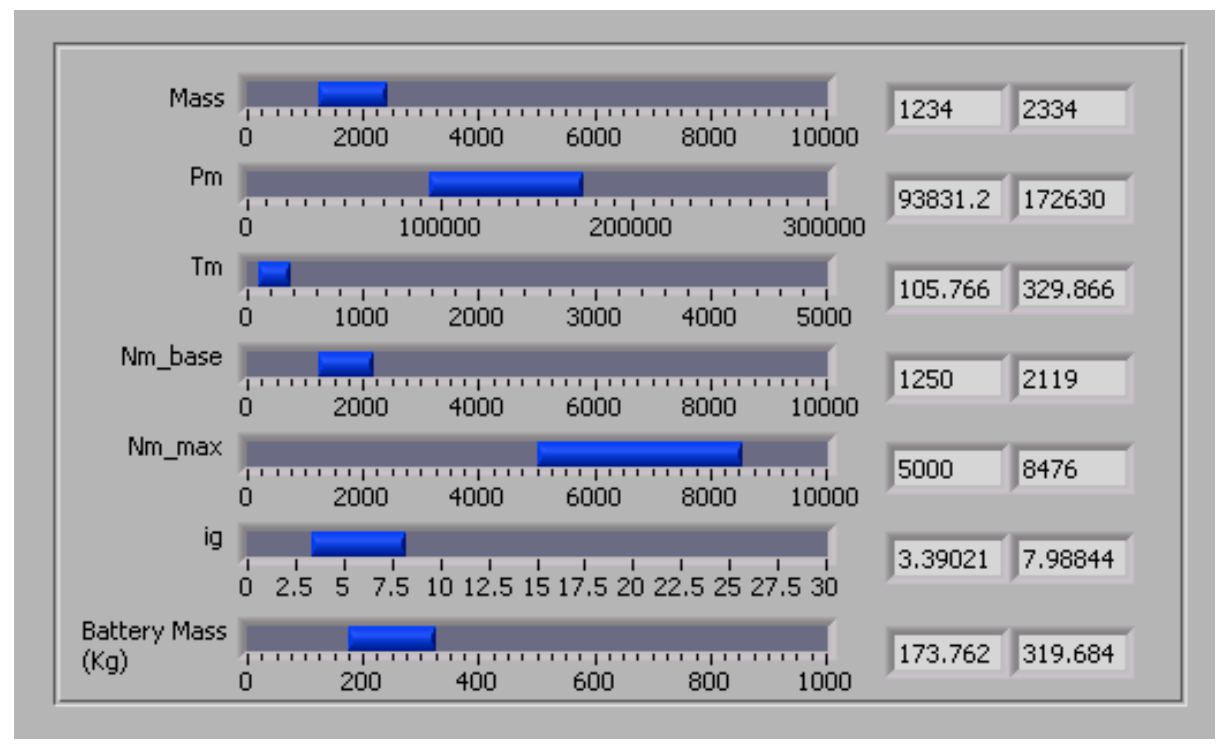

Fig. 55. Feasible ranges for the variables in the solution space.

screen.

Figure 58 shows the gradeability results for different speeds. Figure 59 shows the acceleration time and distance for different speeds. Figure 60 shows the required power of the vehicle engine at different speeds. 


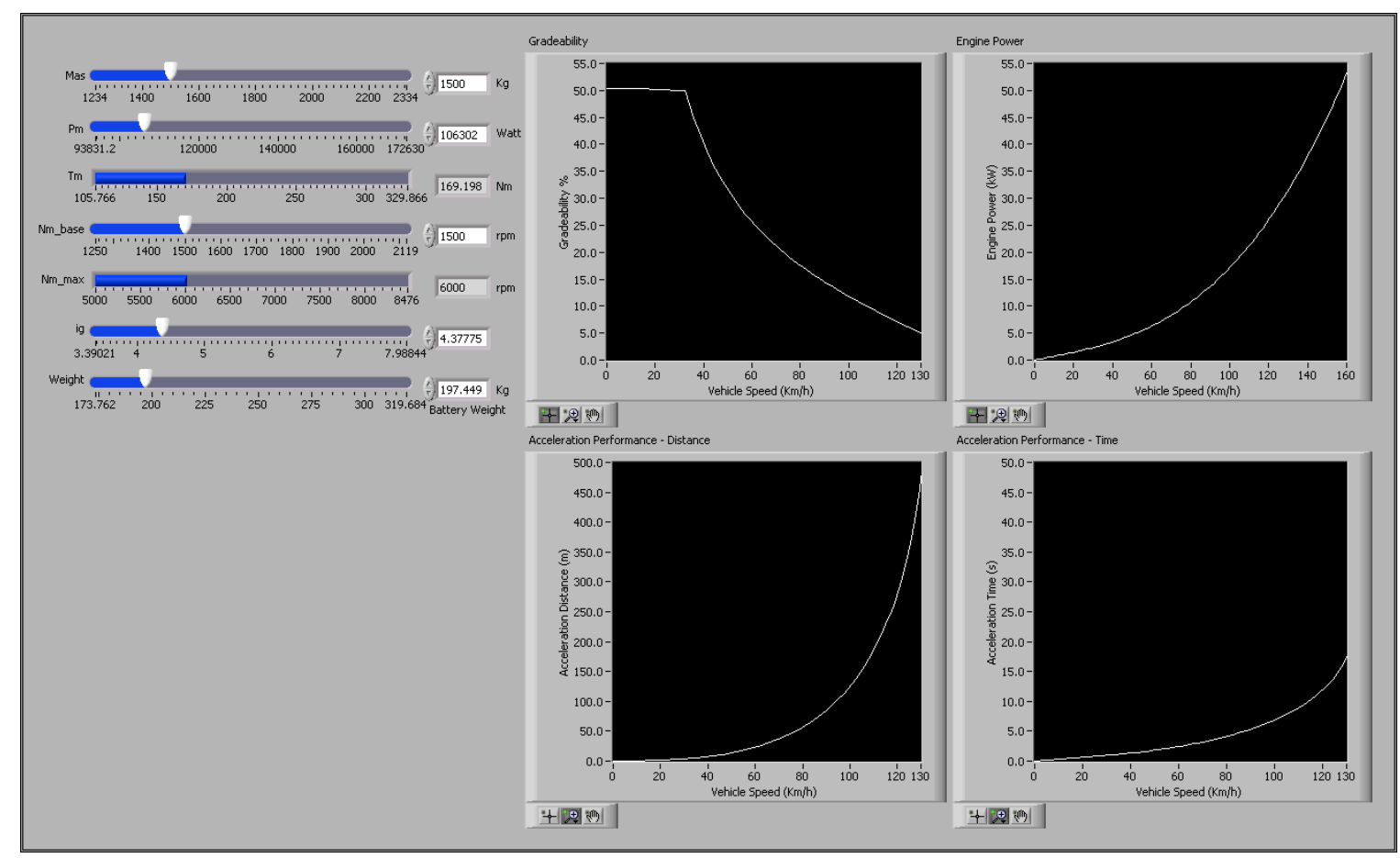

Fig. 56. "Simulation for Performance" interface.

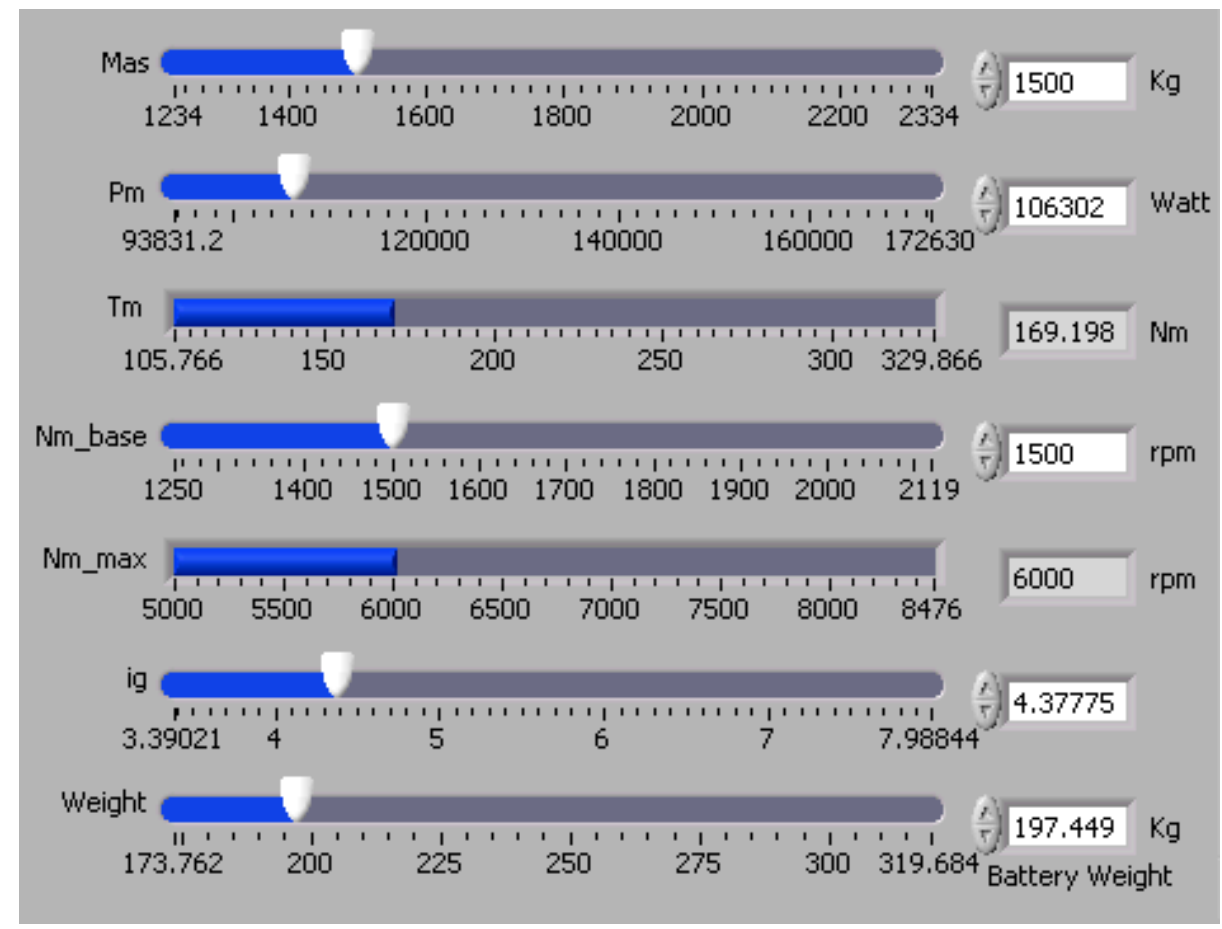

Fig. 57. Choosing a single vehicle from the solution space to be simulated. 


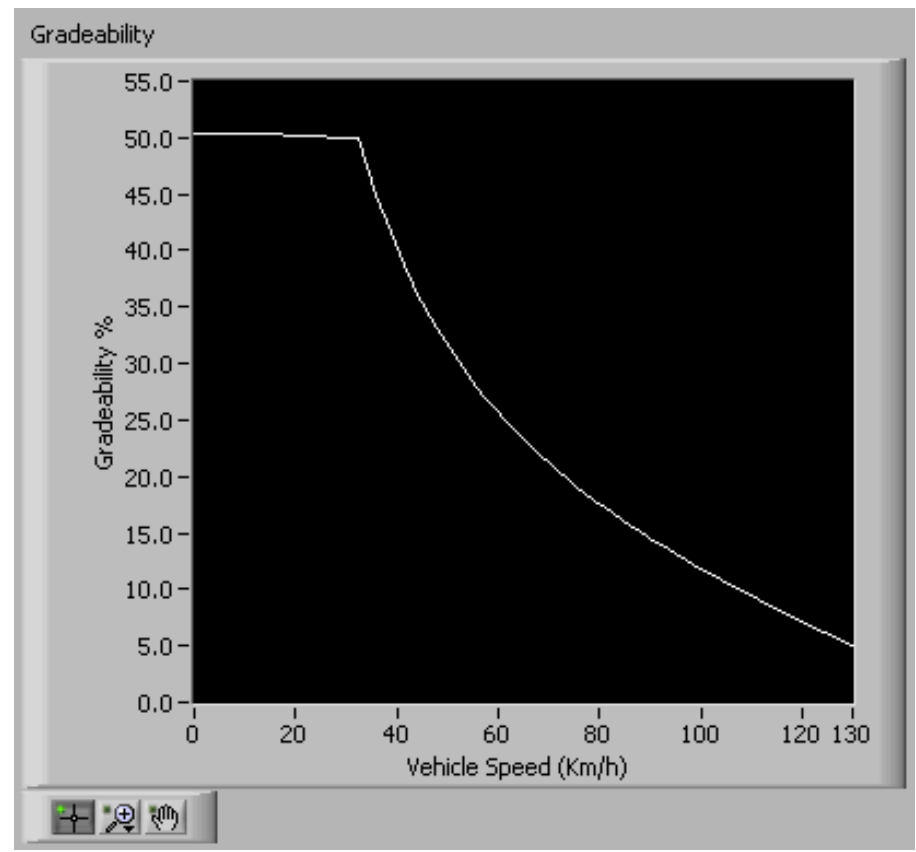

Fig. 58. Gradeability at different speeds.

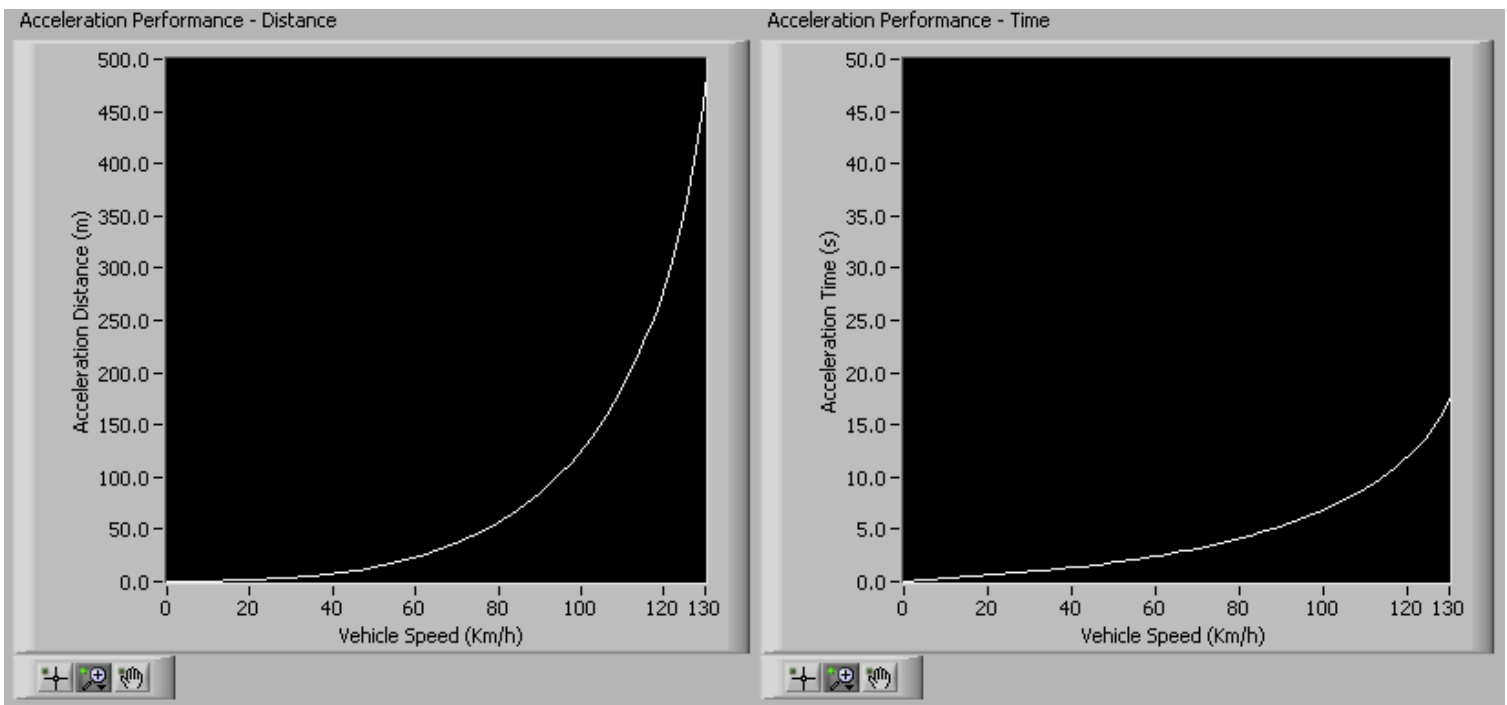

Fig. 59. Acceleration time and distance at different speeds. 


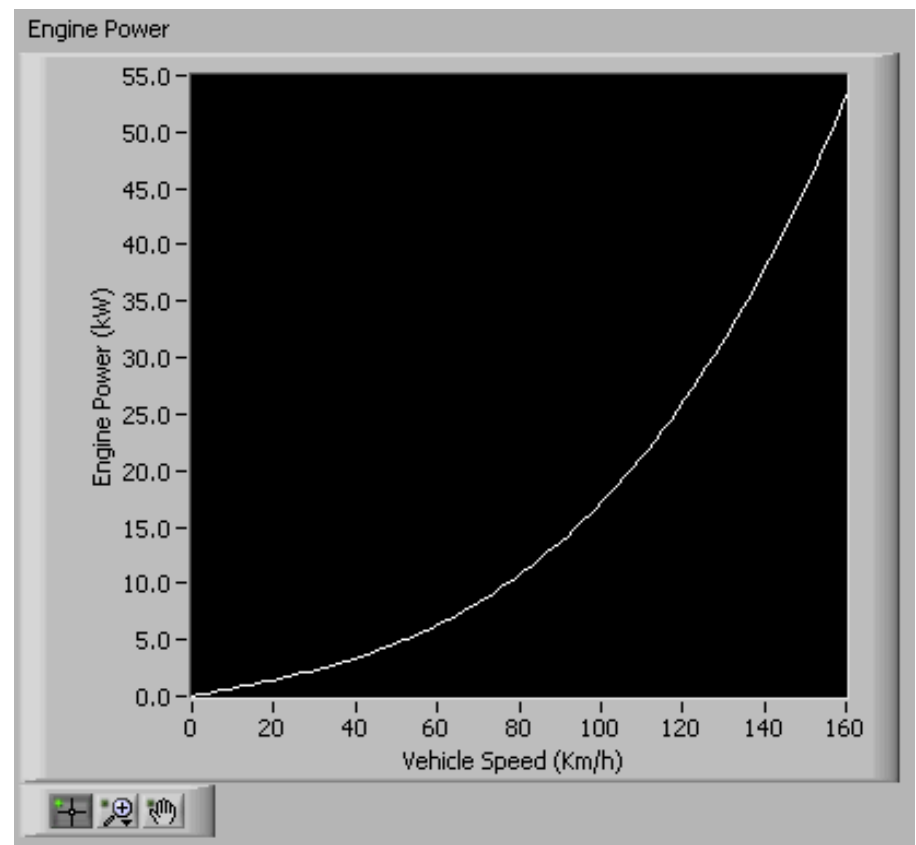

Fig. 60. Required engine power at different speeds. 


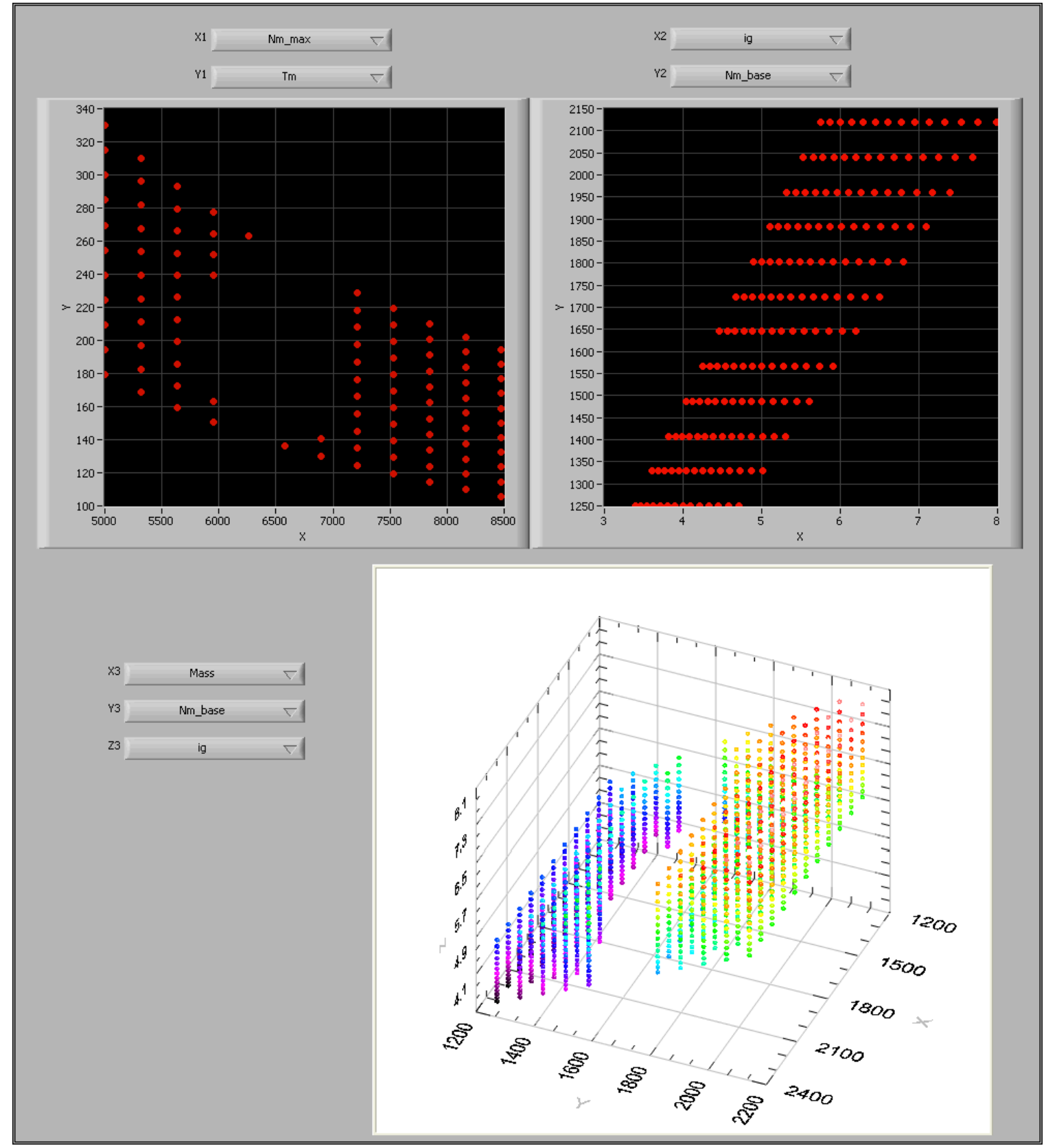

Fig. 61. "Graphs" interface 


\section{Graphs}

The number of dimensions of the solution space depends on the number of variables included in the design process, but is always more than three. Therefore it is never possible to represent the whole space in a graphical mode. However, it is always beneficial to be able to graphically see the two or three dimensional representations of different variables against each other. For this purpose, the "Graphs" interface is also provided which is again working in parallel with the whole system and the graphs are constantly being updated by the latest design results. This interface is shown in figure 61 . There are two 2D graphs are provided at the top, as well as a 3D graph at the bottom. The variables to be displayed could be chosen from the drop-down boxes by the graphs.

\section{Simulation with Drive Cycle and Controller}

Once the vehicle is simulated and its performance characteristics are verified, it is needed to be simulated on a drive cycle. This is necessary to be able to specify the battery specifications since the battery will be discharged along the way in the drive cycle and its charging/discharging pattern is important in determining its size as well as in controlling the engine. For this purpose, the "Simulation with Drive Cycle and Controller" interface is also running in parallel with the whole system to complete whatever is needed to completely design and simulate a vehicle. This interface is shown in figure 62 .

The first step in using this interface is choosing a drive cycle. A library of different common drive cycles are provided in the drop down block at the top left of the interface. This is shown in figure 63. More drive cycles could also be simply added to this library. 


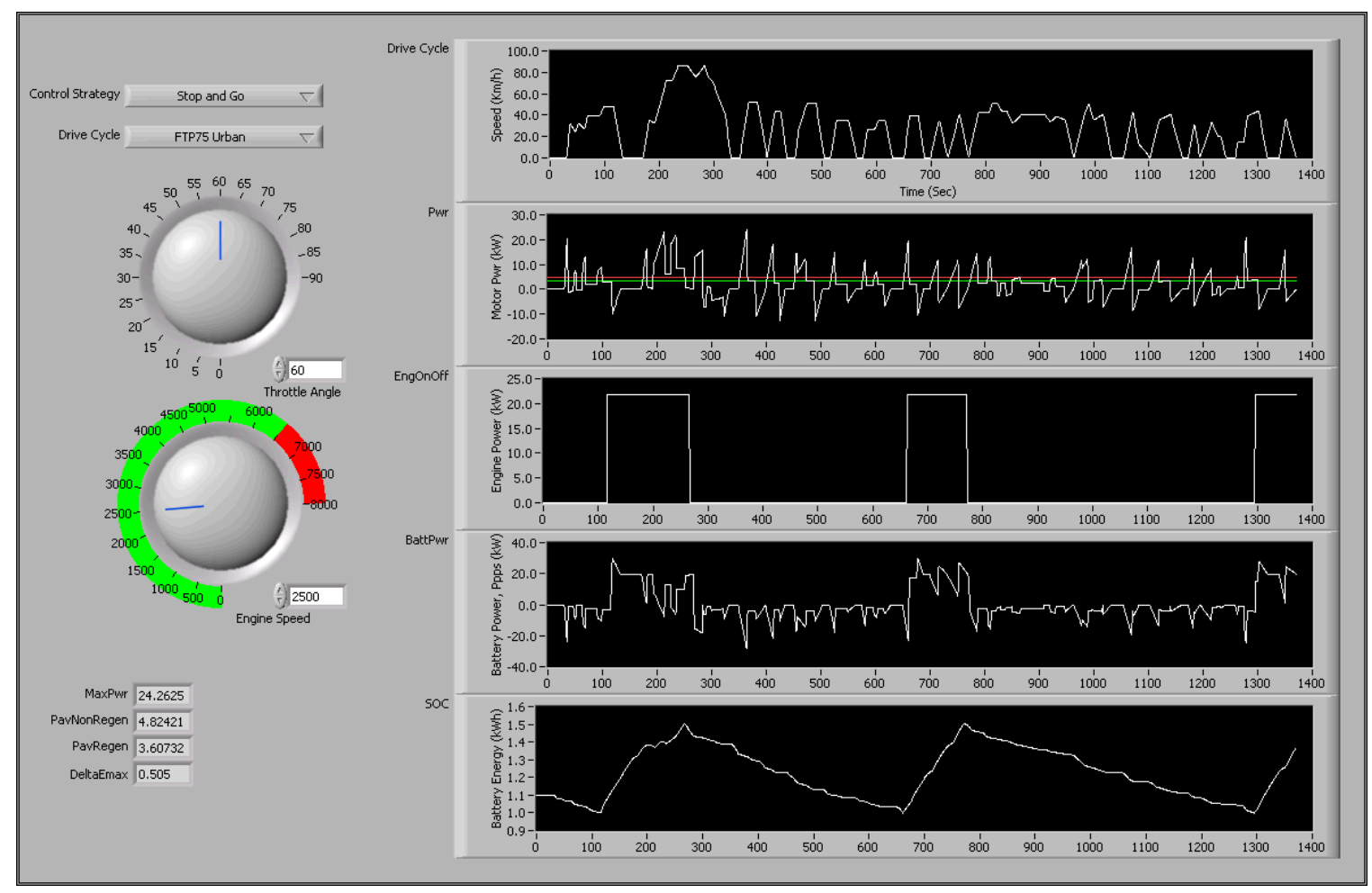

Fig. 62. "Simulation with Drive Cycle and Controller" interface.

\begin{tabular}{rlr} 
Control Strategy & Stop and Go & \\
\cline { 2 - 3 } Drive Cycle & FTP75 Urban & -1 \\
\hline
\end{tabular}

Fig. 63. Choosing a drive cycle and an engine controller.

The next step is to choose a controller for the engine. As discussed before, the controller decides when and at how much power to turn the engine on and when to shut it down to maintain a good state of charge on the battery. A controller could be chosen from the drop down block shown in figure 63 .

Another useful option in accurately simulating the vehicle is to determine the throttle angle and engine speed of the vehicle. These options are also provided in the left side of the interface and could be seen in figure 64 .

Once all these inputs are determined, the simulation will run and the results will 


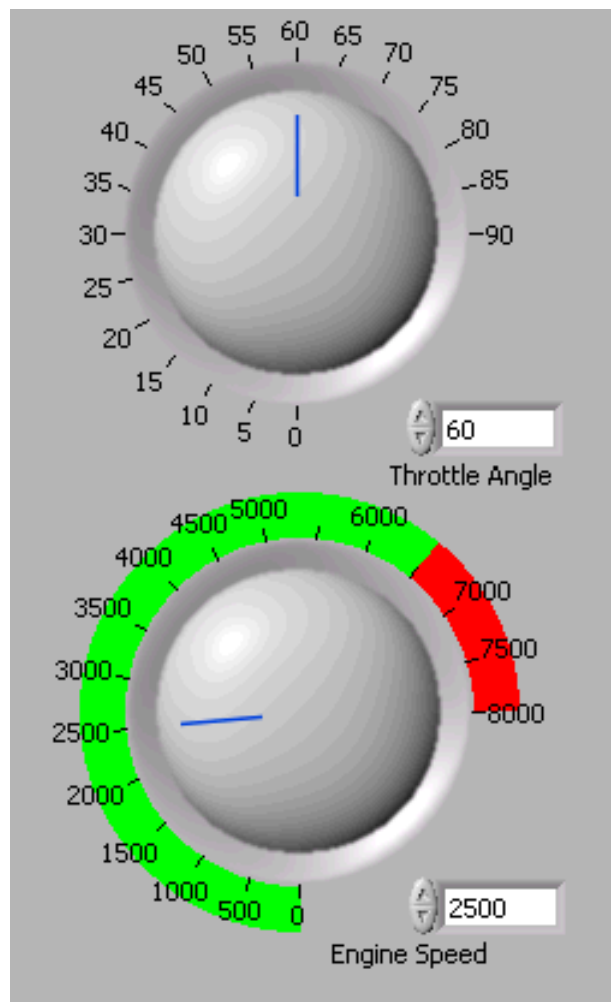

Fig. 64. Determining the throttle angle and engine speed for simulation.

be demonstrated in the right side of the interface. Figure 65 shows the drive cycle that has been used for the simulation and figure 66 shows the instantaneous power needed to be provided by the vehicle to run it at the chosen drive cycle. This figure also shows the average required power in both cases of applying and not applying the regenerative braking.

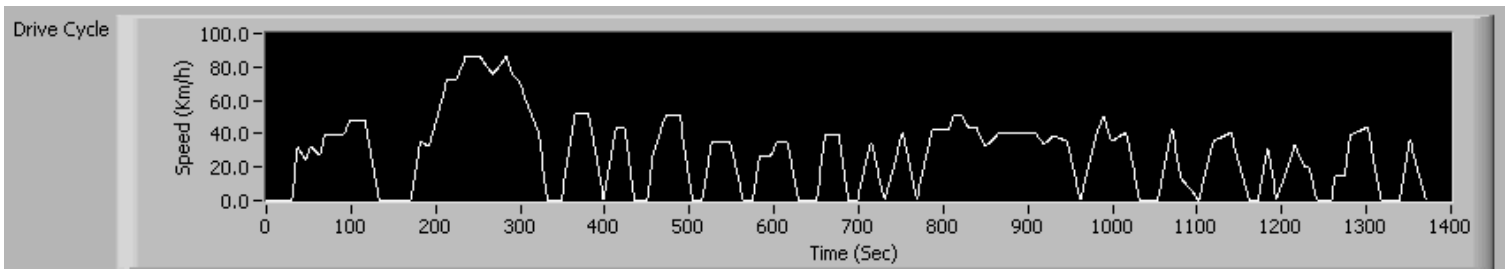

Fig. 65. The drive cycle used for simulation.

Figure 67 shows the engine operation; i.e. the instances that the engine is turned 


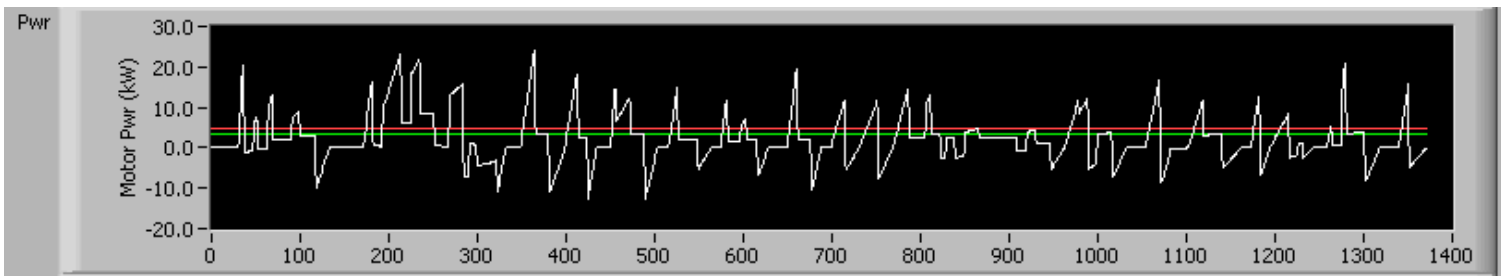

Fig. 66. The power required to run the vehicle: instantaneous, average with and average without regenerative braking.

on and the power that the engine will operate at when on. Figure 68 shows the power received by the battery. When the engine is on, this power will be positive, meaning that the battery is being charged and when the engine is off it will be negative meaning that the battery is supplying power to the vehicle.

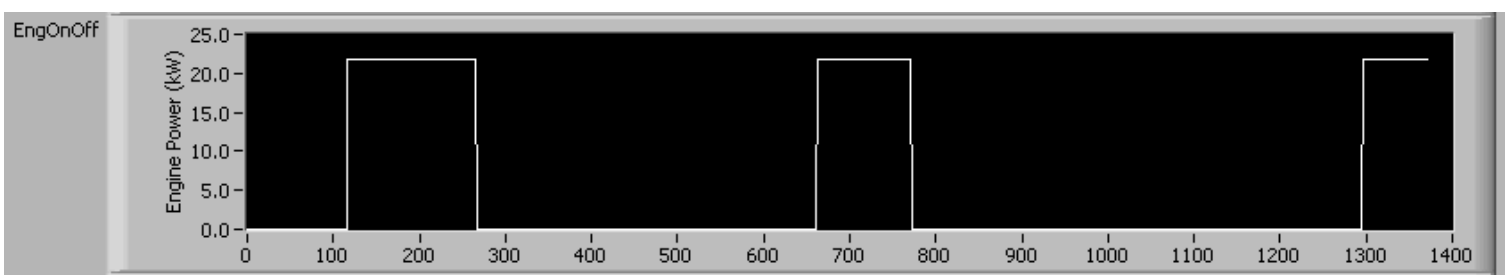

Fig. 67. Engine operation.

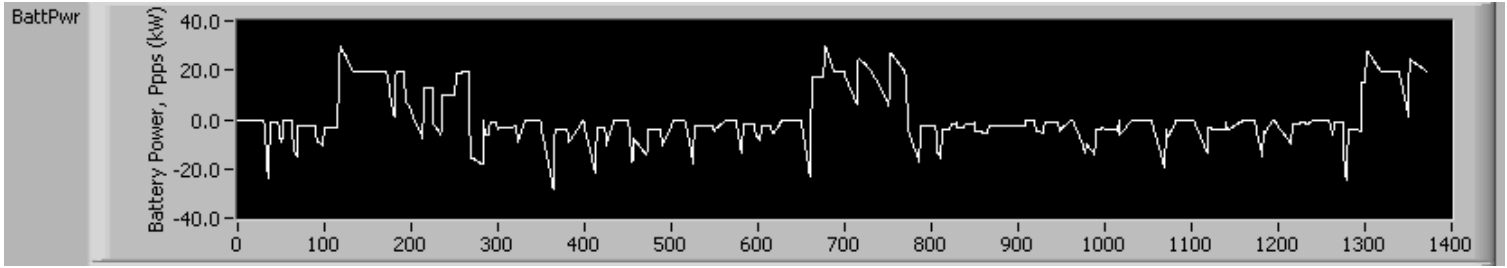

Fig. 68. Power sent to the battery. 


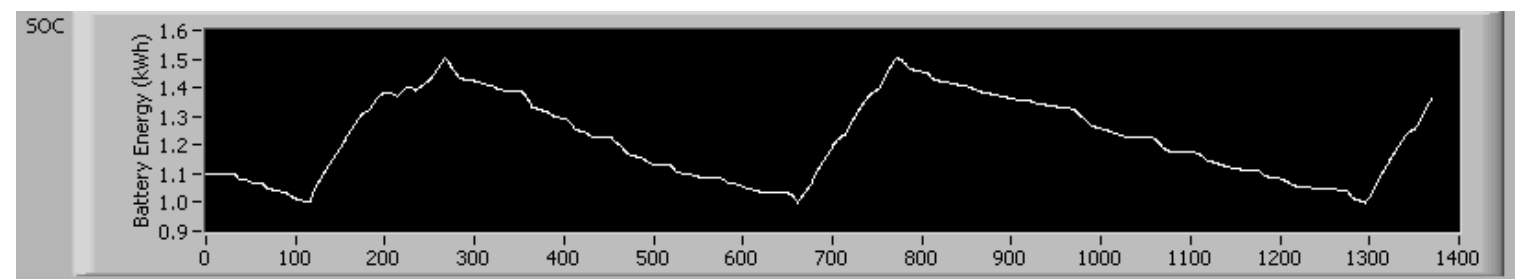

Fig. 69. Battery state of charge.

Finally, figure 69 shows the state of charge of the battery. This is indeed the energy level of the battery varying by time.

E. Designing a Vehicle

\section{Electric Vehicle Design}

An electric vehicle as discussed in Chapter II and shown in figure 70 is the simplest form of vehicle which is consisted of an electric motor, transmission which is usually a single gear one and a battery. So the design question is limited to these three components.

\section{a. Design Question}

The electric vehicle that is going to be designed here should meet the following performance requirements:

$$
\begin{array}{ll}
\text { Acceleration time }(0-100 \mathrm{~km} / \mathrm{h}) & 10 \mathrm{sec} \\
\text { Minimum gradeability } & 5 \% @ 100 \mathrm{~km} / \mathrm{h} \\
\text { Maximum speed } & 160 \mathrm{Km} / \mathrm{h}
\end{array}
$$

This vehicle also has the following given parameters: 


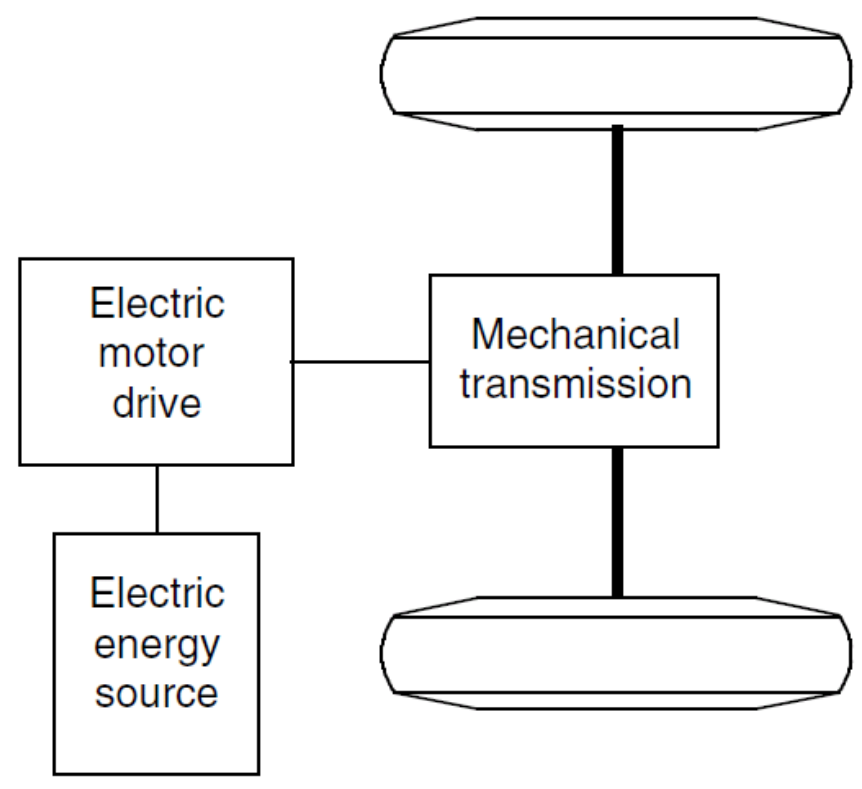

Fig. 70. Major components of an electric vehicle.

Vehicle mass

$1300-1800 \mathrm{Kg}$

Single gear transmission efficiency

$90 \%$

Vehicle front area $\left(A_{f}\right)$

$2.0 \mathrm{~m}^{2}$

Electrical motor and drive efficiency $85 \%$

Generator efficiency

90

Aerodynamic drag coefficient $\left(C_{D}\right)$

0.3

\section{b. Design Using the Proposed Tool}

The first step is to understand what components exist in the vehicle that is going to be designed. An electric vehicle has an electric motor, a battery to power the motor and a single gear transmission to transfer the torque from the electric motor to the wheels.

From the design question we understand that our known variables are vehicle 
mass, acceleration time and the vehicle's maximum speed. The first interface that should be used is the 'Design' that is shown in figure 77.

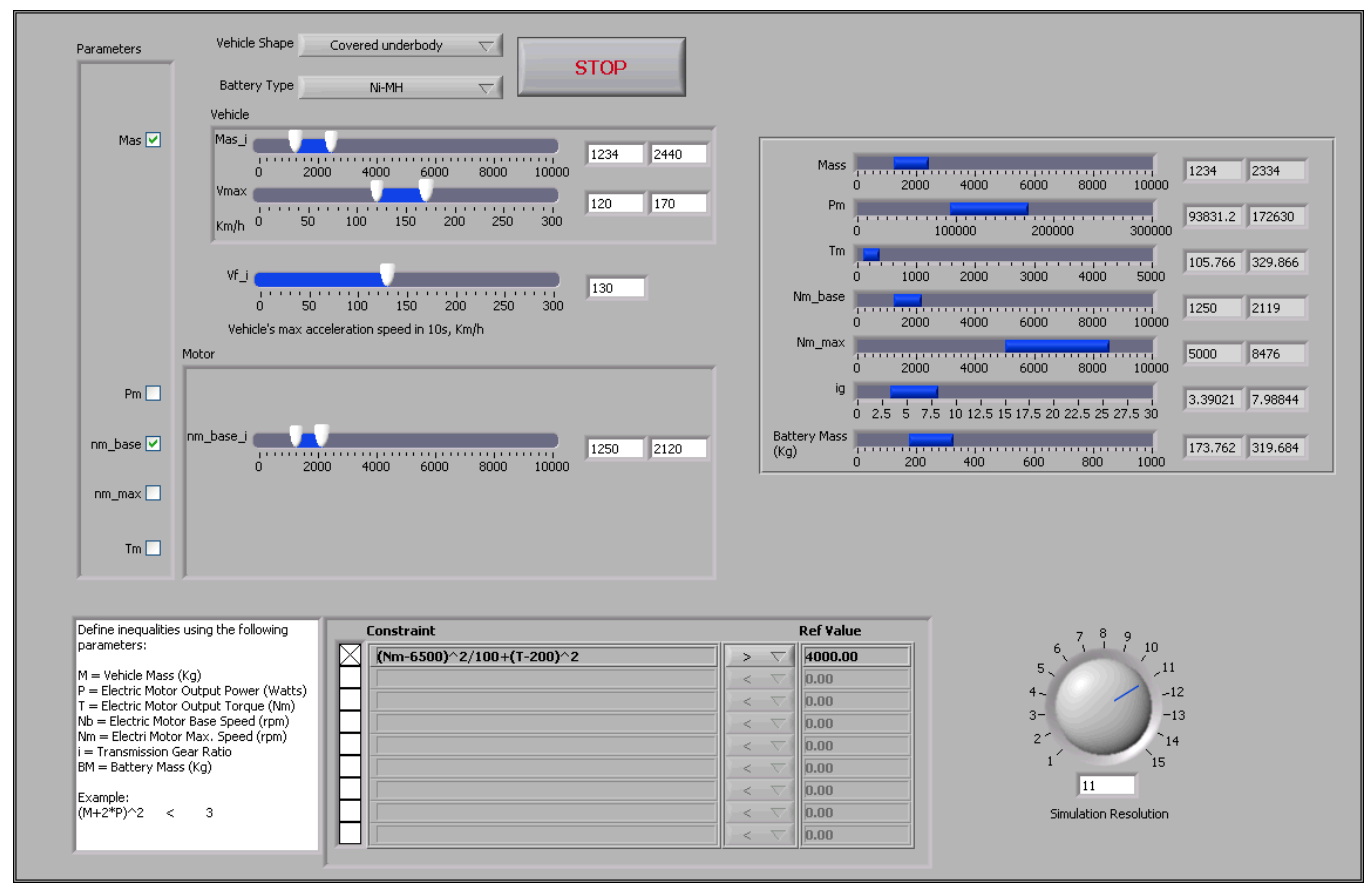

Fig. 71. 'Design' interface is used to specify the known variables and set the values for them.

From the left hand side, we need to enter the vehicle shape and the battery type. This is shown in figure 72 . We need to choose the battery type as Ni-MH and an arbitrary shape for the vehicle. We can assume that we are designing a 'Covered Underbody' shape vehicle.

\begin{tabular}{lcc} 
Vehicle Shape & Covered underbody & \\
\cline { 2 - 3 } Battery Type & Ni-MH \\
\hline
\end{tabular}

Fig. 72. The battery type and the vehicle shape is entered here.

The next step is to enter the vehicle mass and its maximum speed, as well as the acceleration. This could be done in the top left side of the interface as is shown 
in figure 78. The check marks in the left side of different variables determine which ones we wanna choose to be knowns and we would like to enter value ranges for. The application is going to solve for the rest of the variables. Keep in mind that there are two ways to express the acceleration of a vehicle: The time that it takes for a vehicle to from still to a certain speed or the speed that the vehicle can reach in a certain amount of time starting from still condition. The latter is used in the developed application. We may consider a mass range of 1234 to $2440 \mathrm{Kg}$ and the maximum vehicle speed of 120 to $170 \mathrm{Km} / \mathrm{h}$. We also need to choose a base speed for the electric motor but there is no specific guideline in the design question about it. So we just pick 1250 to $2120 \mathrm{rpm}$. We need to remember that there is no engine in the electric vehicle and so any required engine power that is calculated should be delivered by the electric motor.

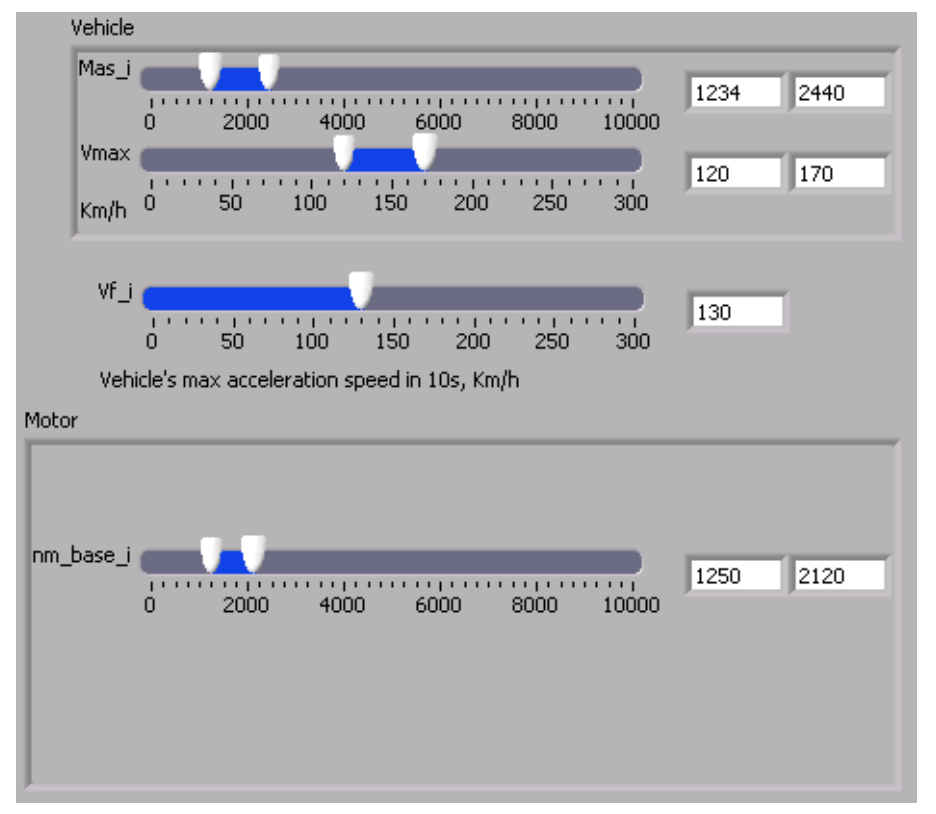

Fig. 73. The vehicle mass, maximum speed and acceleration will be entered here.

Just by determining the values for the variables in their lever markers the application is going to take them into effect and the results would be updated. So all the 


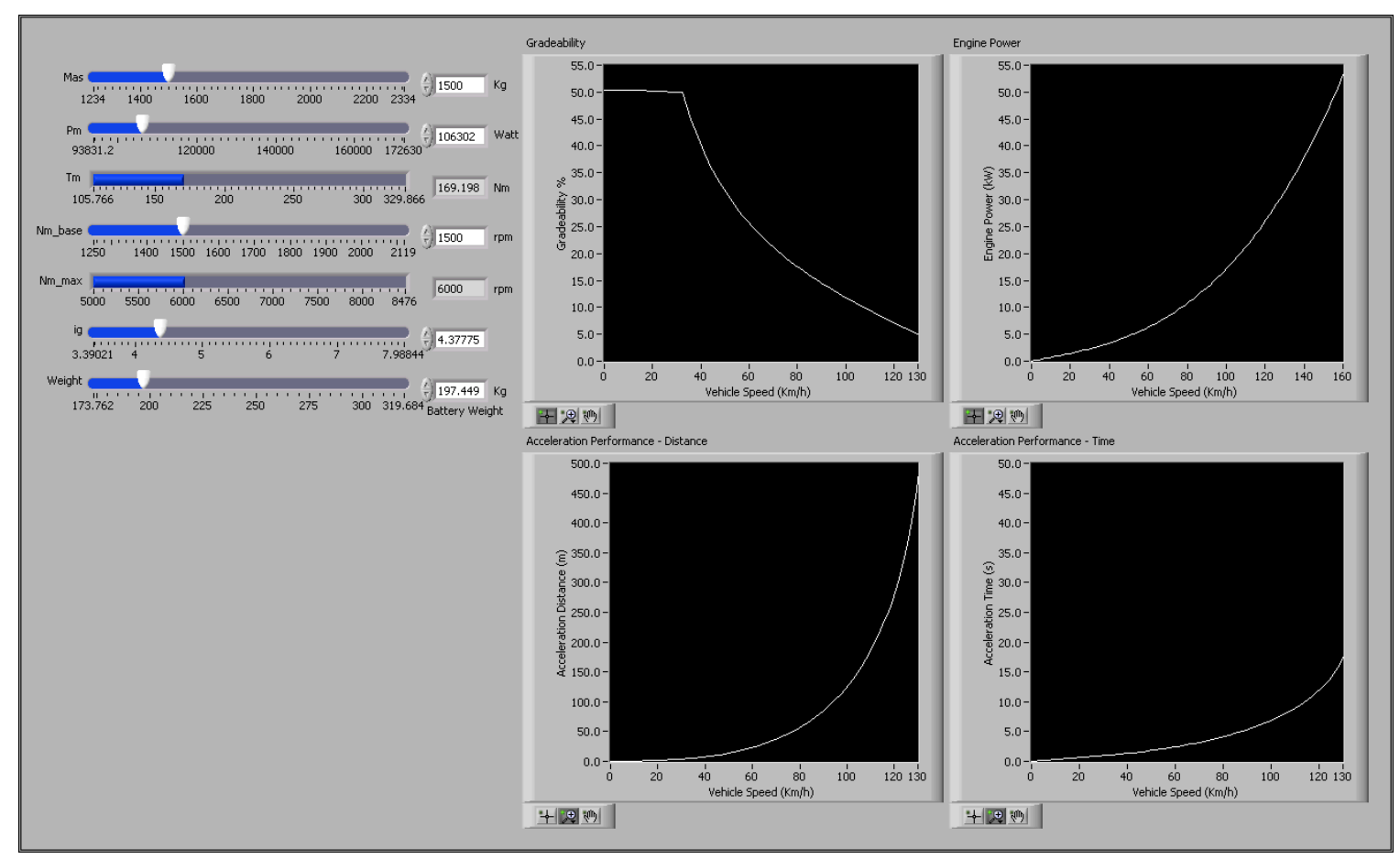

Fig. 74. The initial simulation for performance will be done in this interface.

designer needs to do is to determine a minimum and maximum level for each known variable. The acceptable ranges for all the variables are going to be displayed in the right hand of the screen. These ranges simply mean that any point in those ranges is the representative of a separate vehicle that means the initial design specifications. At the bottom of the screen there is an option of impose more user defined restrictions but no such a restriction is needed in this design. Once the acceptable design ranges are determined we have an idea of different components of the vehicle we need, we can start simulating the possible options and narrow down our design.

The initial simulation is done in the interface shown in figure 79. All the possible ranges for all variables are displayed in the left side of the screen. Every combination of points represent a vehicle. By choosing different values we can select the resulting vehicle and evaluate its performance for acceleration, different grades and etc. 


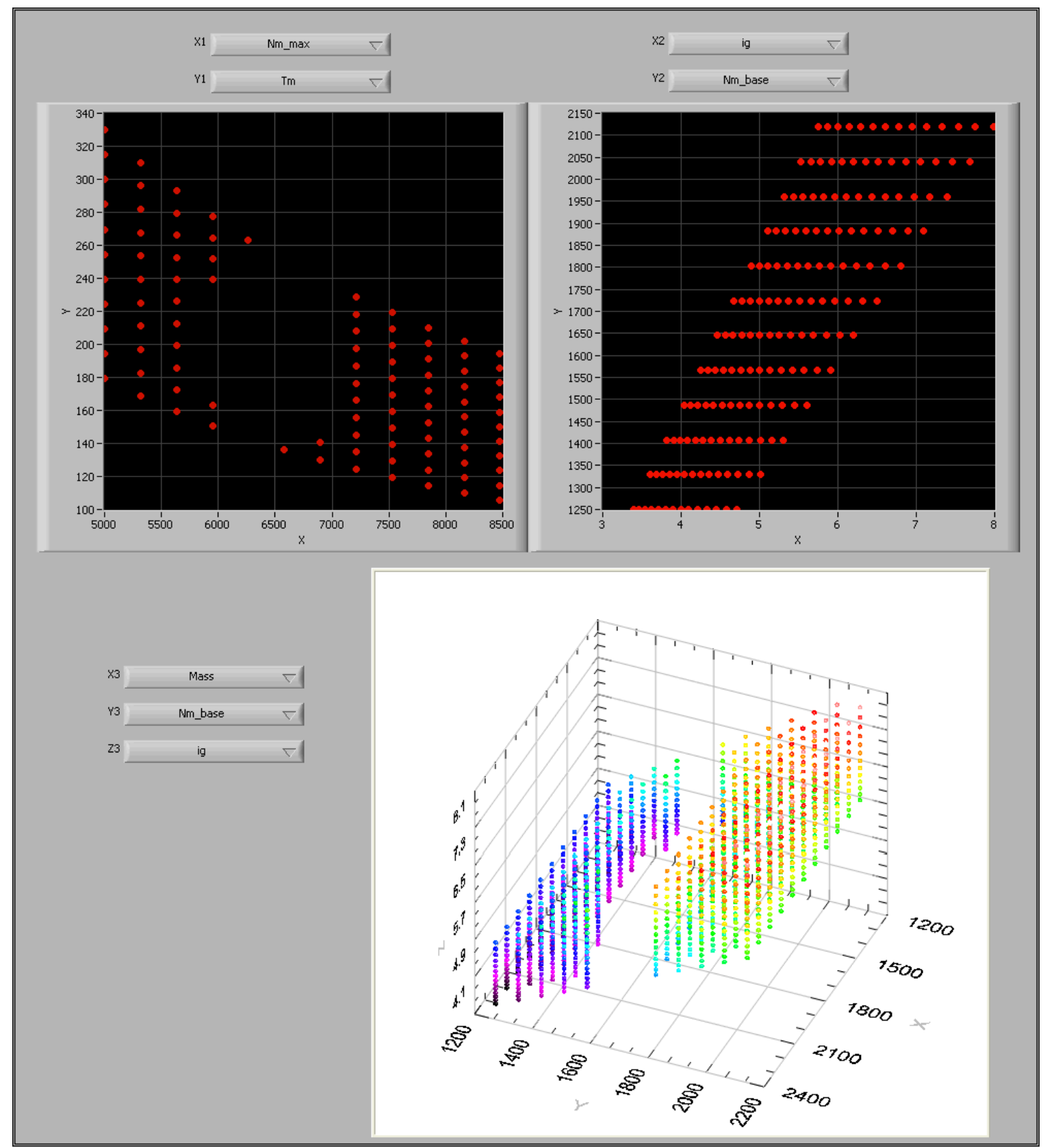

Fig. 75. 2D and 3D plots of the possible ranges for any two or three selected variables in the vehicle.

A very useful means that could help picking a vehicle to simulate smartly is the 2D and 3D graphical representation of the solution space. This is introduced in the interface shown in figure 75. As could be seen, any point inside the solution space 
is a potential solution. These graphical spaced and the range selector values in the simulation interface change their values automatically once any change is imposed in the design interface. From these graphs we can make sure that the vehicle we are choosing is in the right spot with respect to all variables. The vehicle we choose is going to have the following characteristics:

Mass

Electric motor power

Electric motor torque

Electric motor base speed

Electrical motor maximum speed

Gear ratio

Battery mass

\section{$1500 \mathrm{Kg}$}

$106302 W$

$169.2 \mathrm{Nm}$

$1500 \mathrm{rpm}$

$6000 \mathrm{rpm}$

4.38

$197.4 \mathrm{Kg}$

Simulation results are plotted in the right hand of the screen which are as follows: Mass

Acceleration time @ $100 \mathrm{Km} / \mathrm{h}$

Acceleration distance for $100 \mathrm{Km} / \mathrm{h}$

Maximum Gradeability @ 100 Km/h

Engine power needed at $100 \mathrm{Km} / \mathrm{h}$ cruising speed
$1500 \mathrm{Kg}$

$6.1 \mathrm{sec}$

$75 m$

11

$17.5 K W$

Since we don't have an engine present, we will account for the $17.5 \mathrm{KW}$ power required from engine by the electric motor. Since the electric motor already has a power of $106 \mathrm{KW}$ which is greater than 17.5, we don't need to do anything else about it. Also, the battery is charged only by plugging the car to external power source and therefore, no engine management or battery state of charge management system is needed. So there is no need at all for the control strategy simulation. 


\section{Series Hybrid Electric Vehicle Design}

A series hybrid electric vehicle has 4 main components that are going to be addressed: electric motor, internal combustion engine, single gear transmission and battery. The construction of such a vehicle is shown is figure 76 .

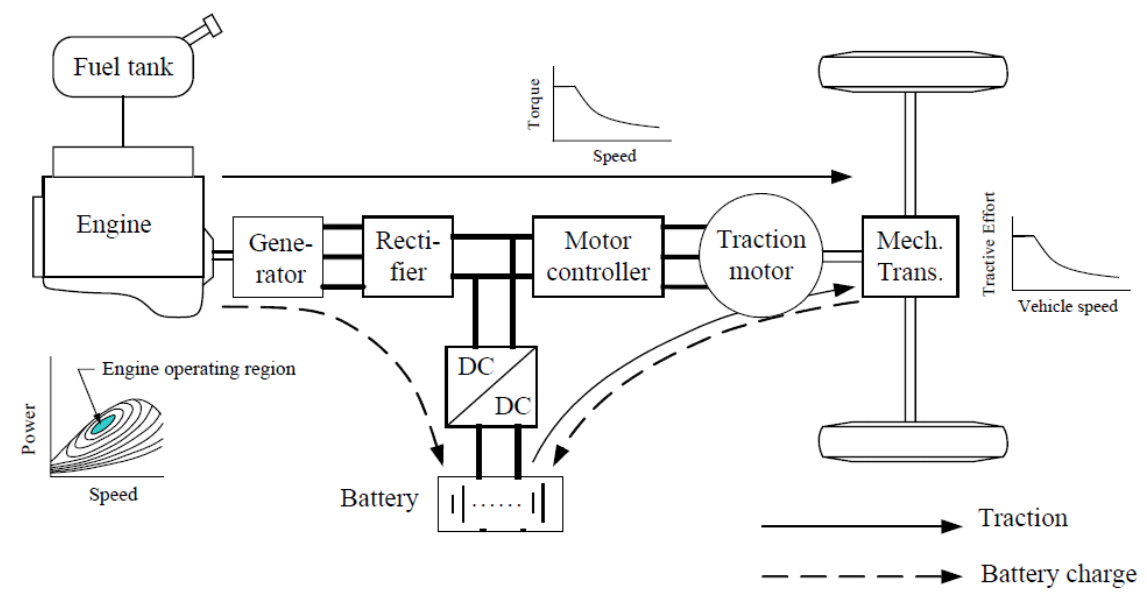

Fig. 76. Major components of a series hybrid electric vehicle.

\section{a. Design Question}

The vehicle that is going to be designed here should meet the performance requirements same as the electric vehicle example designed in the previous section:

$\begin{array}{ll}\text { Acceleration time }(0-100 \mathrm{~km} / \mathrm{h}) & 10 \mathrm{sec} \\ \text { Minimum gradeability } & 5 \% @ 100 \mathrm{~km} / \mathrm{h} \\ \text { Maximum speed } & 160 \mathrm{Km} / \mathrm{h}\end{array}$

This vehicle also has the following given parameters: 
Vehicle mass

Single gear transmission efficiency

Vehicle front area $\left(A_{f}\right)$

Electrical motor and drive efficiency $\quad 85 \%$

Generator efficiency

Aerodynamic drag coefficient $\left(C_{D}\right)$

Rolling resistance coefficient $\left(f_{r}\right)$

Tire radius

Air density $\left(\rho_{a}\right)$
$1500 \mathrm{Kg}$

$90 \%$

$2.0 \mathrm{~m}^{2}$

90

0.3

0.01

$0.3 m$

$1.202 \mathrm{Kg} / \mathrm{m}^{2}$

b. Design Using the Proposed Tool

The first step is to understand what components exist in the vehicle that is going to be designed. As explained earlier in this chapter, a series hybrid electric vehicle has an electric motor, a battery to power the motor, an engine to maintain the state of charge on the battery and a single gear transmission to transfer the torque from the electric motor to the wheels.

From the design question we understand that our known variables are vehicle mass, acceleration time and the vehicle's maximum speed. The first interface that should be used is the 'Design' that is shown in figure 77. 


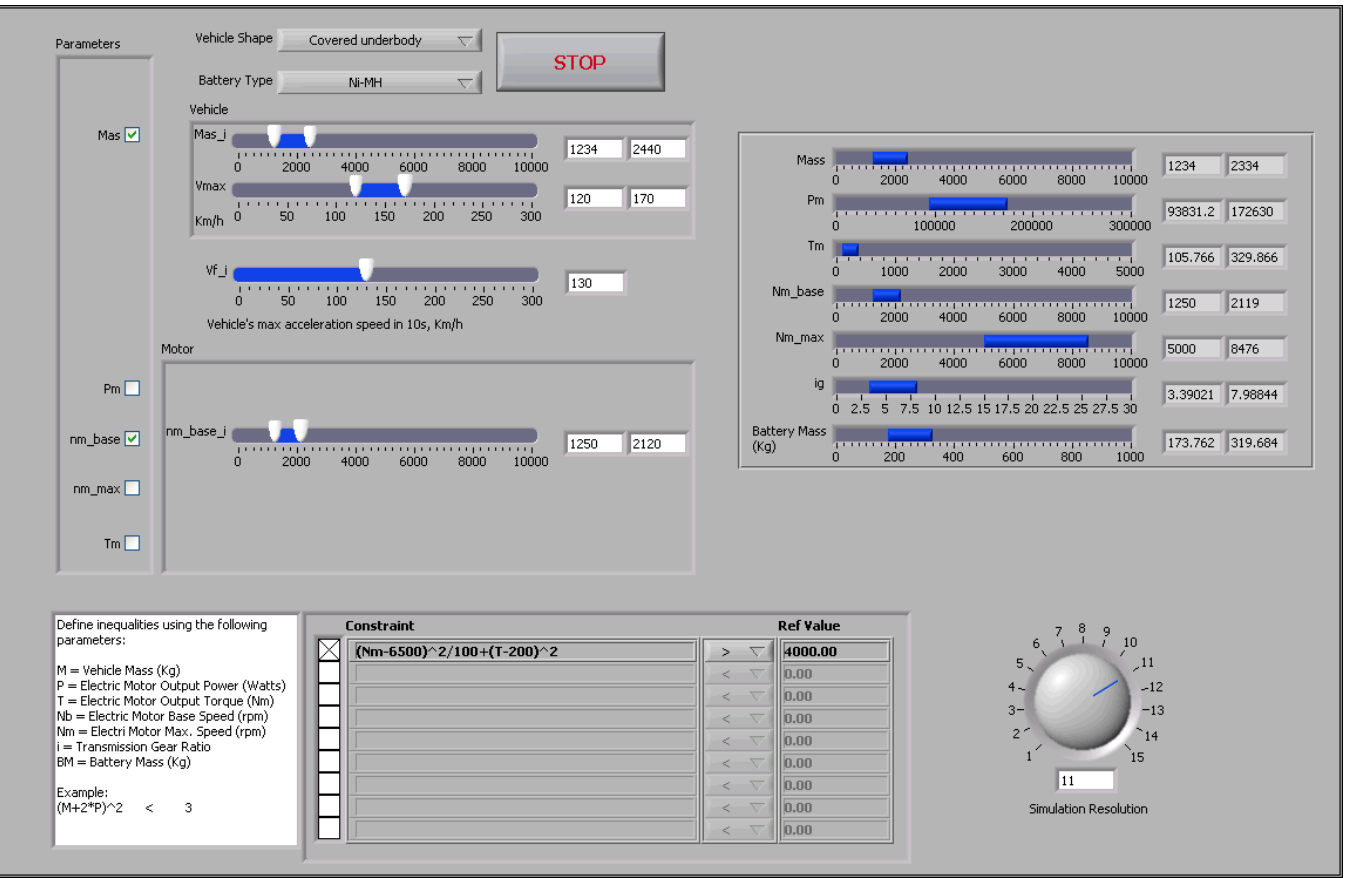

Fig. 77. Specifying known variables.

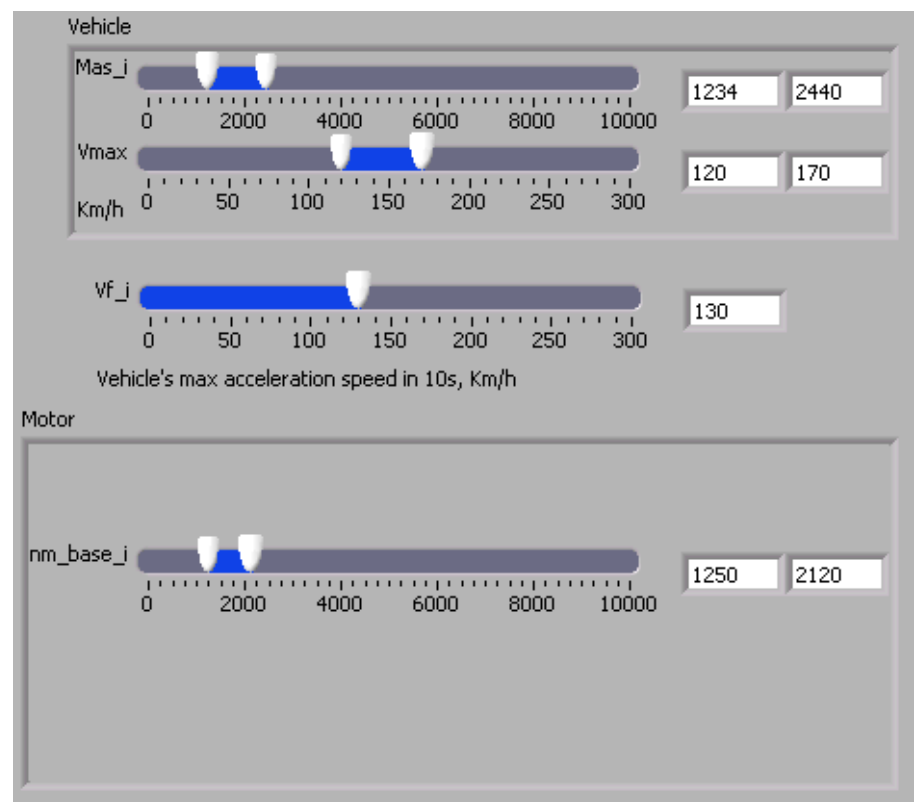

Fig. 78. Determining variable ranges.

From the left hand side, we need to enter the vehicle shape and the battery type. 
We need to choose the battery type as Ni-MH and an arbitrary shape for the vehicle. We can assume that we are designing a 'Covered Underbody' shape vehicle.

The next step is to enter the vehicle mass and its maximum speed, as well as the acceleration. This could be done in the top left side of the interface as is shown in figure 78. The check marks in the left side of different variables determine which ones we wanna choose to be knowns and we would like to enter value ranges for. The application is going to solve for the rest of the variables. Keep in mind that there are two ways to express the acceleration of a vehicle: The time that it takes for a vehicle to from still to a certain speed or the speed that the vehicle can reach in a certain amount of time starting from still condition. The latter is used in the developed application. We may consider a mass range of 1234 to $2440 \mathrm{Kg}$ and the maximum vehicle speed of 120 to $170 \mathrm{Km} / \mathrm{h}$. We also need to choose a base speed for the electric motor but there is no specific guideline in the design question about it. So we just pick 1250 to $2120 \mathrm{rpm}$.

Just by determining the values for the variables in their lever markers the application is going to take them into effect and the results would be updated. So all the designer needs to do is to determine a minimum and maximum level for each known variable. The acceptable ranges for all the variables are going to be displayed in the right hand of the screen. These ranges simply mean that any point in those ranges is the representative of a separate vehicle that means the initial design specifications. At the bottom of the screen there is an option of impose more user defined restrictions but no such a restriction is needed in this design. Once the acceptable design ranges are determined we have an idea of different components of the vehicle we need, we can start simulating the possible options and narrow down our design.

The initial simulation is done in the interface shown in figure 79. All the possible ranges for all variables are displayed in the left side of the screen. Every combination 
of points represent a vehicle. By choosing different values we can select the resulting vehicle and evaluate its performance for acceleration, different grades and etc. From the $2 \mathrm{D}$ and $3 \mathrm{D}$ graphs we can make sure that the vehicle we are choosing is in the right spot with respect to all variables. The vehicle we choose is going to have the following characteristics:

Mass $1500 \mathrm{Kg}$

Electric motor power $106302 W$

Electric motor torque $169.2 \mathrm{Nm}$

Electric motor base speed $1500 \mathrm{rpm}$

Electrical motor maximum speed 6000 rpm

Gear ratio 4.38

Battery mass $197.4 \mathrm{Kg}$

Simulation results are plotted in the right hand of the screen which are as follows: Mass $1500 \mathrm{Kg}$

Acceleration time @ $100 \mathrm{Km} / \mathrm{h}$ $6.1 \mathrm{sec}$

Acceleration distance for $100 \mathrm{Km} / \mathrm{h}$ $75 m$

Maximum Gradeability @ $100 \mathrm{Km} / \mathrm{h}$ 11

Engine power needed at $100 \mathrm{Km} / \mathrm{h}$ cruising speed $17.5 \mathrm{KW}$ 


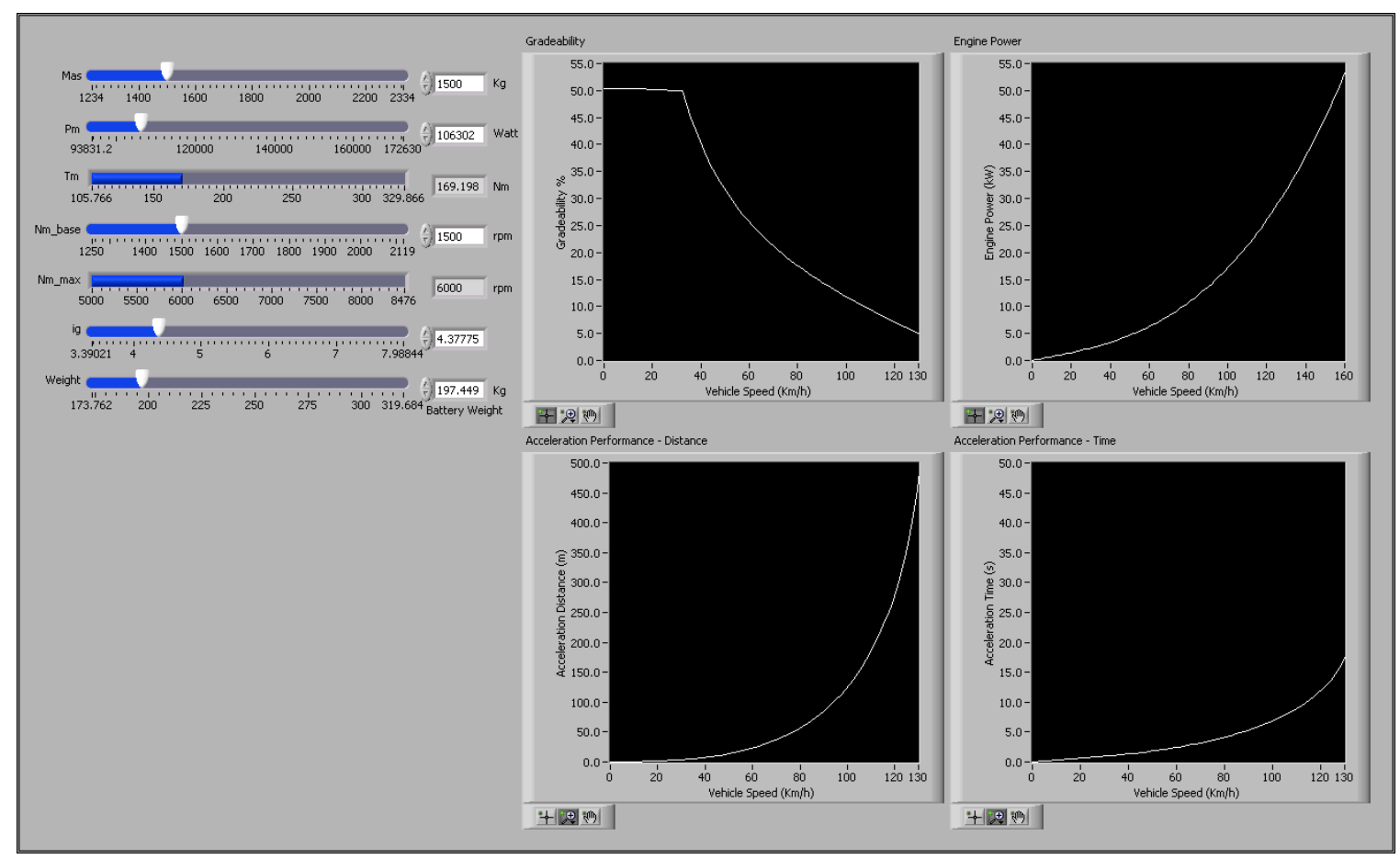

Fig. 79. Initial simulation for performance

The final step is to simulate the chosen vehicle in the road conditions! To do this we can use the DriveCycleSimulation interface which is shown in figure 80.

In the top left side of this interface we can select the proper drive cycle to simulate the vehicle operation at. Also we can choose a controller to be used to manage the battery charging management and engine operation. Here we choose the StopandGo controller and the standard FTP-75 Urban drive cycle. There is also a control that the designer can use to choose a right amount of throttle angle and engine speed. Here we choose the 60 degree throttle angle and $2500 \mathrm{rpm}$ of engine speed.

The results are shown in the ride side of the screen. As is shown here and also through the numbers at the bottom of the page, the maximum engine power needed is $24 \mathrm{KW}$, with the average power equal to $4.8 \mathrm{KW}$ for cruising.

Once we have this information it will be easy to derive other needed details about 
the vehicle.

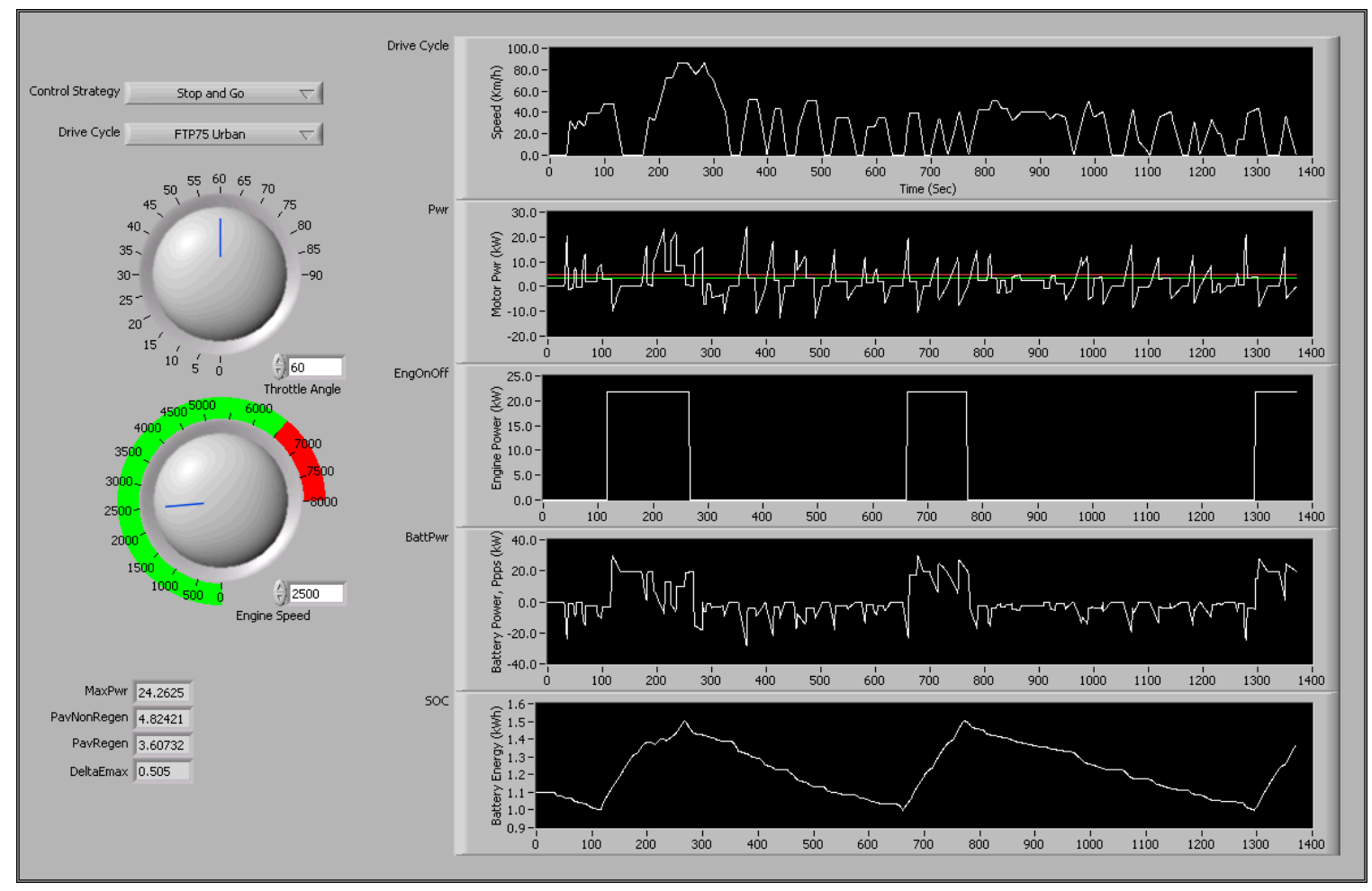

Fig. 80. Simulation for different drive cycles and controllers.

\section{Plug-in Series Hybrid Electric Vehicle Design}

A series plug-in hybrid electric vehicle has exact same components as the regular series hybrid electric vehicle except that its battery could also be charged directly by plugging the car to an external power source like the utility or a charging station. Remember that the regular series hybrid electric vehicle could only be charged by its internal combustion engine. The construction of a plug-in series hybrid electric vehicle is demonstrated in figure 81 . Because there is not any extra component in the plug-in hybrid electric vehicle than regular hybrid electric version, the deign process will be exactly the same and therefore the previous example could thoroughly explain the use of the new concept. 


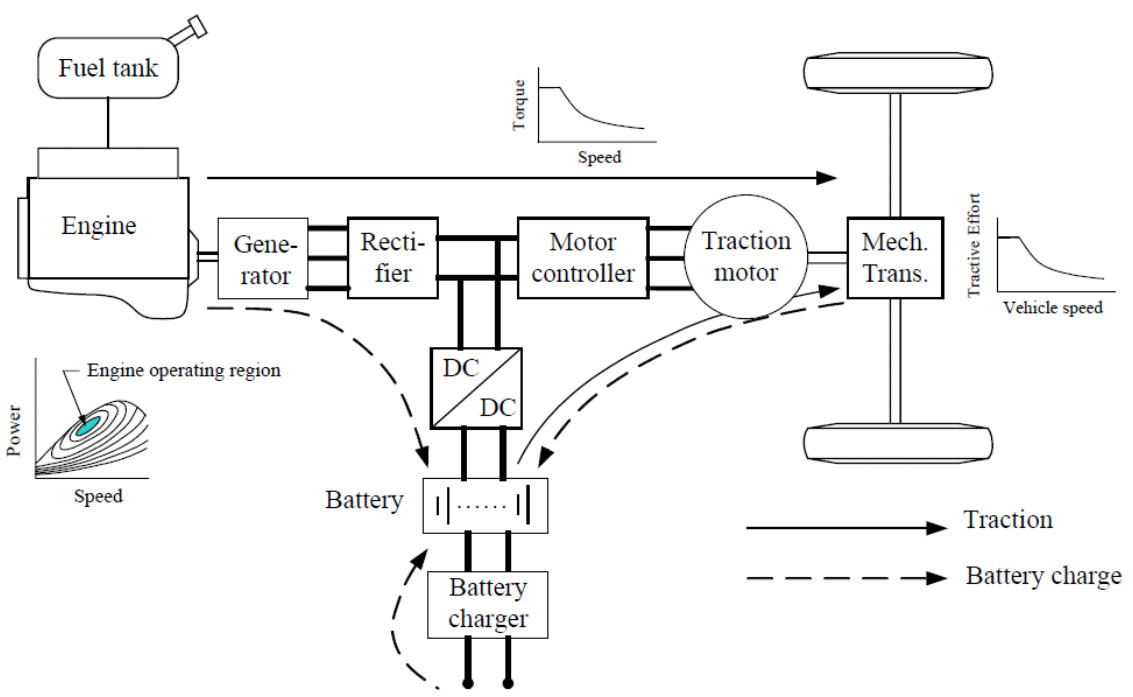

Fig. 81. Structure of plug-in series hybrid electric vehicles. 


\section{VITA}

Ali Eskandari Halvaii received his Bachelors of Science and Master of Science degrees in Electrical Engineering/Controls in 2003 and 2005 respectively from the University of Tehran. He started his Doctorate degree in 2006 at Texas A\&M University at the Power Electronics and Advanced Vehicles research group with Dr. Mark Ehsani and received his Ph.D. in 2011. Ali Eskandari Halvaii can be reached at: Department of Electrical and Computer Engineering Texas A\&M University

214 Zachry Engineering Center

TAMU 3128

College Station, TX 77843-3128

The typist for this dissertation was Ali Eskandari Halvaii. 